\title{
Die Arbo-Viren
}

\author{
Von H. MORITSCH
}

Abkürzungen
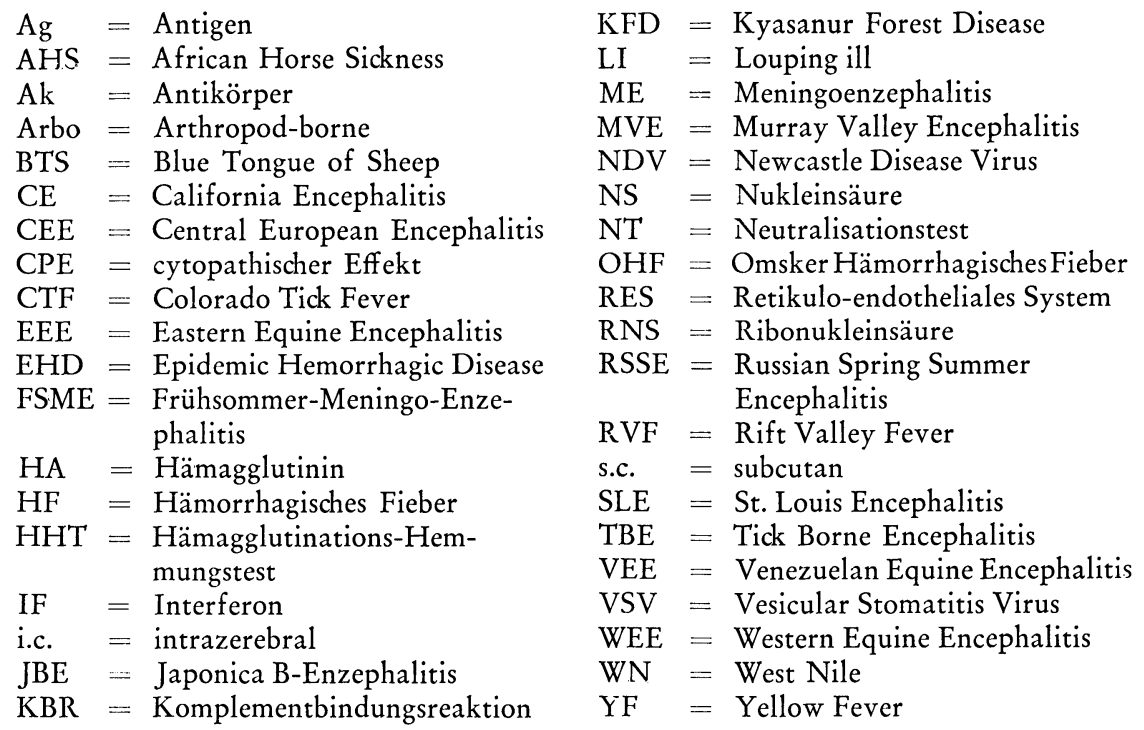

\section{Allgemeiner Teil}

\section{A. Definition}

$\mathrm{Zu}$ den Arbo- (Arthropod borne) Viren werden heute jene Viren gerechnet, welche

1. die Fähigkeit besitzen, sich in Vertebraten und Arthropoden zu vermehren, wobei die Vertebraten als das Reservoir und die Arthropoden als Vektor anzusehen sind. 
Die Vermehrung im Vertebraten ist nachweisbar durch die Virämie und anschließende Antikörperbildung, wobei diese Infektion inapparent oder mit klinisch manifesten Symptomen einhergehen kann. Das Virus selbst kann dabei von laktierenden Tieren durch die Milch ausgeschieden werden; in den Exkrementen wurde es bisher nur bei Mäusen gefunden, die mit VEE-Virus infiziert waren.

Die Infektion der Vertebraten erfolgt durch Stich eines Arthropoden, wobei sich diese Artbropoden zuvor anläßlich einer Blutmahlzeit an einem virämischen Vertebraten infiziert hatten. Man kann aber auch experimentell Stechmücken intrathorakal infizieren, wobei die nachweisliche Vermehrung des Virus als Kriterium für die Zugehörigkeit zu den durch Stechmücken übertragenen Arbo-Viren angesehen wird. Die Vermehrung des Virus in den Arthropoden geht immer symptomlos, d. h. ohne Krankheitserscheinungen und auch ohne histologisch manifeste Läsionen einher.

Demnach sind sogenannte "Insektenviren" (=Viren, die sich in Insekten vermehren und sie dabei schädigen) und Viren, die nur mechanisch durch Arthropoden übertragen werden, nicht als Arbo-Viren zu bezeichnen.

2. sich im Gehirn der Babymaus vermehren,

3. gegen Gallensalze empfindlich sind [190],

4. ein Hämagglutinin (HA) mit Antigencharakter besitzen und

5. RNS enthalten.

Nicht immer können aber alle Postulate (vor allem die Darstellung des HA) für die Zugehörigkeit zu den Arbo-Viren bei der primären Einteilung erfüllt werden.

So weiß man auch von dem aus den Speicheldrüsen einer Fledermaus (Tadarida [Chaerephon] limbata Peters) in Uganda isolierten Entebbe Bat-Virus nur, daß es in der Babymaus angereichert werden kann und daß das daraus gewonnene HA (siehe Immunbiologie) eine Kreuzreaktion mit Immunsera der Gruppe B gibt, ohne daß mit einschlägigen bekannten Sera eine Identifizierung möglich wäre. Jeder Hinweis auf einen Zyklus Vertebrat-Arthropode in der Natur fehlt; dennoch reiht man auf Grund der Antigenverwandtschaft (zumindest vorläufig) derartige Viren schon zu den ArboViren ein.

Eine Definition der Arbo-Viren von physikalischen Gesichtspunkten aus ist dagegen nicht möglich, da sie von heterogener Größe sind und vermutlich auch eine unterschiedliche Zahl von Capsomeren besitzen.

Bei den meisten Arbo-Viren ist auf Grund von Antigenverwandtschaften eine Einteilung in einzelne Gruppen möglich geworden; die restlichen Arbo-Viren werden vorläufig als „ungruppiert“ bezeichnet.

Als verwandt und in eine eigene Gruppe eingeordnet werden [32] jene Viren, die entweder im HHT oder in der KBR bzw. in beiden Serotesten deutliche Kreuzreaktionen erkennen lassen. Eine exakte Unterscheidung der einzelnen Stämme ist dann im HHT und in der KBR nur durch die wesentlich höheren Titer mit den homologen Sera, ansonsten aber - abgesehen vom TBE-Komplex - auf jeden Fall im NT möglich, bei welchem zwar auch Kreuzreaktionen vorkommen können, die aber nur sehr schwach ausfallen (z. B. mit konzentriertem oder nur wenig verdünntem Serum) 
und daher leicht von einer Neutralisation mit dem homologen Serum differenziert werden können.

Im allgemeinen bedient man sich zur Gruppeneinteilung nur des HHT, wie beispielsweise für die Einteilung in Gruppe A oder B; für die Gruppierung in $\mathrm{C}$ aber ist schon eine Kombination von HHT und KBR notwendig (Schema) [167].

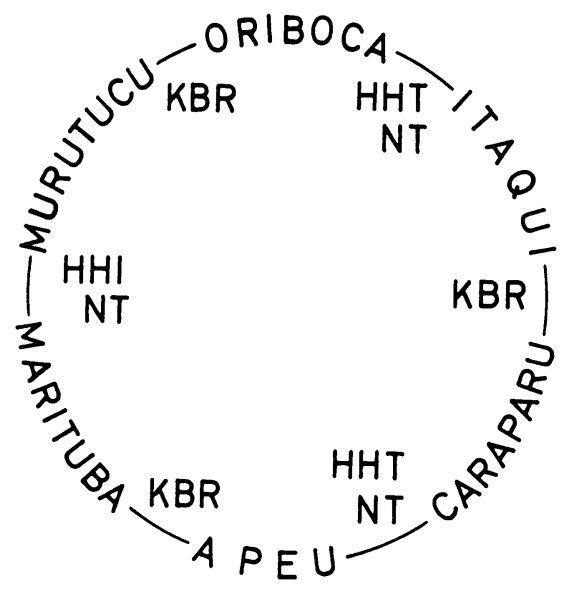

Abb. 1: Die serologischen Beziehungen der Viren der Gruppe C. - Schema aus

R. E. Shope und O. R. Causey, Amer. J. Trop. Med. Hyg. 11, 283-290 (1962)

Darüber hinaus können aber auch innerhalb einer Gruppe im Antigenaufbau besonders eng verwandte Viren zu einem Komplex zusammengefaßt werden, wie innerhalb der Gruppe B zum TBE-Komplex. Hier ist eine exakte Differenzierung der einzelnen Typen nur durch subtile Methoden wie Kreuzpräzipitationsmethoden im Agar-Gel und HHT mit typspezifischen (durch Kreuzabsorption gewonnenen) Hyperimmunsera [40] oder durch die kombinierte Anwendung von Immunofluoreszenz und Mikrophotometrie möglich [88a].

Diese Gruppeneinteilung ist bei der Vielzahl der bereits entdeckten Arbo-Viren und den schon bekannten Gruppen ein komplizierter und langwieriger Vorgang. Dabei stößt man gelegentlich noch auf die Schwierigkeit, daß es einzelne Virusstämme gibt, die mit zwei Gruppen Kreuzreaktionen aufweisen und scheinbar wie ein Brückenglied zwischen diesen beiden Gruppen aufscheinen:

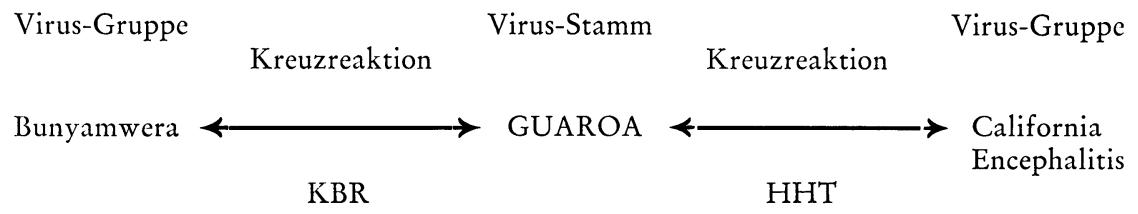


Trotz all dieser Schwierigkeiten stellt aber das serologische Einteilungsverfahren die bisher einzige Möglichkeit dar, diese Viren nach konstanten und stabilen Eigenschaften zu ordnen.

Der vielleicht mehr vom Kliniker ausgehende Wunsch, die Viren nach den klinischen Erscheinungsformen bei Mensch (oder Tier) einteilen zu können, ist aber bei den Arbo-Viren unmöglich, da

1. diese Kriterien nicht konstant sind und

2. auch das klinische Bild selbst nie so exakt erfaßt werden kann wie der Antigenaufbau eines Virus, so daß es schon hierbei zu Mißdeutungen kommen kann, die bei der Antigenanalyse sicher auszuschließen sind.

\section{B. Einteilung}

In den Tabellen sind die bisher bekannten Arbo-Viren nach Gruppen geordnet der Übersicht halber im einzelnen aufgeführt. Die Bezeichnung der Gruppen erfolgte ursprünglich nach den Großbuchstaben des Alphabets (A, B und C). Mit der Entdeckung der vierten Gruppe (1960) wurde aber dieser Modus verlassen und jede Gruppe nach dem Namen ihres erstentdeckten Virus bezeichnet. Die detailliert angeführten Viren entsprechen einteilungsmäßig einem Typ. Innerhalb des Typbegriffes kann man aber auch auf Grund eines verfeinerten HHT noch Subtypen (Varianten) unterscheiden [31 a].

\section{Physikalische, chemische und biologische Eigenschaften}

\section{Physikalische Eigenschaften}

Die Größe der Arbo-Viren wurde mittels Ultrazentrifuge und Elektronenmikroskop gemessen und beträgt bei den meisten 20-50 $\mathrm{m} \mu$. Einige Ausnahmen mit größerem Durchmesser sind Blue tongue-, Ilesha-, Turlock-, Wyeomia-, Anopheles A- und B-, Bunyamwera-, Bwamba-, Ntaya- und VEE-Virus. Diese Angaben beziehen sich auf die Gesamtgröße des Elementarteilchens; sie ist abhängig von dem Durchmesser der Außenmembran, der eine größere Variationsbreite hat als die Ausmaße der Strukturelemente des Innenkörpers.

\section{Chemische Eigenschaften}

Nach R. M. Franklin [52] werden die Arbo-Viren als Viren mit peripher gelegenen strukturellen Lipiden bezeichnet. Nach Behandlung mit Chloroform $[110,209]$, Äthyläther (18 Stunden bei $4^{\circ} \mathrm{C}$ ) sowie Na-Desoxycholat $(0,1 \%$ 30 Min. $22^{\circ}$ C) [190] verlieren sie sehr rasch ihre Infektiosität. Diese Inaktivierung wird auch als wesentliches Merkmal der Arbo-Viren gewertet. 


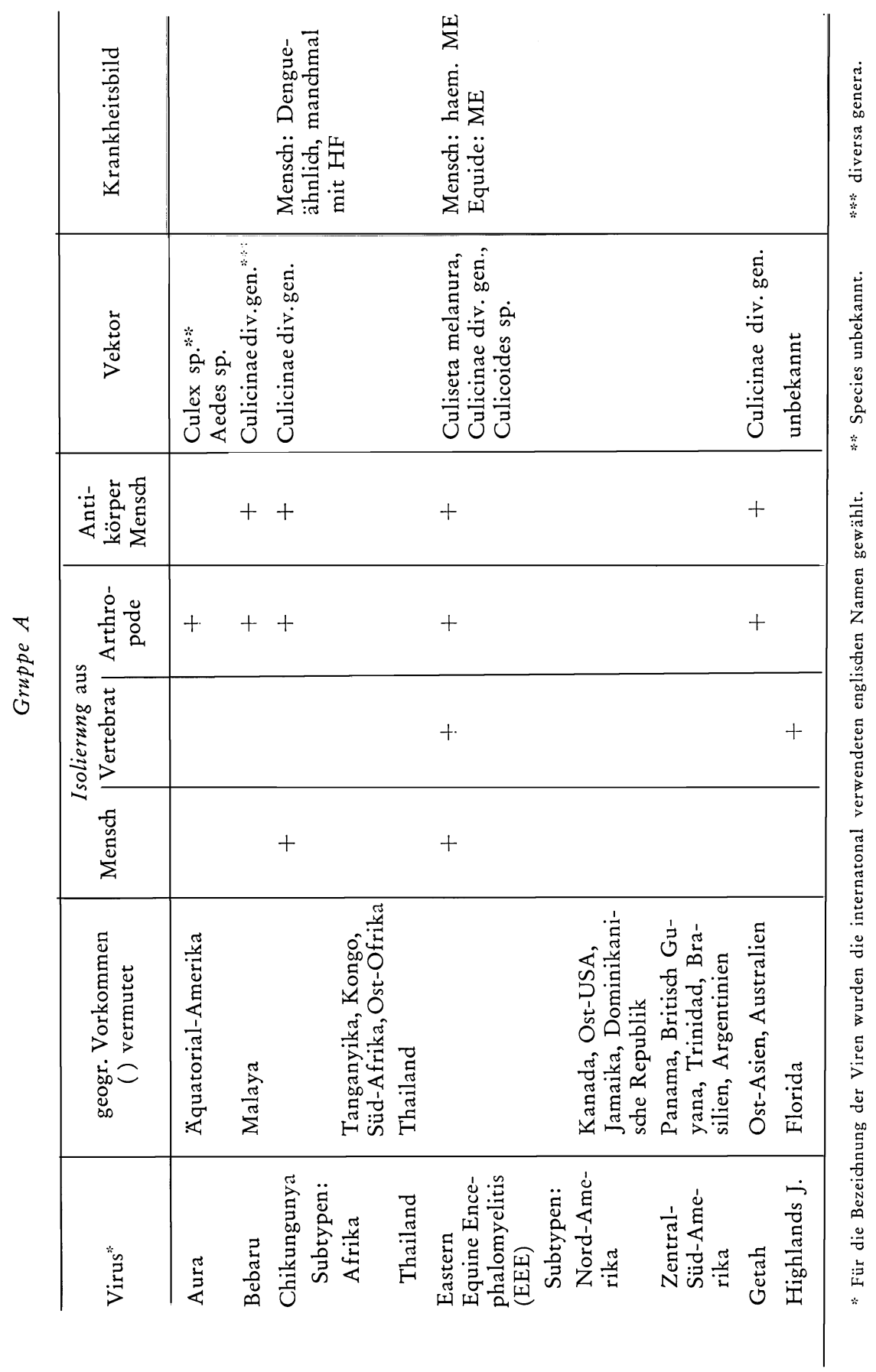




\begin{tabular}{|c|c|c|c|c|c|c|c|c|c|}
\hline 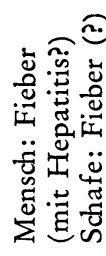 & & 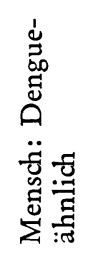 & & & & 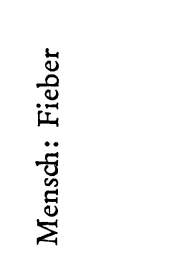 & & 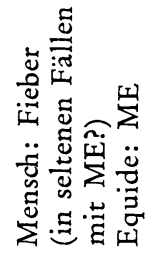 & 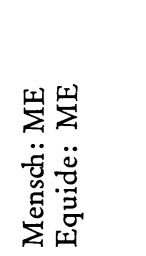 \\
\hline 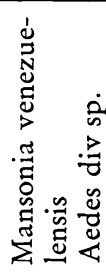 & 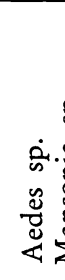 & 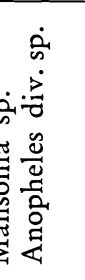 & 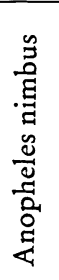 & 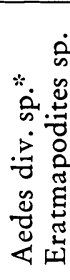 & & 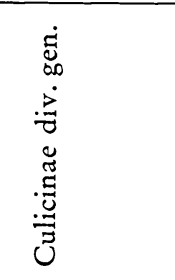 & 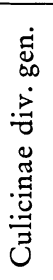 & 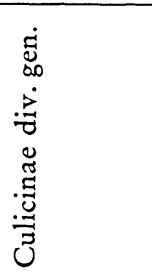 & 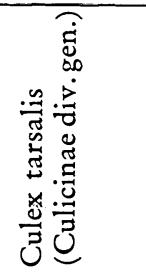 \\
\hline+ & + & + & & + & + & & + & + & + \\
\hline+ & + & + & + & + & + & & + & + & + \\
\hline & & & + & & + & & & + & + \\
\hline+ & & + & & & + & & & + & + \\
\hline 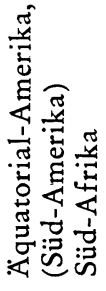 & 离 & 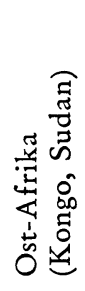 & 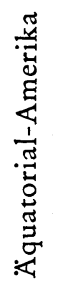 & 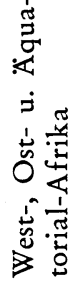 & & 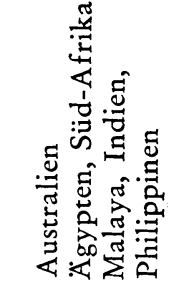 & 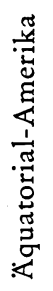 & 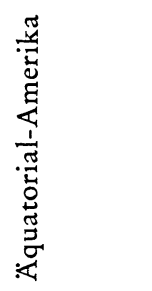 & 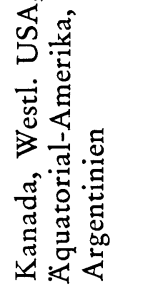 \\
\hline 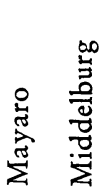 & $\begin{array}{l}\vec{\Xi} \\
\stackrel{\Xi}{Z} \\
Z\end{array}$ & 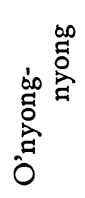 & 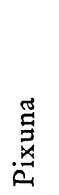 & 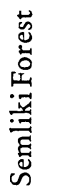 & 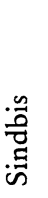 & 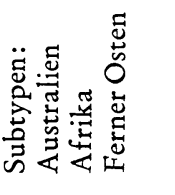 & 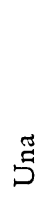 & 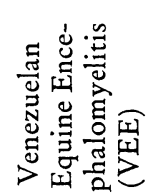 & 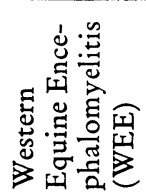 \\
\hline
\end{tabular}

27 Haas / Vivell 


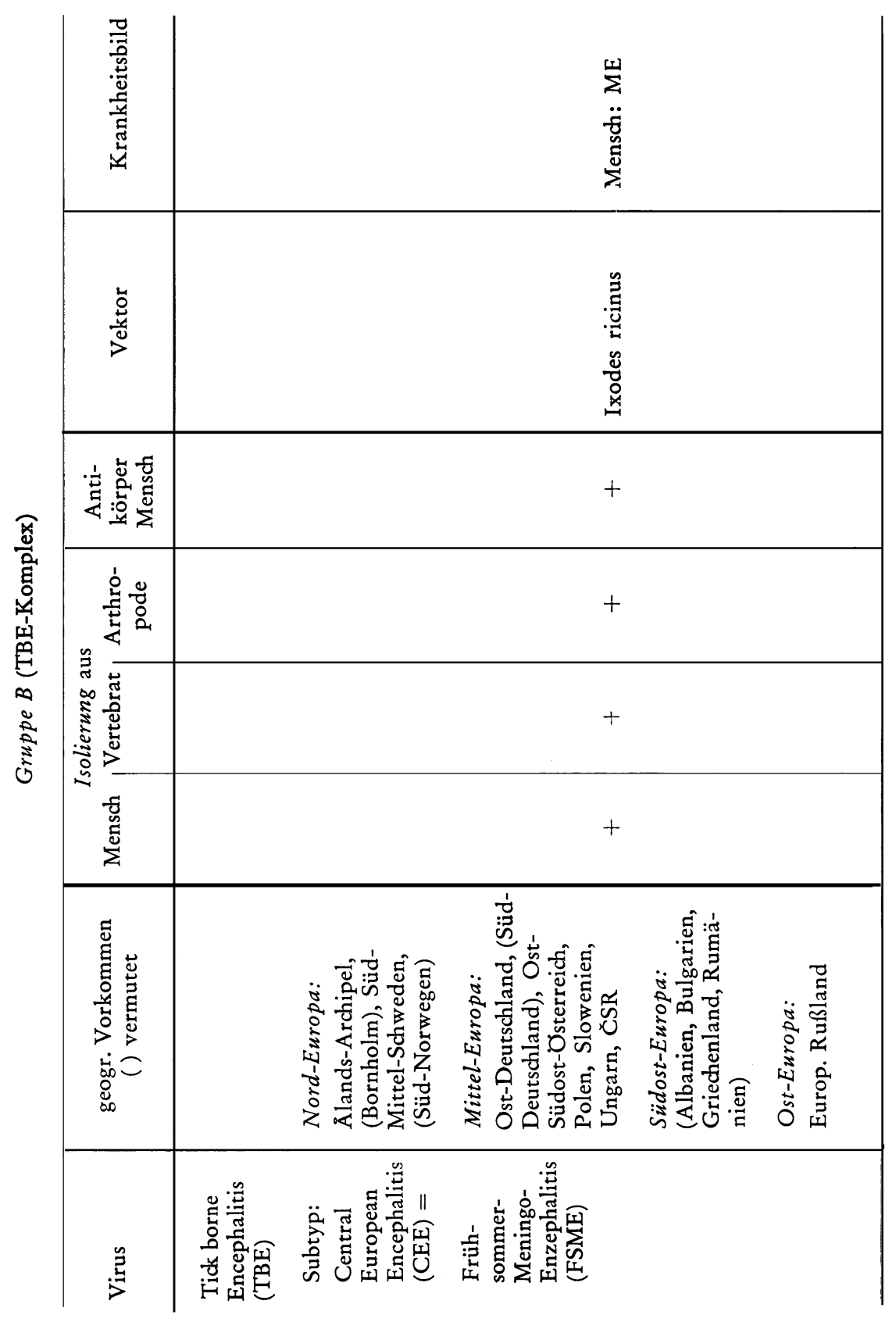




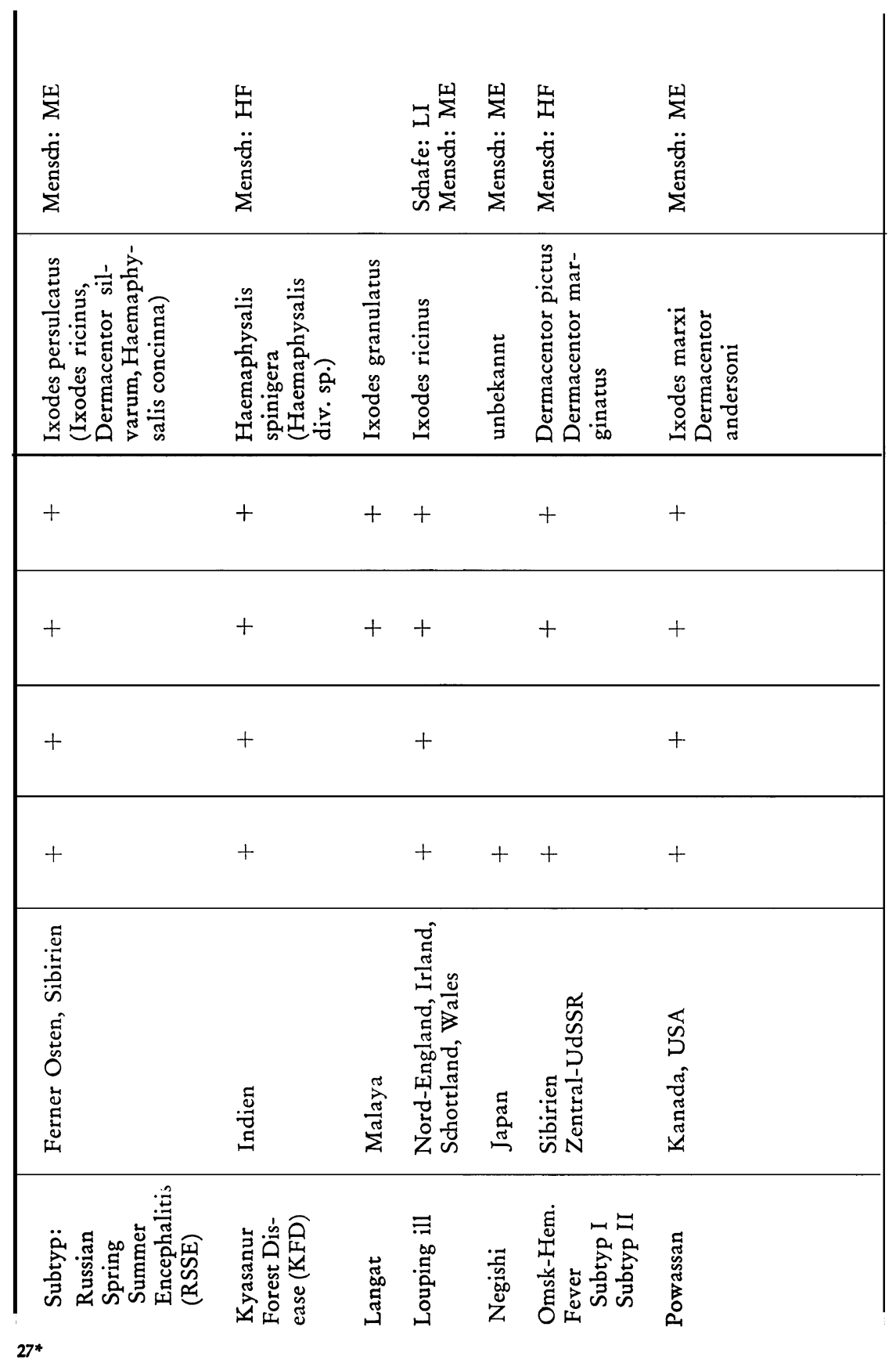




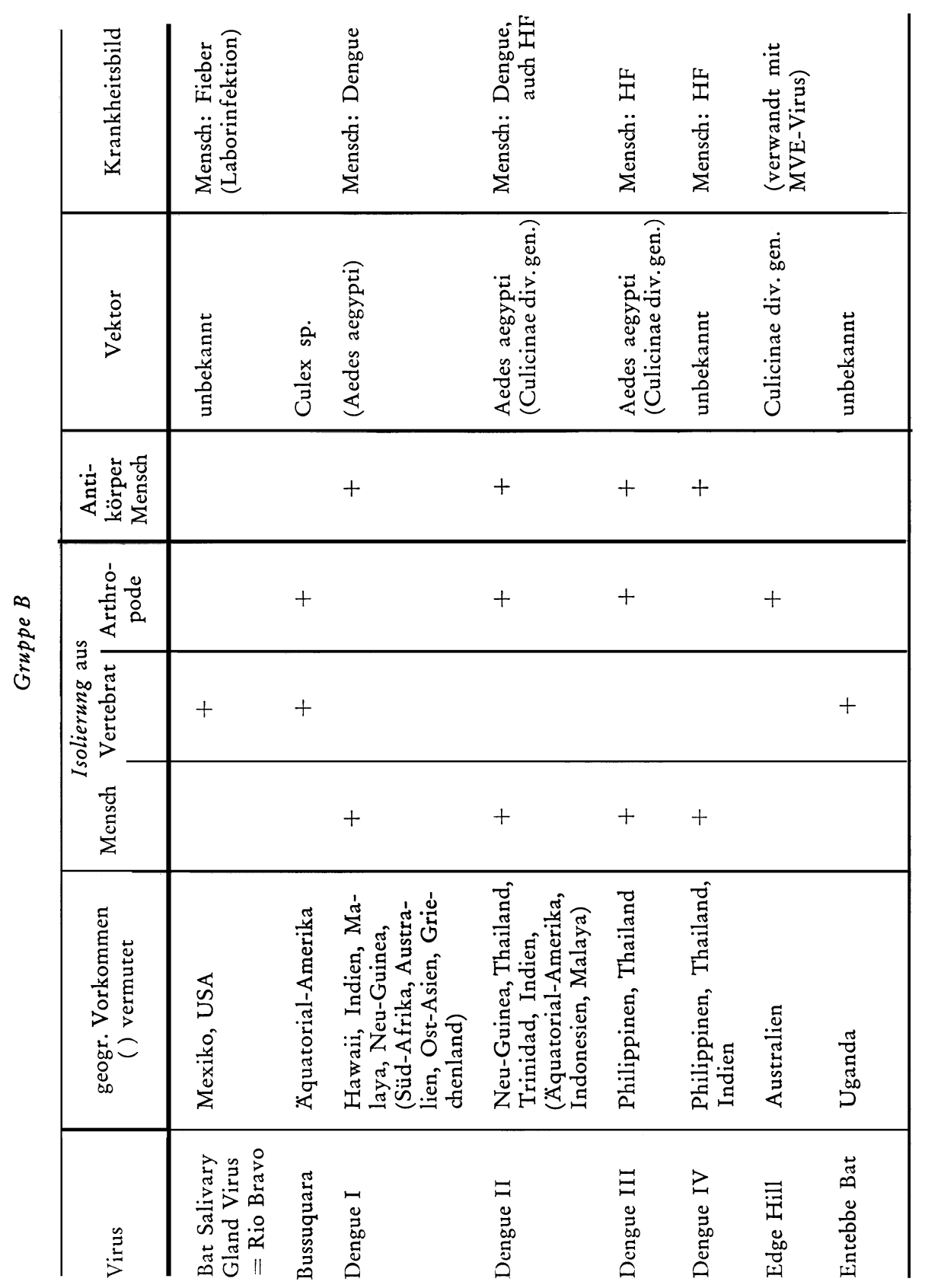




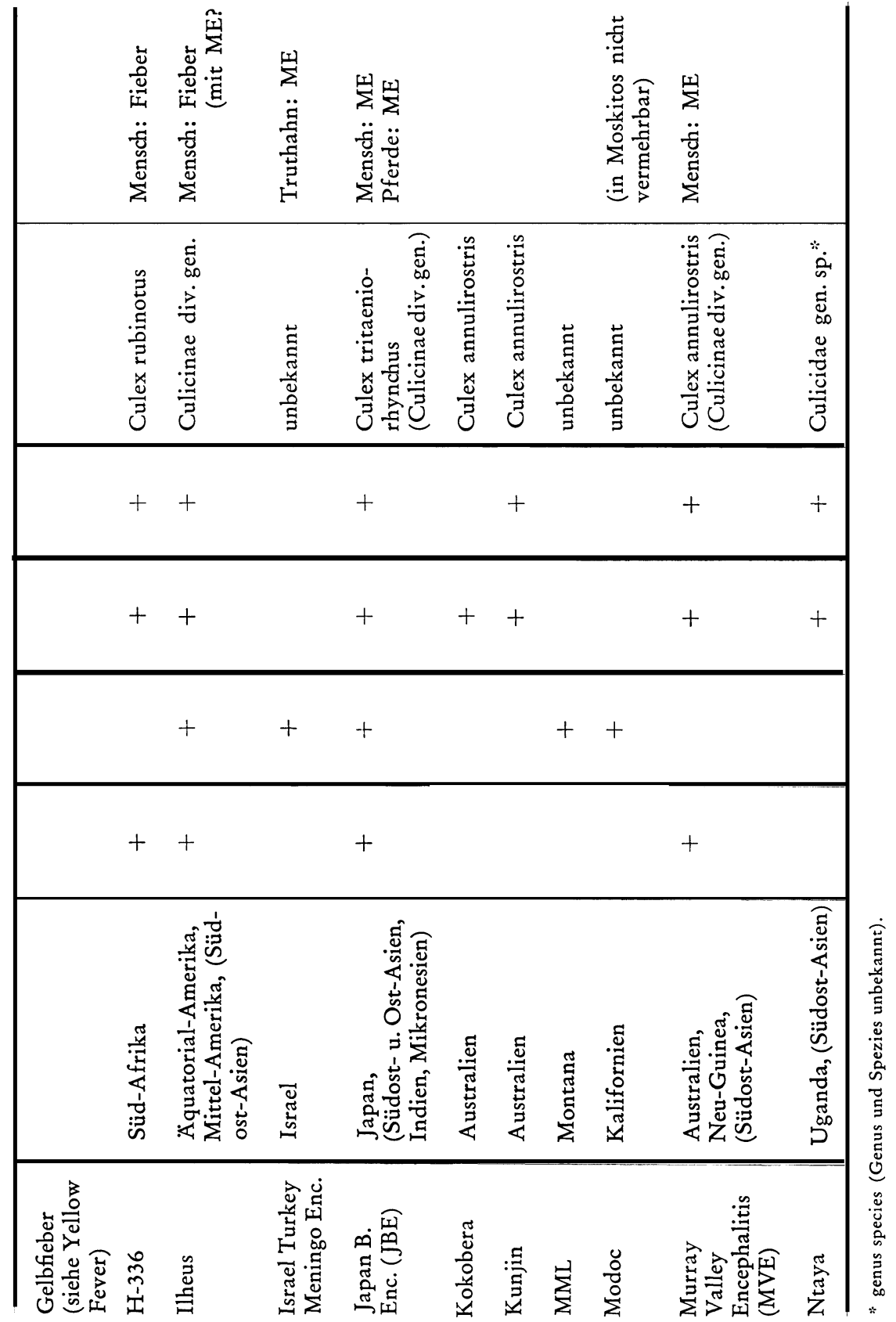




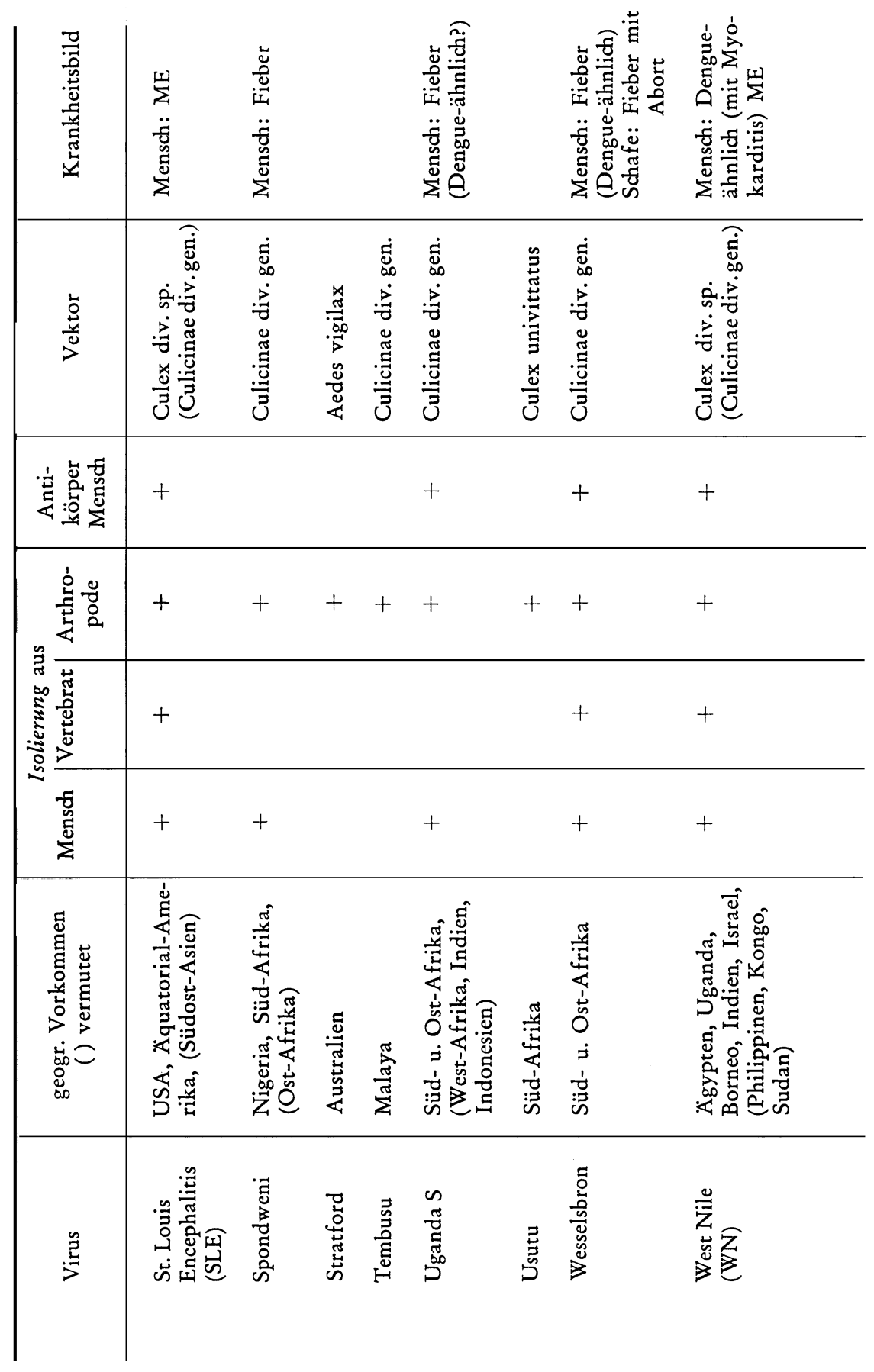




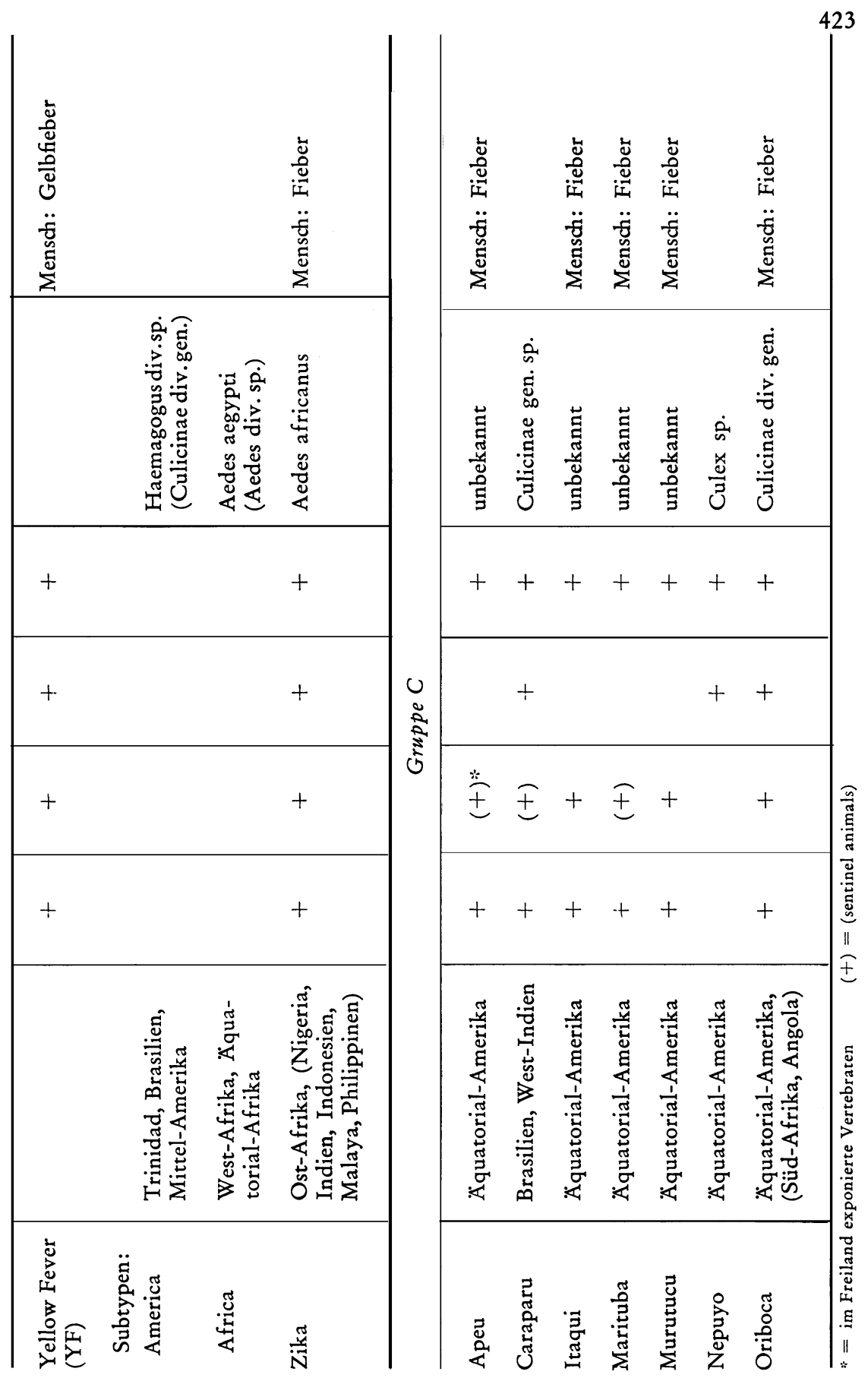




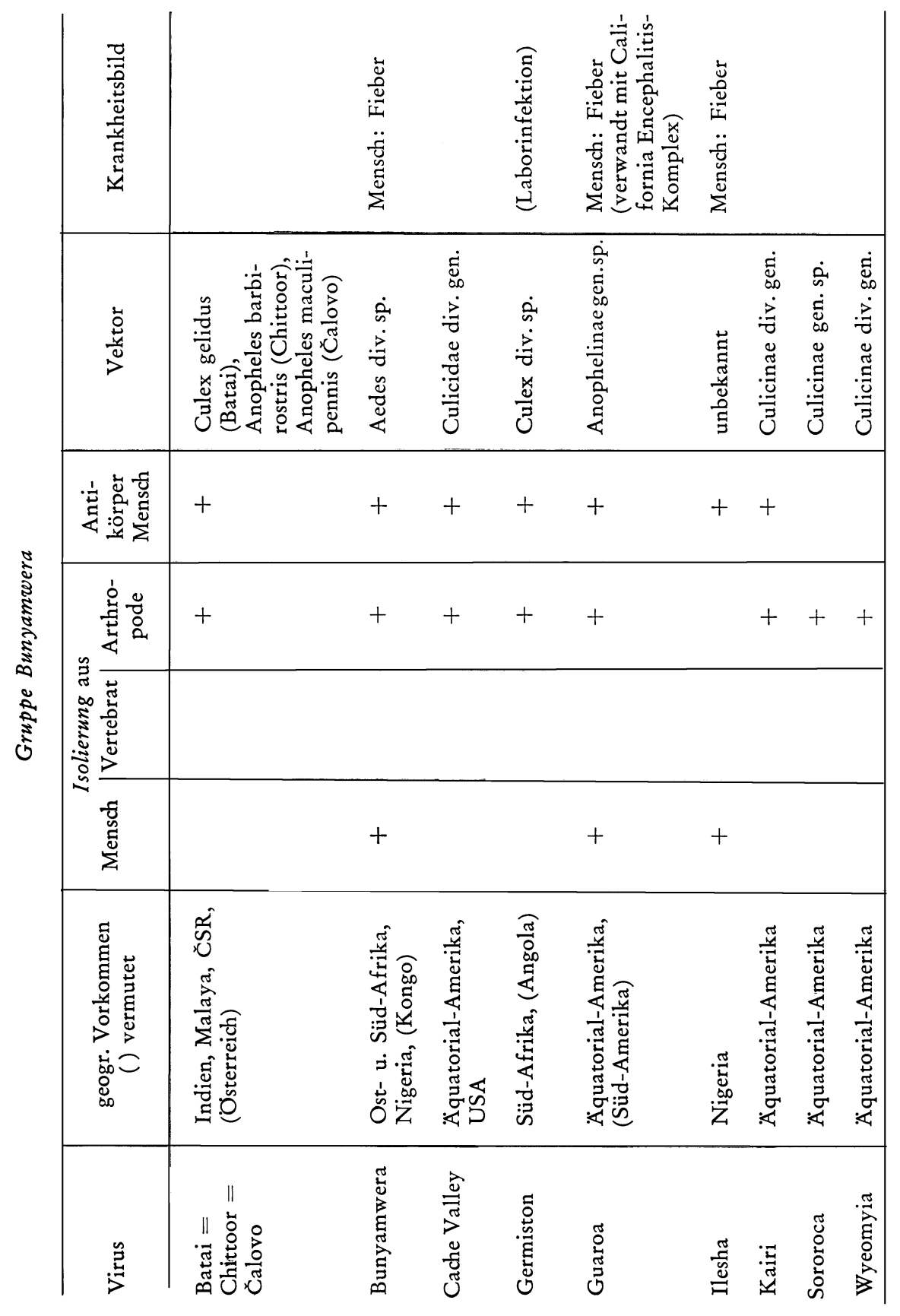




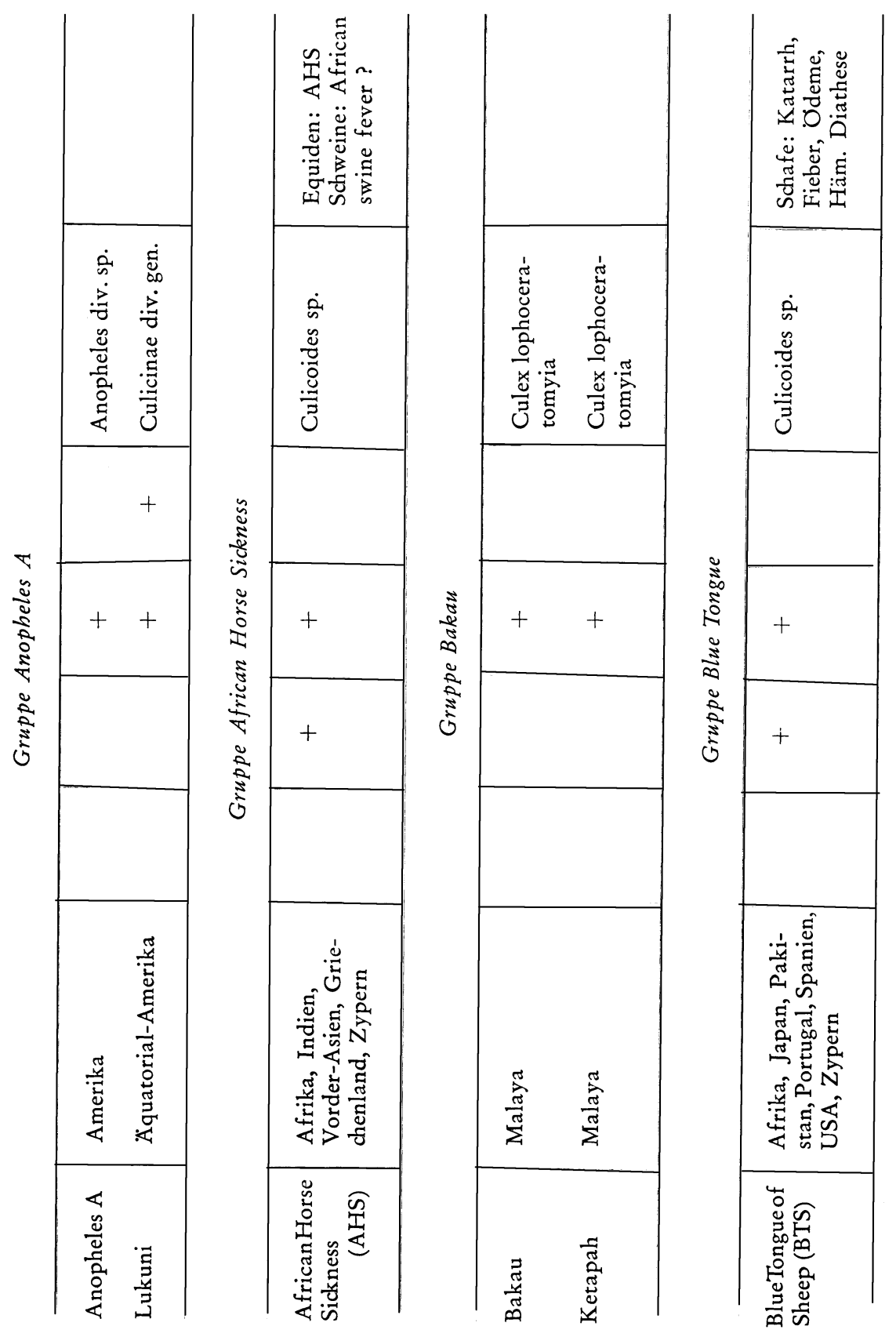



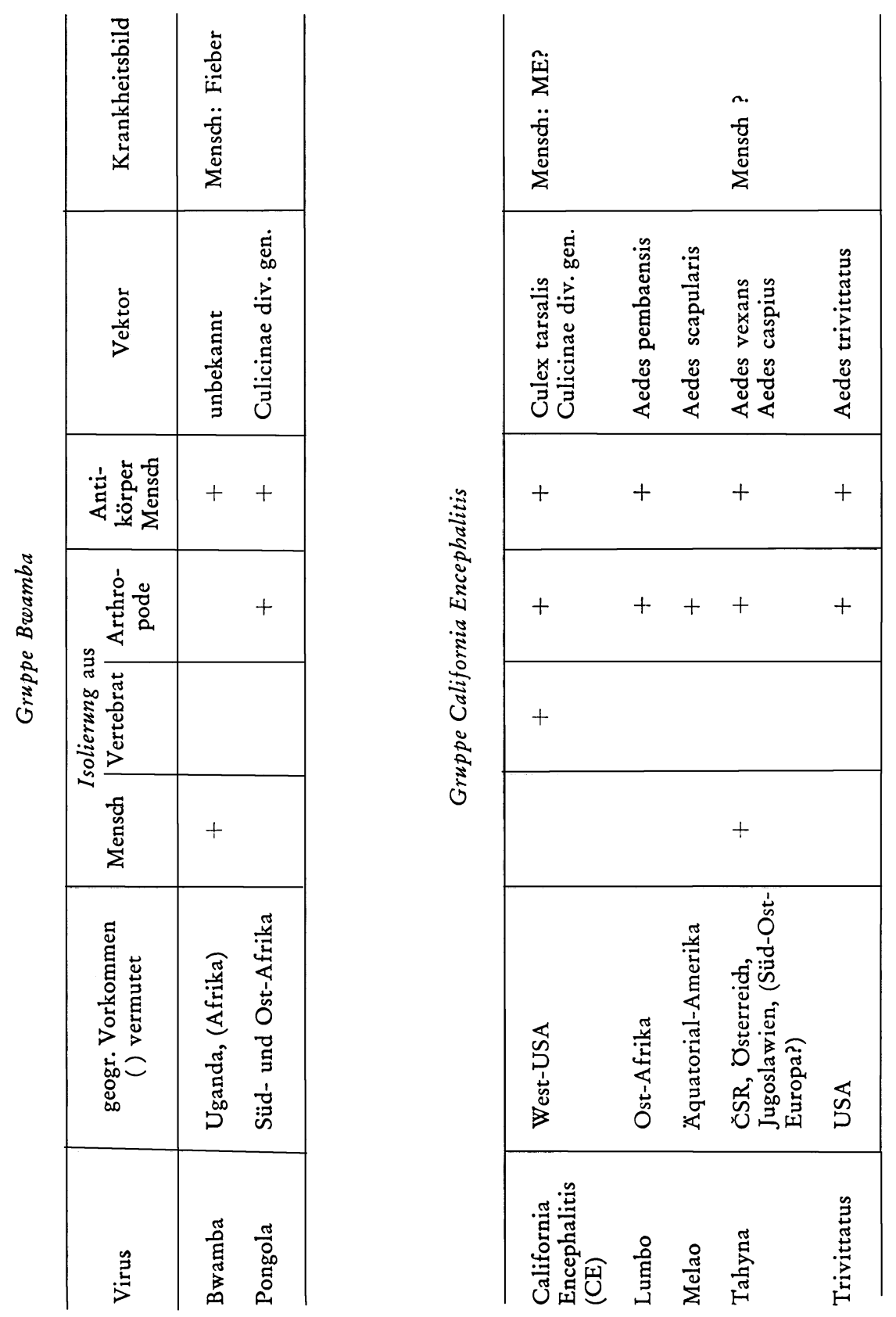

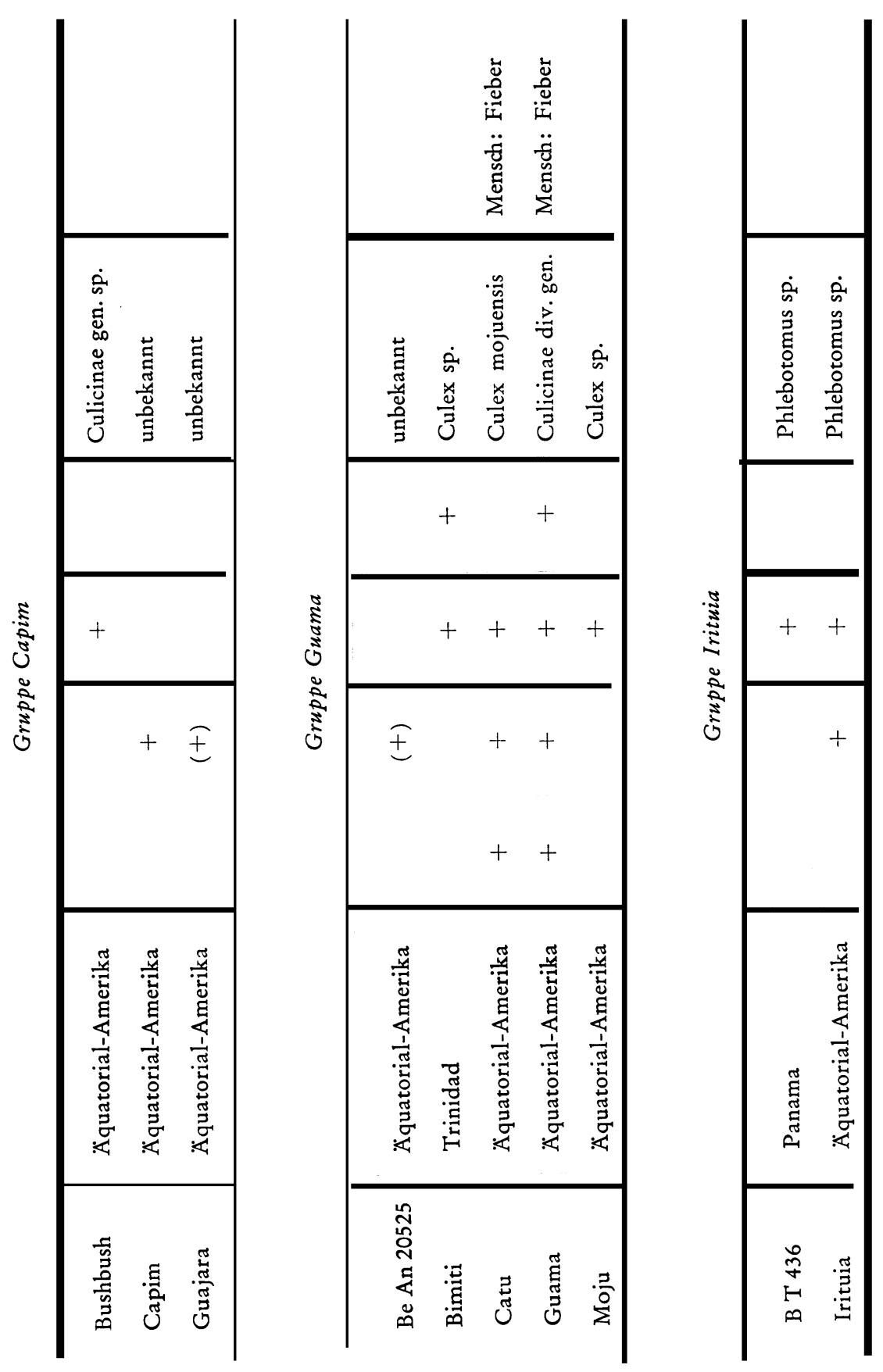


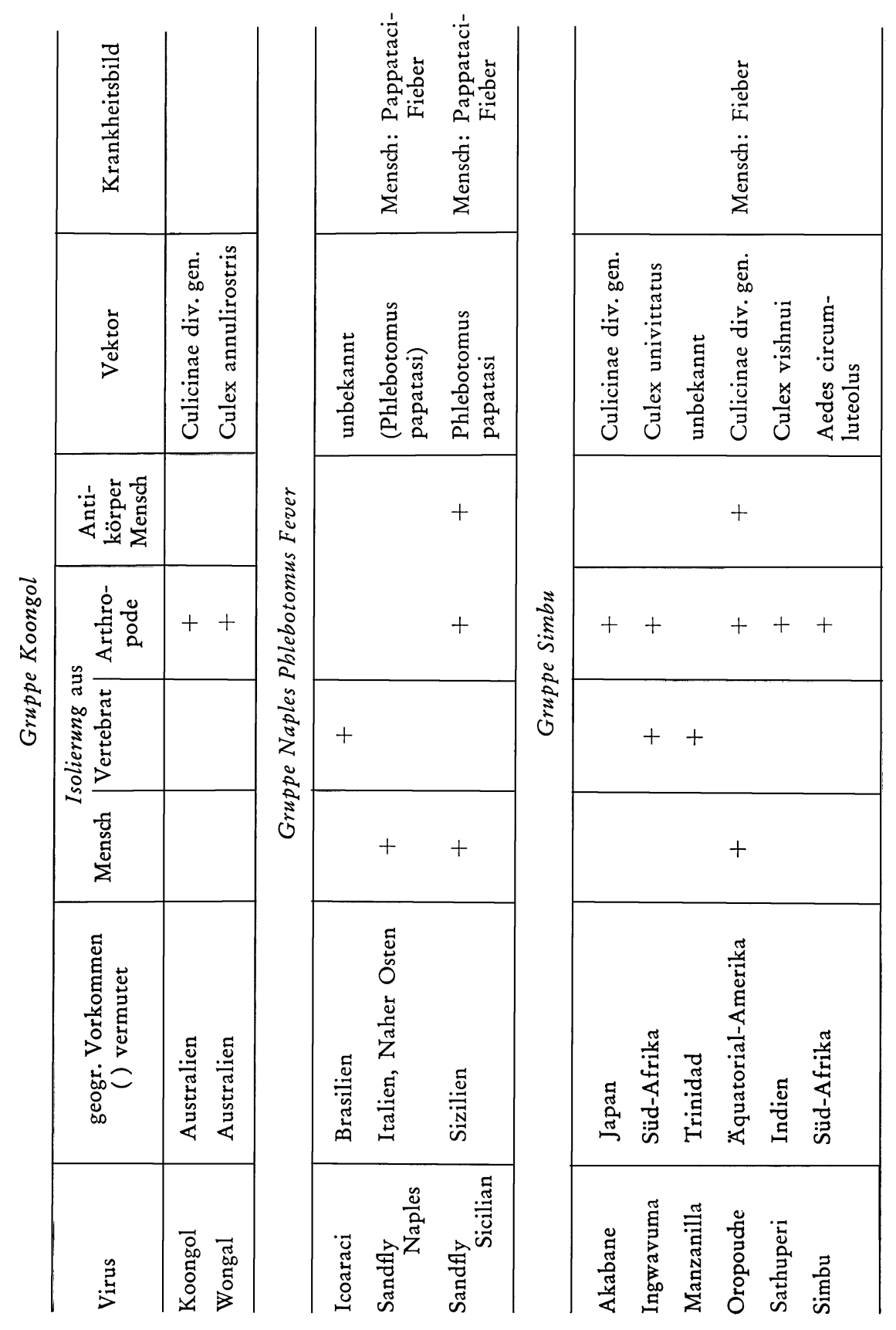




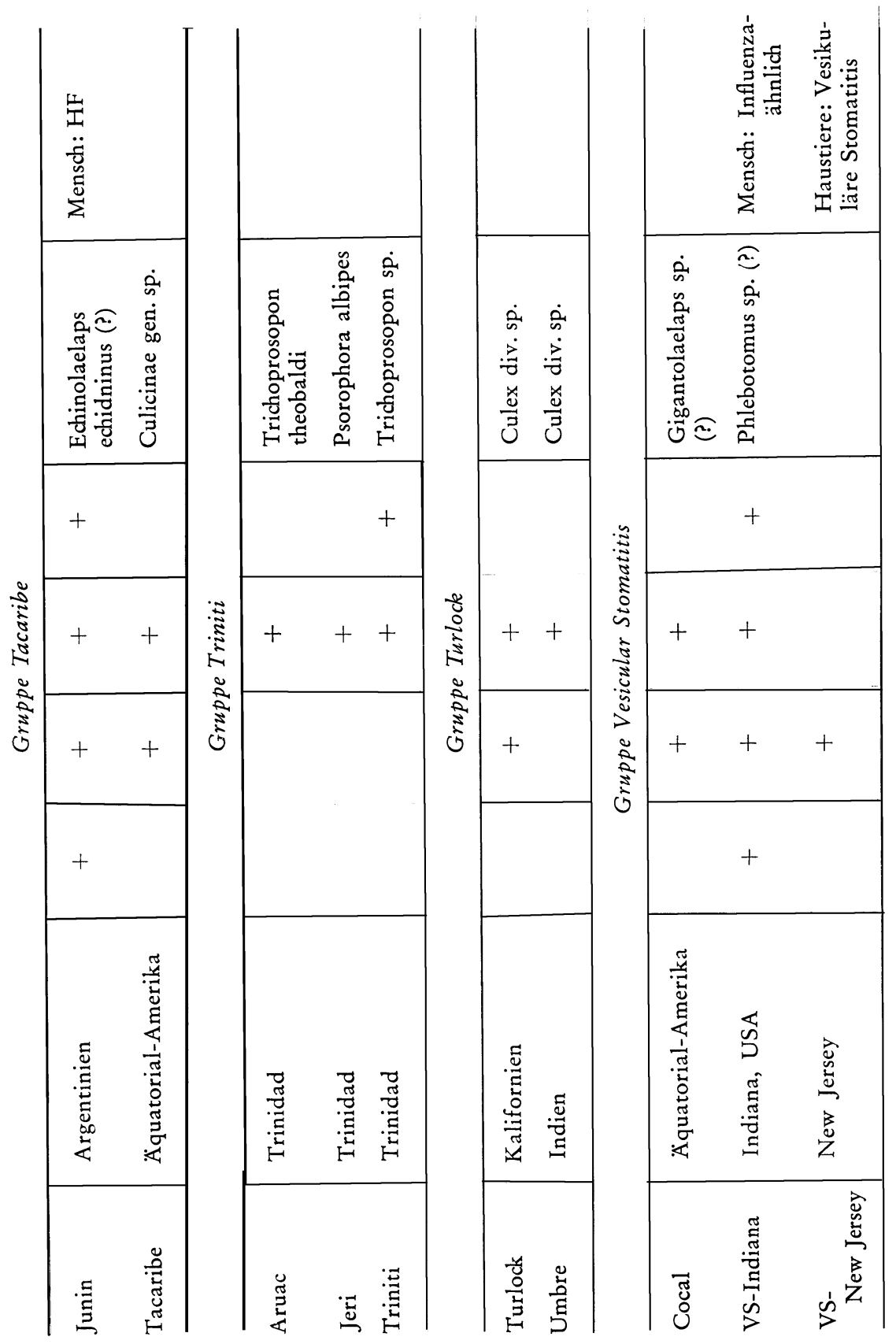




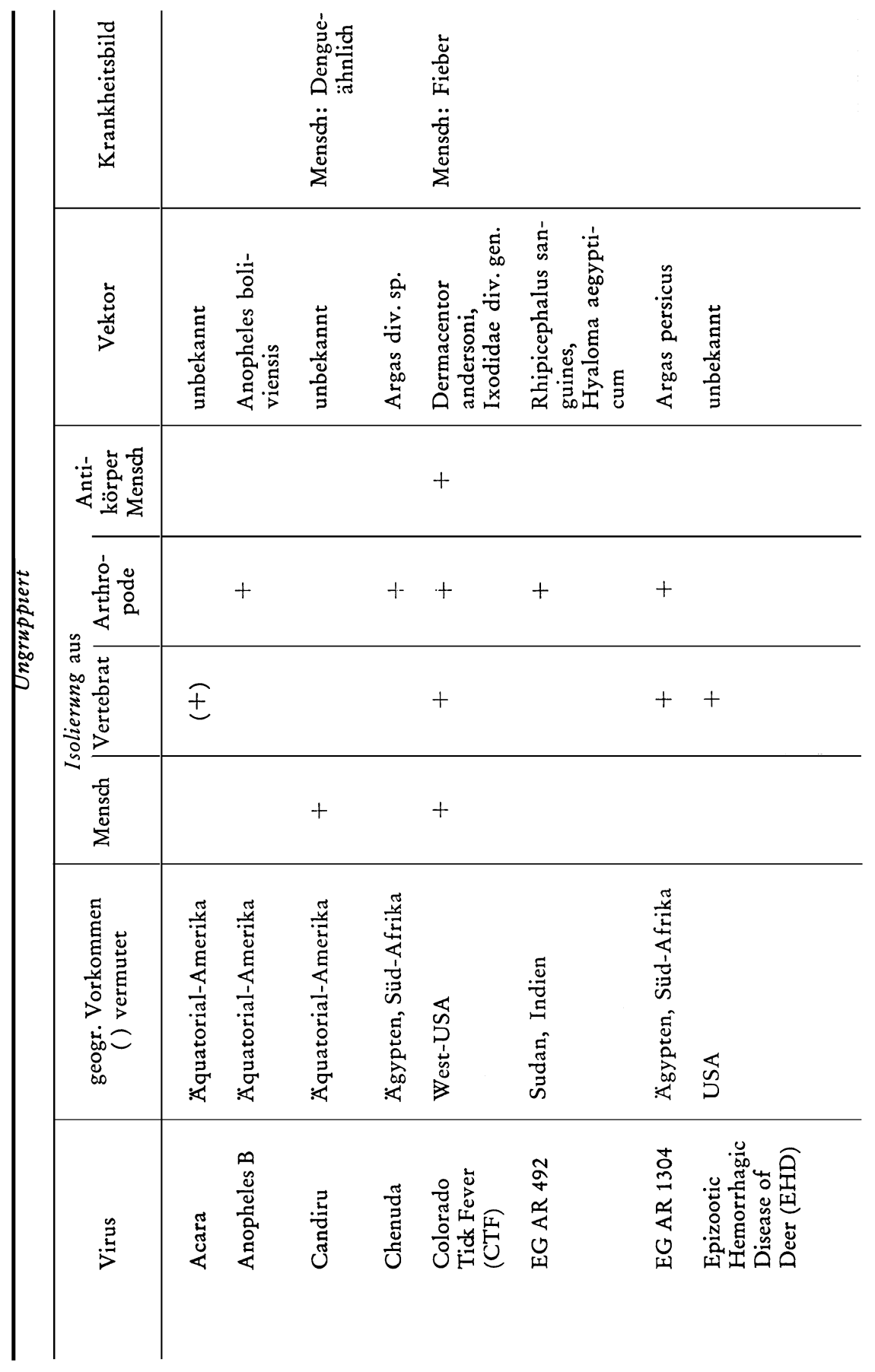




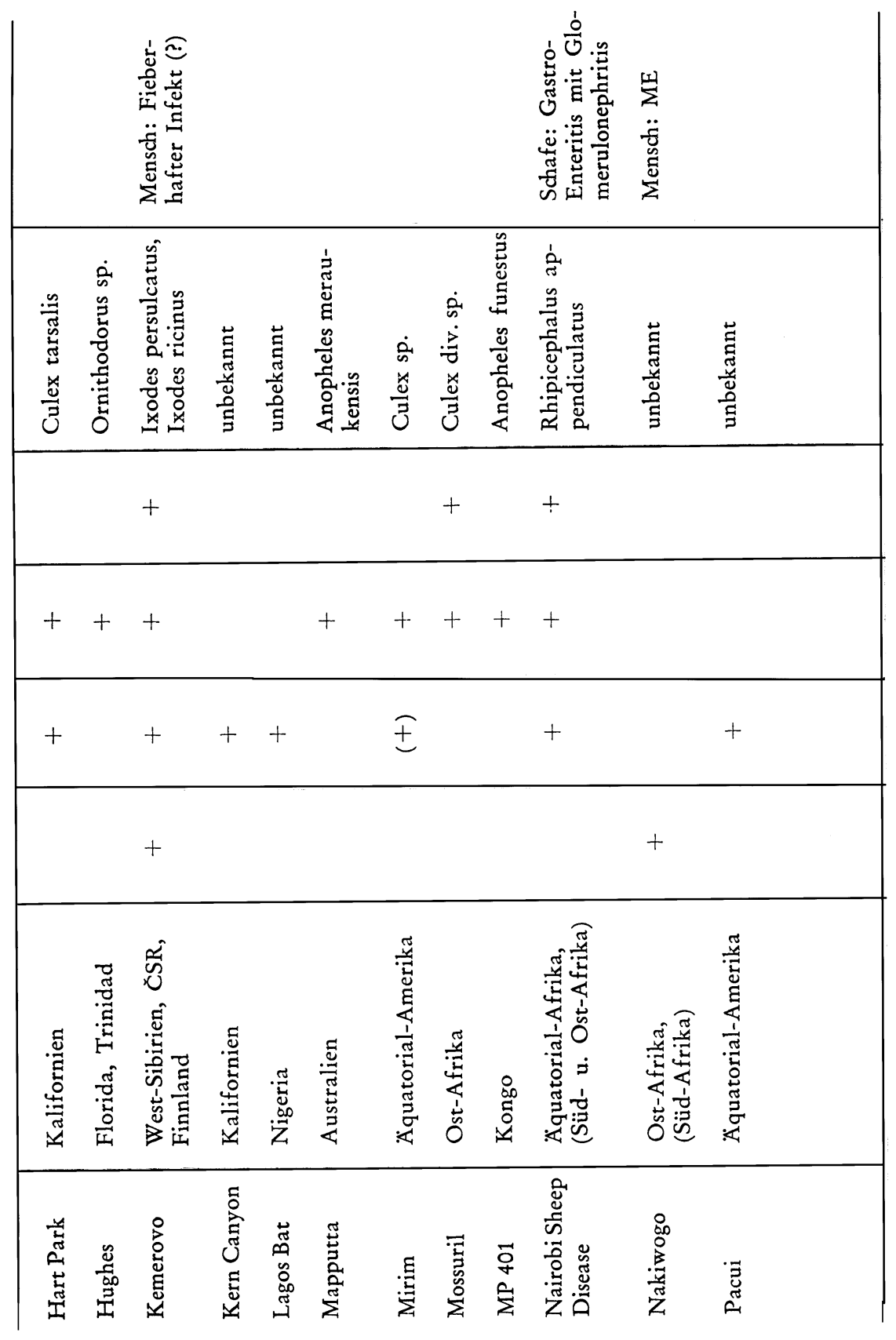




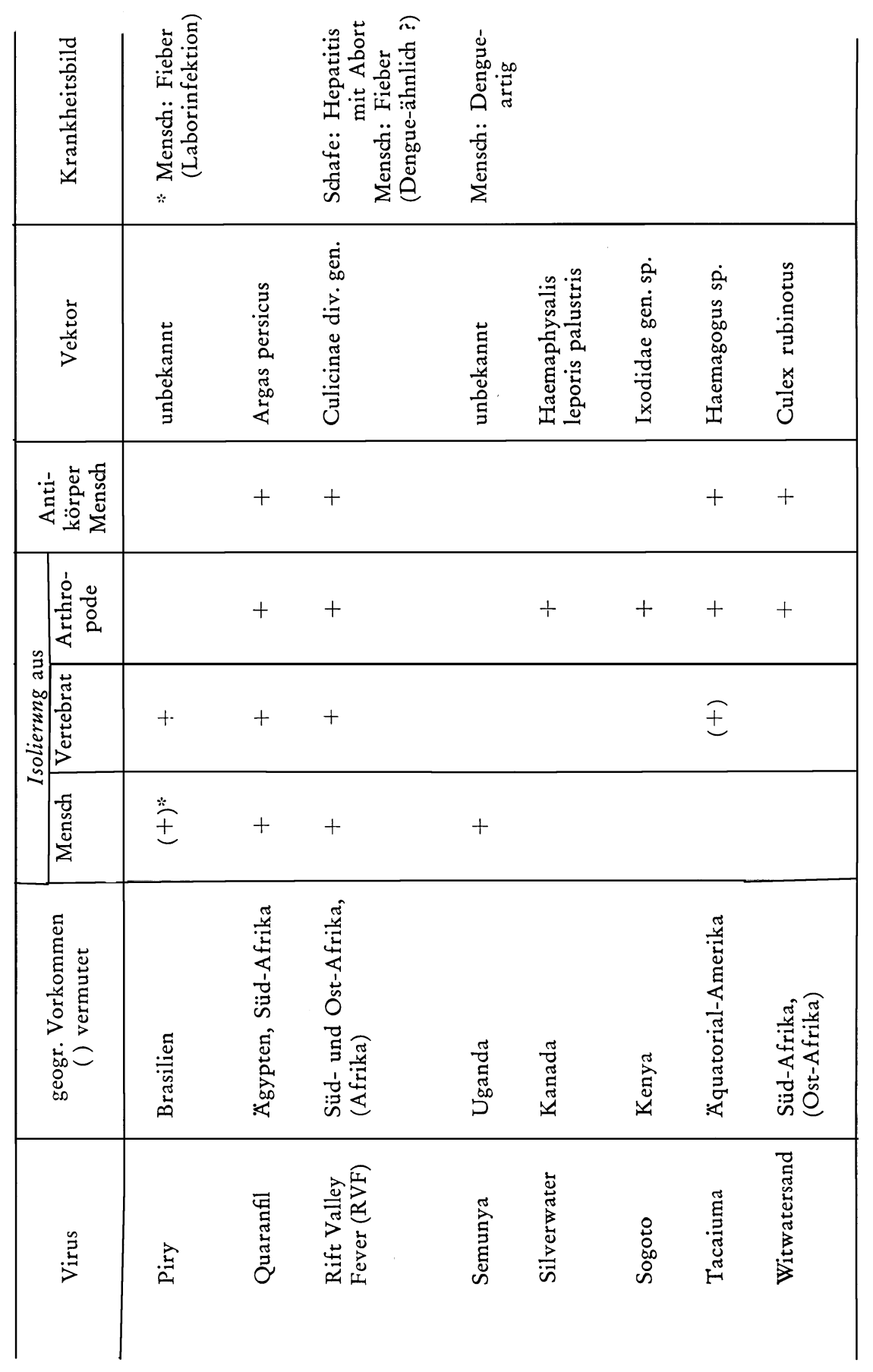


Auch die Untersuchungen von S. G. Anderson und G. L. AdA [3], welche mit Phospholipase A das MVE-Virus inaktivieren konnten, sprechen dafür, daß peripher gelegene Phospholipide für die Integrität des Virus von wesentlicher Bedeutung sein dürften. Der Lipidgehalt dieses Virus wurde später mit $11 \%$ genau festgestellt [1a]. Wenn man durch die Behandlung mit heißem Phenol $\left(50^{\circ} \mathrm{C}\right)$ diese Lipide gemeinsam mit den Proteinen entfernt, kann man infektiöse RNS gewinnen [202]. Eine Behandlung mit Freon u. a. verändert den Infektionstiter selbst nicht, so daß diese Methode zur Reinigung auch dieser Viren verwendet werden kann [177].

Die Darstellung infektiöser Ribonukleinsäure wurde mit Erfolg mit Hilfe der von Gierer und Schramm angegebenen Extraktion mit kaltem Phenol schon bei West Nile [43], Murray Valley [1], TBE [47, 178], WEE und EEE [108, 200, 201, 203], Semliki Forest [37] und Gelbfieber [125] versucht.

\section{Biologische Eigenschaften}

\section{a) Antigenaufbau}

Grundsätzlich muß zwischen drei mit verschiedenen serologischen Methoden erfaßbaren Antigenen unterschieden werden:

1. Das V(-irus)-Antigen entspricht dem kompletten infektiösen Viruspartikel und wird durch den NT quantitativ erfaßt.

2. Das Hämagglutinin (HA) konnte bisher vom Viruspartikel nicht abgetrennt werden. Erstmalig gelang Hallauer (1946) der Nachweis eines HA bei einem viszerotropen Gelbfieberstamm. SABIN und seine Mitarbeiter (1950-1954) konnten später dieses HA bei einer Reihe von Arbo-Virusstämmen demonstrieren und CASALS und BROwN [32] verwendeten das HA zur Einteilung der Arbo-Virusstämme in Gruppen. Es wird heute durch Saccharose-Azeton-Extraktion oder Azeton-Äther (Standard-Vorschrift) aus dem Gehirn infizierter Babymäuse gewonnen [39]. Diese Extraktion geht in der Kälte vor sich, so daß die Infektiosität des Viruspartikels nicht völlig verlorengeht. Die Hämagglutination ist sehr $\mathrm{pH}$-empfindlich und kann auch durch Phospholipide, wie sie beispielsweise in jedem Serum vorkommen, inhibiert werden $[138,157$, $159,160]$.

Die höchsten und verläßlichsten Titerwerte der Hämagglutination erhält man mit Gänse- oder Hahn-Erythrozyten [152]. Die Agglutinierbarkeit der Erythrozyten scheint vom Hormonhaushalt der Spender abhängig zu sein [155, 156]. Nach SALminen, der die Kinetik bei den TBE-Viren genau untersucht hat, handelt es sich bei Adsorption und Elution von Arbo-Viren nicht wie bei den Myxo-Viren um einen enzymatischen Vorgang, sondern es deutet die hohe Geschwindigkeit der Elution bei hohen $\mathrm{pH}$-Werten auf elektrostatische Wirkungen hin [153]. Untersuchungen über Inhibitoren der Hämagglutination bei TBEVirus [159, 160] und später bei anderen Viren der Arbo-Gruppe [157] machten 
es wahrscheinlich, daß es sich bei den Rezeptoren der Zelloberfläche um einen Komplex von Cholesterin mit einem negativ geladenen Lipid (freie Fettsäure oder Phosphatid) handelt.

3. Das komplementbindende (KB-) Antigen wird in der KBR quantitativ erfaßt, wobei aber die Titerhöhe ungefähr nur ${ }^{1 / 10}$ des Titers im HHT erreicht. Schon einfache Präparationen (Veronalpuffer-Aufschwemmung von Gehirnen i.c.-infizierter Saugmäuse) geben in der KBR spezifische Ablenkungen und sind vor allem für die rasche Identifizierung frisch isolierter Virusstämme von praktischer Bedeutung. Noch höhere Antigentiter erhält man nach Extraktion der inhibierenden Lipide z. B. mit Saccharose-Azeton in der Kälte wie für die Darstellung des HA [39].

\section{b) Wirtsspektrum}

Als gemeinsame Eigenschaft aller Arbo-Viren gilt, daß sie in der weißen Babymaus angereichert werden können.

Bei vielen Stämmen vermehrt sich auch nach extraneuraler Applikation das Virus im ZNS unter dem Bild einer Enzephalitis. Größere Mäuse sind i.a. auch nach intrazerebraler Applikation, insbesondere der "neurotropen“ Stämme, empfänglich, aber doch wesentlich weniger empfindlich, so daß man zur Isolierung, insbesondere noch unbekannter Stämme, vor allem aus Arthropoden, nach Tunlichkeit immer nur Babymäuse verwenden sollte.

Alle anderen Vertebraten reagieren nach natürlicher oder künstlicher Infektion mit der Bildung von Antikörpern, wobei diese Infektion auch unter dem Bild von bekannten Krankheiten einhergehen kann.

An Stelle von Tieren zieht man aber heute immer mehr die Gewebekultur zur Virusanreicherung heran. Die meisten Arbo-Virusstämme lassen sich in Gewebekulturen nach Adaptierung gut vermehren. Dabei haben sich unter anderem vor allem frische Hühnerembryonalzellen, Hamsternierenzellen, aber auch HeLa-Zellen bewährt. Ein CPE tritt allerdings nicht immer auf. Die Gewebekultur findet daher im allgemeinen weniger für Isolierungen, wohl aber in der serologischen Diagnostik immer häufiger Anwendung.

\section{c) Variationen}

Die Möglichkeit der Entstehung von Mutanten, die im Geno- und Phänotyp von den ursprünglichen Viren abweichen, ist auch bei den Arbo-Viren gegeben, wobei eine Reihe von Umständen, wie z. B. eine Änderung des Zyklus des Virus in der Natur, die Mutationsrate erhöhen dürfte. Die Aufnahme in ein neues Reservoir, aber vermutlich noch stärker der Übergang auf einen anderen Arthropoden, dürfte durch die hierbei wirksame Selektion von wesentlicher Bedeutung sein und eine Anpassung des Virus bewirken. 
Soweit man diese stabilen Änderungen serologisch objektivieren konnte, wurde dies in Form von Subtypen ausgedrückt. Aber auch die feinen Unterschiede zwischen den einzelnen Typen des TBE-Komplexes wären hier anzuführen. Auffallend ist dabei, daß bei den einzelnen Typen jeweils andere Arthropoden als Vektoren auftreten (siehe TBE-Komplex).

Eine Mutation kann sich aber auch in Richtung einer Abschwächung auswirken, so daß sich dabei auch die Möglichkeit eröffnet, attenuierte Stämme für Vakzinationszwecke zu gewinnen.

Dabei sei einerseits auf die attenuierten Stämme 17 D (ASIBI) und Dakar verwiesen, die durch Passagen in Gewebekulturen bzw. Hühnerembryonen und in Mäusen abgeschwächt wurden und heute als genetisch stabile Gelbfieber-Vakzinen für den Menschen verwendet werden.

Andererseits wurde aus Zecken der Stamm Langat TP 21 des TBE-Komplexes isoliert (siehe dort), der sich als nicht neurotrop für den Menschen erwies und somit als präsumptiver Impfstamm anbietet [59, 141].

\section{d) Interferenz}

Die Fähigkeit der Arbo-Viren, nach Infektion einer Zelle Interferon (IF) (siehe auch Kapitel Interferenz-Interferon, Seite 202) zu bilden, wurde für mehrere Stämme nachgewiesen.

VILCEK [195] berichtet, daß es ihm gelungen war, in Gewebekulturen aus Hühnerembryonalfibroblasten einen TBE-Virusstamm ohne CPE anzureichern und dadurch die Vermehrung des 48 Stunden später hinzugegebenen WEE-Virus (= challenge virus) nachweislich zu unterdrücken. In weiteren Untersuchungen wies VILCEK gemeinsam mit ZEMLA und RADA nach, daß es sich auf Grund zahlreicher auch physikalisch-chemischer Untersuchungen um Interferon handelte $[196,197,198,199,212]$.

Weitere IF bildende Arbo-Viren sind Chikungunya-Virus, O'nyong-nyong-Virus, Kumba-Virus [147a], Sindbis-Virus [72a], EEE-Virus [199a], WEE-Virus [98a] und Vesicular Stomatitis-Virus [42b, 199b].

Wahrscheinlich sind auch die von verschiedenen Autoren beschriebenen homologen und heterologen Interferenzerscheinungen auf die Bildung von IF zurückzuführen. LENNETTE und Koprowski [91a] beobachteten bereits 1946, daß der Gelbfieberstamm 17 D in der Gewebekultur nicht nur den Gelbfieberstamm Asibi unterdrücken konnte, sondern auch andere Arbo-Viren, West Nile und VEE. Die Bildung von Influenza A wurde durch West Nile unterdrückt, umgekehrt schien Influenza A aber nicht imstande zu sein, die Bildung der genannten Arbo-Viren zu hemmen. WEE-Virus zeigt sowohl homologe Interferenz [98b], als auch heterologe Interferenz mit NDV [91b]. Auch verschiedene Stämme von Vesicular Stomatitis-Virus interferieren miteinander [42a]. TBE-Virus hemmt Poliovirus [2a], Mayaro-Virus ist wirksam gegen Sindbis-Virus [70].

Arbo-Viren zeigen sich auch empfindlich gegen Interferon. TAYLOR [188a] beschrieb, daß Influenza A mit EEE- und WEE-Virus interferierte. Auch ein anderes Myxovirus, NDV, unterdrückte sowohl VEE-Virus [83a], als auch WEE-Virus [91a]. Rabies-Virus unterdrückte ebenfalls WEE-Virus. Vesicular Stomatitis-Virus wurde vom Polyoma- 
Virus gehemmt [46a] und - wie schon erwähnt [70] - ist Sindbis-Virus gegen IF aus Mayaro-Virus empfindlich.

Es scheint bemerkenswert, daß nur nichtinaktiviertes und mittels Desoxycholat inaktiviertes Mayaro-Virus interferierend wirkt. Eine Inaktivierung durch Hitze, UVStrahlen oder durch Antiserum zerstört die Fähigkeit zur Interferenz. Auch bei TBEVirus wird die Fähigkeit, IF zu bilden, durch Hitze-Inaktivierung vernichtet [198].

MAYER et al. [107] konnten an mit Interferon vorbehandelten Hühnerembryonalzellen zeigen, daß die Latenzzeit des EEE-Virus deutlich verlängert war. Da dies nicht nur nach Beimpfung mit intaktem Virus, sondern auch mit infektiöser RNS aus diesem Virus zu beobachten war, ist anzunehmen, daß das Interferon erst nach der Entfernung der Proteinhülle die Virussynthese beeinflußt.

\section{Pathogenese und Klinik}

Der Infektionsmodus des Menschen erfolgt unter natürlichen Bedingungen durch Stich des blutsaugenden Arthropoden, wobei das Virus mit dem Speichel des Arthropoden ausgeschieden wird; ausnahmsweise können aber auch andere Infektionswege vorkommen.

Das perkutan passiv eingebrachte Virus dürfte -- in Analogie zu den Studien über die Verbreitung des Virus im Versuchstier - zunächst auf dem Lymphweg abtransportiert werden und dabei in das „Primär affine Organ“ [109] gelangen. Dies scheint - zumindest für TBE - regionär gelegenes lymphatisches Gewebe zu sein, in welchem dann die erste Vermehrung des Virus stattfindet. Damit wird die erste Phase des häufig biphasischen Verlaufs der Arbo-Virusinfektionen eingeleitet, wobei im Gefolge dieser primären Vermehrung das Virus in die Blutbahn abgegeben wird.

So konnte man in Infektionsversuchen an empfänglichen Tieren, wie Maus [103, 106] und Schaf [104, 102] im Gegensatz zum Kaninchen [105] nachweisen, in welchem Ausmaß schon nach wenigen Stunden die Virusvermehrung in den regionären Lymphknoten beginnt, bevor noch das TBE-Virus in die Blutbahn abgegeben wird. Auch wenn das Virus per os aufgenommen wird, gelangt es nach einer resorptiven Virämie zunächst in die Milz, um dort primär angereichert und erst später sekundär ins Blut abgegeben zu werden [120].

$\mathrm{Ob}$ die vom Tierexperiment abgeleitete Entwicklung in allen Fällen aber auch sinngemäß auf den Menschen übertragen werden kann, ist allerdings noch unbewiesen. Es spricht aber nichts dagegen, daß man dies zumindest für jene Viren annehmen darf, bei welchen die erste Phase klinisch inapparent oder nur mit leichten Symptomen, wie Fieber (bis $\mathrm{zu} 38^{\circ} \mathrm{C}$ ), zusammen mit charakteristischen Allgemeinbeschwerden einhergeht. Geht aber diese erste Phase mit besonderen klinischen Symptomen, wie z. B. einem Exanthem (Dengue, Chikungunya, O'nyong-nyong, West Nile [2047) oder gar einem Hämorrhagischen Fieber einher, dann muß wohl ein Gewebsschaden vermutet werden, der im letzteren Fall zu der hämorrhagischen Diathese Anlaß gab. 
Bei Obduktionen findet man zwar die für alle HF charakteristischen Veränderungen, wie Blutstauungen in erweiterten Gefäßbezirken, Odeme und Blutungen in allen Geweben sowie perivaskuläre Infiltrate von großen mononukleären Zellen und eine auffallende Proliferation der Zellen des RES. Es ist aber dabei noch unklar, ob hier das Virus die Endothelzellen direkt angegriffen hat oder ob es sich um eine biochemisch $\mathrm{zu}$ erklärende hämodynamische Reaktion wie bei einem Schock gehandelt hat [132].

Die erste Phase stellt - unabhängig vom klirischen Verlauf und unbeschadet aller konsekutiven Komplikationen - die eigentliche "Grundkrankheit“ der Arbo-Virusinfektion dar. In den meisten Fällen heilt die Infektion auch komplikationslos $a b$, und oft stellt nur der Nachweis neutralisierender Antikörper den einzigen Hinweis über die Durchseuchung mit einem Arbo-Virus dar. Dennoch kann es vorkommen, daß das während der Phase 1 im Blut zirkulierende Virus in Zellen anderer Organe eindringt und $\mathrm{zu}$ einer neuerlichen Virusvermehrung in einer zweiten "Organ"phase Anlaß gibt. Dabei ist der Übergang von Phase $1 \mathrm{zu}$ Phase 2 nicht fließend, sondern man findet oft dazwischen ein völlig symptomfreies Intervall, wobei dessen Dauer sehr stark von Krankheit zu Krankheit variiert. So beträgt die „Remission“ (symptomfreies Intervall) bei Gelbfieber durchschnittlich nur einen Tag, während bei TBE meist eine ganze Woche symptomfreies Intervall dazwischen liegt.

Bei den lokalisierten Organmanifestationen findet man im wesentlichen nur drei bevorzugte Orte, nämlich das ZNS, die Leber, aber auch das Mesenchym, so daß wir auch demzufolge mehrere Arten von Erkrankungssystemen kennen, wie die Meningo-Enzephalitis, die Hepatitis und das Dengue-Fieber.

In der Phase 2 haftet das Virus in dem betroffenen Organ, wobei es in den empfänglichen Zellen unter Zerstörung derselben angereichert wird. Eine Ausschüttung des Virus in die Blutbahn ist nicht mehr nachzuweisen, da zu diesem Zeitpunkt - zumindest bei den Infektionen des ZNS - immer schon neutralisierende Antikörper im Serum vorhanden sind; jedoch kann das Virus im Organ selbst nachgewiesen werden.

Die histologischen Veränderungen variieren naturgemäß von Organ zu Organ, da die Möglichkeiten der unspezifischen und spezifischen Abwehr schon von anatomisch-physiologischer Seite aus unterschiedlich angelegt sind. Dagegen unterscheiden sich die pathologischen Veränderungen eines Organs auch nach Infektion mit verschiedenen Arbo-Viren oft nur sehr gering.

So gibt es auch noch keinen sicheren Hinweis, der eine pathologisch-histologische Differentialdiagnose der meisten durch Arbo-Viren hervorgerufenen Infektionen des ZNS ermöglicht.

Der Tierversuch mit Arbo-Viren vermittelt nicht die geeignete Unterlage, um richtige Vergleiche zwischen dem Verhalten des Virus im Tier und im Menschen zu stellen, so daß man bei Betrachtungen über die Pathogenese der Infektion des Menschen in konkreter Weise nur auf Obduktionsbefunde angewiesen ist, die aber infolge der geringen Letalität der Arbo-Virosen zu selten sind, um dar- 
aus ein lückenloses Bild über die Dynamik dieser Infektion zu gewinnen. Insbesondere bleibt noch ungeklärt, warum sich im Einzelfall im Anschluß an die Phase 1 eine Phase 2 überhaupt entwickelt. Als konstant erweist sich bei den Arbo-Viren nur der Organ-Tropismus, der allerdings mit dem Antigenaufbau der Viren nicht korreliert. Vielleicht wäre aber in diesem Zusammenhang an die unterschiedliche Affinität der einzelnen Viren zu bestimmten Phospholipiden zu denken, die als Bestandteile der Zelloberfläche die Adsorption eines Virus beeinflussen könnten.

Das klinische Bild der Arbo-Virosen ist mannigfach, wobei diese Unterschiede nicht nur auf den "Tropismus“ der Viren zurückzuführen sind, sondern auch auf die Variationsbreite innerhalb einer Systemerkrankung überhaupt. Ohne auf die Einzelheiten einzugehen (siehe Einzelkapitel) ist entsprechend der Pathogenese zwischen dem Verlauf der beiden Phasen grundsätzlich zu unterscheiden.

Die Phase 1 läßt alle Übergangsformen von klinisch inapparent $\rightarrow$ leichtes bis mittelhohes (bis $38^{\circ} \mathrm{C}$ ) Fieber $\rightarrow$ hohes Fieber zu. Außer dem Fieber können in der gleichen Reihenfolge neben Allgemeinbeschwerden wie Kopf- und Gliederschmerzen, katarrhalische Erscheinungen (Konjunktivitis, Pharyngitis, Bronchitis) und in der schwersten Form Blutungen als Folge der hämorrhagischen Diathese auftreten. Im allgemeinen dauert die Phase 1 nur ein paar Tage, aber in schweren Fällen von HF bis zu 10 Tage.

Die Phase 2 wird im wesentlichen durch den Organbefall charakterisiert, so daß das allgemeine Krankheitsbild im Hinblick auf Länge, Schweregrad, Prognose dadurch bestimmt wird. Abgesehen von diesen organbedingten Umständen kann sich auch in dieser Phase als Ausdruck eines Gefäßschadens noch ein Exanthem (Dengue, Chikungunya, West Nile) entwickeln oder in besonders schweren Fällen eine hämorrhagische Diathese, wie z. B. beim Gelbfieber oder bei EEE, wobei dann letztere unter dem Bild einer hämorrhagischen Enzephalomyelitis ablaufen kann.

\section{E. Immunbiologie}

Jede Infektion eines Vertebraten führt - im Gegensatz zur Infektion des Arthropoden - stets zur Bildung spezifischer Antikörper, die im Serum mit den einschlägigen diagnostischen Verfahren vorgefunden werden können. Diese Antikörperbildung geht auf die Sensibilisierung des Organismus während der virämischen Phase (= Phase 1 ) zurück, wobei die neutralisierenden und hämagglutinationshemmenden Antikörper zumeist schon nach ca. 7-10 Tagen nachzuweisen sind.

Bei jenen biphasisch ablaufenden Erkrankungen, wie z. B. den Infektionen des ZNS, bei denen zwischen Beginn der Virämie ( $=$ Phase 1) und Beginn der Erkrankung des ZNS (= Phase 2) ein Zeitraum von mehr als einer Woche (bei TBE sind es durchschnittlich 12 Tage) verstreicht, sind diese Antikörper dann immer schon vor Ausbruch 
der Phase 2 vorhanden. Dies ist vor allem auch für die Diagnostik von wesentlicher Bedeutung, weil im Verlauf derartiger Erkrankungen wohl ein Titeranstieg im NT und HHT, nicht aber mehr eine Konversion in diesen Seroreaktionen, erwartet werden darf.

Im Gegensatz hierzu sind die komplementbindenden Antikörper nicht regelmäßig am Beginn der Phase 2 nachweisbar, so daß eine Konversion erwartet und dadurch eine frische Infektion relativ einfach nachgewiesen werden kann. Eine Eigenart der Antikörperbildung bei den Arbo-Virosen ist, daß mit Dauer der Sensibilisierung (sei es im Verlauf einer Infektion oder auch während einer aktiven Immunisierung mit inaktivierten Viren) die Spezifität des Antikörpers gegen das ursprüngliche Virusantigen abnimmt und in zunehmendem $\mathrm{Maß}$ auch gegen andere - meist eng verwandte - Stämme derselben Gruppe Antikörper gebildet werden. Dies kann man sehr leicht im HHT und auch in der KBR verfolgen, weil hier diese Úberschneidungen innerhalb einer Gruppe besonders deutlich manifest werden. Ein Antikörper-Breitspektrum kann man auch durch Immunisierung mit ein paar Stämmen einer Gruppe crzielen, wobei dann Kreuzreaktionen mit fast allen Stämmen der gleichen Gruppe auftreten können.

Dieses Phänomen wirkt sich zwar zum Nachteil eines Untersuchers aus, wenn er in einer Gegend, in welcher mehrere Stämme der gleichen Gruppe nebeneinander vorkommen, nach spezifischen Antikörpern sucht, so daß er hier ohne quantitativen NT keine verläßliche Aussage machen kann. Einer Population gereicht es dagegen zum Vorteil, weil sich mit jeder neuerlichen Infektion (bzw. Immunisierung) das Immunitätsspektrum auch auf andere heterologe Antigene erweitert (siehe Prophylaxe).

\section{Serologische Untersuchungsmethoden}

\section{a) Der Neutralisationstest (NT)}

Im NT wird die Infektiosität eines Virus neutralisiert, wobei die intrazerebrale Applikation des Serum-Virusgemisches in Mäusen den Standardtest darstellt.

Die Empfindlichkeit des Testes zum Nachweis von Antikörpern ist aber sehr deutlich abhängig von der Inokulationsroute (i.p. empfindlicher als i.c., Babymaus empfindlicher als erwachsene Maus); außerdem hat sich gezeigt, daß frisches normales Rhesusserum einen Faktor (accessory oder labile factor) enthält, der die Empfindlichkeit des Antikörpernachweises steigert. Beim NT in der Maus wird heute auch nach Theiler dic durchschnittliche Úberlebenszeit (avcrage survival time) der Überlebensrate für die Bewertung vorgezogen.

Darüber hinaus werden in letzter Zeit auch Gewebekulturen verwendet, die cinen sehr empfindlichen Indikator darstellen und sich im Vergleich zum Mäusetest als die rationellere Methode erweisen.

Dabei kann das Serum-Virusgemisch auf einen dichten Zellrasen übertragen oder simultan mit einer relativ niedrigen Zellzahl $(15000-30000 \mathrm{ml})$ in Röhrchen eingesät 
werden $[95,96]$. In jedem Einzelfall wird es aber davon abhängig zu machen sein, ob geeignete Zellen zur Verfügung stehen, in denen eine Vermehrung durch CPE bzw. Hämadsorption [26] leicht ablesbar ist.

Der NT kann quantitativ angesetzt werden, wobei es sich - zumindest bei TBE als sehr gut erwies, eine hohe Antigen-Konzentration (3000-5000 TCID $50 / 0,1 \mathrm{ml}$ ) mit fallenden Serumverdünnungen anzusetzen. Dagegen wird man bei qualitativen Untersuchungen (screening-test) die Antigenkonzentration sehr niedrig halten (ca. $100 \mathrm{TCID}_{50} / 0,1 \mathrm{ml}$ ) [91].

Eine besondere Methode des Neutralisationstests stellt der Einsatz der „PlaqueTechnik" dar, wobei man unterscheiden kann zwischen einem

a) Plaque-Neutralisationstest [48] (Virus-Serumbindung in vitro vor Beimpfung des Zellrasens),

b) Plaque-Reduktionstest (Serumzugabe zur Agarschichte nach Beimpfung des Zellrasens) und

c) Plaque-Inhibitionstest [136].

Der Plaque-Test bzw. der Plaque-Reduktionstest ist sehr empfindlich und für subtile quantitative Untersuchungen geeignet. Der Plaque-Inhibitionstest ist einem AntibiotikaHemmhof gegenüber Bakterien sehr ähnlich, weil auch hier der Durchmesser der Hemmung des CPE einer Gewebekultur unter einer Agarschichte gemessen wird, wobei dieser Hemmhof durch Diffusion eines antikörperhaltigen Serums, aber auch anderer inhibierender Substanzen, wie z. B. Interferon [135], durch die Agarschichte auf den infizierten Zellrasen erfolgt.

\section{b) Der Hämagglutinations-Hemmungstest (HHT)}

Dieser Test wird nach einer genauen Standardvorschrift [39] heute überall einheitlich ausgeführt. Er stellt ein ausgezeichnetes Verfahren für Durchseuchungsuntersuchungen (Survey) dar, weil infolge der Agglutinations-Gemeinschaften innerhalb der einzelnen Gruppen es auch mit nicht homologen Antigenen möglich ist, Antikörper in einer Population zu erfassen.

Der HHT wird quantitativ angesetzt, wobei eine lineare Korrelation zwischen Agglutination und Antikörper-Konzentration besteht, wie man aus zweidimensionalen Ansätzen entnehmen kann, die sich auch zum Nachweis von Subtypen unerläßlich erweisen (31a).

\section{c) Die Komplementbindungsreaktion (KBR)}

Diese Reaktion wird in der Praxis zum Nachweis frischer Infektionen (aber auch zur Identifizierung frisch isolierter Stämme) verwendet, wobei man sich heute der Mikro-Tropfmethode nach Fulton und Dumbell [53] bedient, den Reaktionsansatz aber in der üblichen Weise (mit Serumverdünnungen gegen konstante Ag und Komplementmengen) nach CaSals et al. [33] vornimmt. Hierzu eignen sich Plastikplatten (Disposo-Trays der Linbro Chemical Co.), deren Näpfchen so geformt sind, daß man trotz des geringen Gesamtvolumens von ca. $0,15 \mathrm{ml}$ die Reaktion scharf ablesen kann. 


\section{F. Epidemiologie}

Das auffallendste Charakteristikum der Arbo-Virosen stellt wohl der eigentümliche Zyklus des Virus in der Natur dar, wobei immer Arthropoden, und zwar - soweit bisher bekannt - Zecken oder blutsaugende Mücken als Vektoren eingeschaltet sind. Dadurch resultiert ein eigentümlicher Rhythmus in der Infektionskette, der von den Lebensgewohnheiten der betroffenen Wirtstiere, den einzelnen Arten der Arthropoden, aber auch den Klimaunterschieden (Tropen - gemäßigte Zone) abhängig ist. Dies kommt auch im saisonmäßigen Ablauf mancher Infektionen deutlich zum Ausdruck (Frühsommer-MeningoEnzephalitis [FSME] und Herbst-Enzephalitis [JBE].

\section{Eigenschaften der Arthropoden}

Arbo-Viren sind bisher aus Culiciden, Ceratopogoniden (Culicoides), Simuliiden, Psychodiden (Phlebotominae), verschiedenen brachyzeren Fliegen, Ixodiden und verschiedenen anderen Milben (Gamasina) isoliert worden. Von diesen Arthropoden - durchwegs aus der Gruppe der Diptera (Zweiflügler) einerseits und der Gruppe der Acarina (Milben) andererseits - ist die Vektorfunktion - was die Arbo-Viren des Menschen betriff - durch den Nachweis der Vermehrungsfähigkeit des Virus nach Aufnahme mit der Blutmahlzeit bisher lediglich bei den Culiciden (deutsch: Stechmücken), bei den Phlebotominen (deutsch: Sandfliegen; siehe Pappataci-Fieber) und den Ixodiden (deutsch: Zecken) sichergestellt.

\section{a) Die Stechmücken}

Die Culiciden (englisch: mosquitoes) gliedern sich in mehrere Subfamilien (z. B. Anophelinae; Culicinae) und zahlreiche Genera (z. B. Anopheles; Aedes, Mansonia, Culex, Psorophora, Haemagogus, Culiseta). Diese Genera bzw. auch deren Spezies unterscheiden sich keinesfalls allein durch morphologische Charakteristika, sondern vor allem auch in ihrem Verhalten in der Umwelt, Wirtsspezifität, Lebensdauer und Art der Hibernierung sowie auch in ihrer geographischen Verbreitung.

Die Aufnahme des Virus erfolgt mit der Blutmahlzeit, wobei eine kritische Minimalmenge in dem aufgenommenen Blut vorhanden sein muß. Das Virus wird dann im Gewebe vermehrt und in der Speicheldrüse ausgeschieden. Das Intervall zwischen Virusaufnahme und Virusausscheidung wird als „äußere Inkubationszeit" (extrinsic incubation period) bezeichnet. Die Dauer dieses Intervalls ist in erster Linie von der Temperatur und relativen Feuchte der Umwelt und nur in zweiter Linie von der virusïbertragenden Spezies abhängig. Die Mücke ( $q$ ) bleibt zeitlebens infektiös und kann bei allen weiteren Blutmahlzeiten den Wirt infizieren. Eine transovarielle Übertragung des Virus auf 
die $F_{1}$-Generation ist noch nie gefunden worden. Die Entwicklung verläuft holometabol, d. h. über die wohl abgegrenzten Stadien des Eies, der Larven, der Puppe und der Imago. Die Larven der Culiciden sind durchwegs aquatisch (stehende Gewässer!) und ernähren sich vom Plankton. Die Lebensdauer der Mücken (Imagines) ist in Abhängigkeit von der Ókologie resp. Biologie der einzelnen Arten sehr verschieden und schwankt zwischen wenigen Wochen; sie kann sich im Fall der Úberwinterung (z. B. Culex Anopheles, Theobaldia) bis auf 8 Monate ausdehnen. Abgesehen von der Mückenspezies spielen aber auch die Klimafaktoren, insbesondere in den gemäßigten Zonen, die Art der Hibernierung, ob als Ei, Larve, oder Imago, eine wesentliche Rolle, sowie ob es sich um frei in der Natur oder vorwiegend im Bereich menschlicher Siedlungen (Keller, Stallung usw.) lebende Mücken handelt. Der Aktionsradius einer Mücke ist ebenfalls von Art zu Art schwankend, überschreitet aber im wesentlichen nicht $20 \mathrm{~km}$; manchmal kann aber die passive Lokomotion (Wind!) sich über weitaus größere Entfernungen hin erstrecken.

Auf Grund des großen Aktionsradius und der Fähigkeit der Weibchen (Männchen stechen nie!), mehrmals Blutmahlzeiten einzunehmen, ist ein oftmaliger Wirtswechsel möglich, so daß auch in den gemäßigten Zonen innerhalb einer warmen Saison eine rasche Verbreitung einer Virusinfektion unter Menschen, aber auch domestizierten und frei lebenden Tieren, resultieren kann. Dabei werden auch schon Säuglinge und Kleinkinder infiziert, so daß auch die Durchseuchung dieser Population meist schon im frühen Lebensalter einsetzt. Die Aktivität der Mücken ist von der Temperatur und von der relativen Feuchte abhängig, so daß sie vor allem in der Abenddämmerung schwärmen.

Der Mückenstich führt zu objektiv feststellbaren Hautreaktionen, die als Folge des Traumas und des eingespritzten Speicheldrüsensekretes auftreten; diese Hautreaktion steht aber in keiner Beziehung zur Inokulation des Virus.

\section{b) Die Zecken}

Für die Übertragung von Arbo-Viren kommen Vertreter der Familien Argasidae (Lederzecken) und Ixodidae (Schildzecken) in Frage, die zwar eine Fülle spezifischer morphologischer Merkmale aufweisen, im Hinblick auf ihre Bedeutung als Vektoren aber gemeinsam behandelt werden können.

Im Gegensatz zu den blutsaugenden Steckmücken können die Zecken schon im Larven- und Nymphenstadium Blut saugen und somit in allen Stadien cin Virus übertragen. Ein weiteres Charakteristikum der Zecken ist, daß sie in jedem Stadium nur „einwirtig“ sind, d. h. daß die nächste Blutmahlzeit erst im nächsthöheren Stadium erfolgt, ausgenommen die adulten Argasidae-Weibchen, die mehrmals Blut saugen. Der Saugakt selbst dauert einige Tage. Im Prinzip sind nur 3 Hauptstadien (Larve, Nymphe, Adulte) abzugrenzen, jedoch kommen bei den Argasidae mehrere Nymphenstadien (1., 2., 3. Ordnung) vor. Es gibt daher auch bei den Zecken keine sogenannte äußere Inkubations- 
zeit, sondern das Virus vermehrt sich während der Metamorphose in den verschiedenen Organen und wird zunächst mit den Fäzes und im nächsthöheren Stadium mit dem Speichel ausgeschieden. Dabei kann das Virus auch transovariell auf die nachfolgende Generation übergehen. Ob dieses Phänomen der transovariellen Übertragung nur auf den Umstand zurückzuführen ist, daß bei den Zecken die Eier von nur einer Membran und bei den Mücken aber von drei Membranen umhüllt werden, ist allerdings nicht geklärt [181].

Diese transovarielle Ưbertragung wurde im Laboratorium mehrfach nachgewiesen (siehe TBE) und findet ihre Bestätigung auch darin, daß man in der Natur immer wieder aus hungrigen Larven das Virus isolieren kann. Der Prozentsatz der transovariellen Übertragung des Virus auf die $\mathrm{F}_{1}$-Generation dürfte aber nur sehr gering sein und wird mit ca. $5 \%$ pro Gelege eingeschätzt; er reicht jedenfalls allein nicht aus, um das Virus in einem Fokus zu erhalten.

Die Zecken leben viel länger als die Stechmücken, manchmal sogar mehrere Jahre, wenn aus z. T. noch unbekannten Gründen die Stadienfolge nicht regelmäßig einsetzt, sondern u. U. um ein ganzes Jahr unterbrochen wird. Im Laboratorium kann man aber unter optimalen Bedingungen alle Stadien eines dreiwirtigen Ixodes ricinus innerhalb von 8 Monaten erleben.

$\mathrm{Da}$ die Zecken in der freien Natur leben und keine Beziehung zur menschlichen Zivilisation besitzen, wird im Gegensatz zu den Stechmücken der Mensch nur dann als Blutspender fungieren, wenn er sich in das Territorium der Zecken begibt. Das hat auch unmittelbar zur Folge, daß die Durchseuchung einer Population nie den Grad wie bei den durch Stechmücken übertragenen Infektionen erreicht, wobei hier die Lebens- (und Berufs-) gewohnheiten der autochthonen Bevölkerung von entscheidender Bedeutung sind; insbesondere ist auffallend, daß die Durchseuchung erst in einem viel späteren Lebensalter einsetzt als bei den durch Stechmücken übertragenen Infektionen, so daß die Zecken somit auch nicht für die Übertragung von „Kinderkrankheiten“ verantwortlich sind. Möglicherweise ist auch diese "späte“ Erstinfektion für die oft mit (wahrscheinlich altersbedingten) Komplikationen einhergehende klinische Verlaufsform verantwortlich (siehe TBE). Der "aktive“ Aktionsradius der Zecken ist sehr gering, so daß er praktisch vernachlässigt werden kann, jedoch können die Zecken passiv während des Saugaktes an Vertebraten über auch sehr weite Entfernungen hin (durch Zugvögel von Kontinent zu Kontinent) verschleppt werden. Die Aktivität der Zecken ist unmittelbar von der relativen Feuchte abhängig. Entsprechend den drei Stadien unterscheidet sich das Wirtsspektrum, da die Larven nur Kleintiere (vor allem Nager), die Adulten immer aber größere Tiere befallen, während Nymphen hilsichtlich ihres Wirtsspektrums keine signifikante Präferenz aufweisen; das hängt einerseits vom Verhalten der Tiere, andererseits aber auch von der Unfähigkeit der Larven ab, mit ihren Mundwerkzeugen das dicke Stratum corneum eines großen Tieres zu perforieren. Der Mensch wird somit nur von Nymphen und Adulten ( $(+)$ gestochen, wobei das Trauma nicht gespürt wird. Erst nach einiger Zeit (12 bis 
24 Stunden) wird ein Juckreiz um die lokal gerötete Einstichstelle mit der noch saugenden Zecke wahrgenommen. Manche Zecken, insbesondere Dermacentor-Arten, geben bei dem Stich ein neurotrop wirkendes Toxin mit dem Speichel ab, das zur "Zeckenparalyse“ bei Mensch und Tier führen kann. Dieses Neurotoxin hat aber nichts mit neurotropen Viren gemein.

\section{Eigenschaften der Wirtstiere}

Die von den Arthropoden gestochenen und dabei infizierten Vertebraten bekommen nach einer Inkubationszeit von wenigen Tagen bis maximal einer Woche eine Virämie und stellen in diesem Stadium für alle zu diesem Zeitpunkt stechenden Arthropoden die Infektionsquelle dar. Darüber hinaus wird das Virus von laktierenden Tieren im Stadium der Virämie mit der Milch ausgeschieden. Die Dauer der Virämie ist bei den einzelnen Vertebraten unterschiedlich lang, im allgemeinen aber nicht länger als eine Woche.

Es wird aber auch über Untersuchungen mit CTF-Virus berichtet [27, 28], welches beim Stachelschwein und bei einigen Nagetieren Virämien mit einer Dauer bis zu 50 Tagen auslöst. Außerdem kann man ein virämisches Stadium dadurch künstlich verlängern, daß man das Tier hiberniert [193].

Die Virämie geht im natürlichen Wirtstier ohne klinisch manifeste Erkrankungen einher und wird von der Bildung neutralisierender Antikörper gefolgt, ohne daß es nach einem kurzen Intervall zu einer zweiten Phase kommt.

Ändert sich dieser natürliche Zyklus bzw. erweitert man das natürliche Infektionsspektrum in ein „künstliches“ Infektionsspektrum (nach DoERR), dann kann es zu Krankheitserscheinungen kommen, die man beim Tier (z. B. PferdeEnzephalitis) und beim Menschen (alle bekannten Arbo-Virosen) beobachten kann. Eine Ausnahme bilden Infektketten, bei denen zumindest ein Teil der Vertebraten, die für die Aufrechterhaltung des natürlichen Zyklus benötigt werden, in typischer Weise erkrankt (z. B. Schafe bei Louping ill).

Im Rahmen einer Fokusbildung kommt den Vertebraten die besondere Rolle des Virusreservoirs zu. Befindet sich dieser Fokus in den Tropen, ist eine kontinuierliche Infektionskette mit Arthropoden gegeben, da keinerlei klimatische Schwankungen die Vermehrung der Vertebraten und Arthropoden beeinflussen. In den gemäßigten Zonen aber ist die Frage der Überwinterung des Virus noch nicht geklärt. Wahrscheinlich überwintert das Virus an Ort und Stelle in hibernierenden oder poikilothermen Tieren bzw. in den Zecken (transovarielle Übertragung); die Möglichkeit aber, daß es durch Zugvögel immer wieder neu eingeschleppt wird, darf nicht außer Betracht gelassen werden.

Grundsätzlich muß man aber in einem Fokus zwischen Vertebraten des natürlichen Grundzyklus und jenen Vertebraten unterscheiden, die - genau so wie der Mensch - nur fakultativ infiziert wurden, ohne für die Erhaltung des Zyklus unbedingt notwendig zu sein; sie können zwar die Verbreitung des 
Virus zusätzlich fördern, sind aber nicht imstande, allein den Zyklus zusammen mit den Arthropoden aufrechtzuerhalten. Eine genaue Analyse der Bedeutung der einzelnen Vertebraten in einem Fokus ist daher sehr schwierig.

\section{Der Fokus}

Ein natürlicher Infektionsherd setzt neben dem Virus einerseits ein Wirtsreservoir und Vektoren, andererseits eine entsprechende Dichte der Vertebraten und Vektoren voraus, um von Bestand sein zu können. Die Verlustraten im Rahmen derartiger Zyklen sind jedenfalls sehr hoch, so daß bei engem und regem Kontakt zwischen Vertebrat und Arthropode - zumindest zu bestimmten Jahreszeiten - das Virus in großer Zahl weiter vermittelt werden muß, um die Verluste vor allem in den gemäßigten Zonen während der Wintermonate kupieren zu können. Somit wird auch die Durchseuchung durch eine möglichst lange Virämiedauer und durch rasche Generationsfolge der als Reservoir dienenden Vertebraten gefördert.

Abgesehen von der Dezimierung der Vertebraten und Arthropoden durch natürliche Feinde, Klimafaktoren u. ä. wirkt sich als gegenläufiger Mechanismus einer Durchseuchung die Antikörperbildung der einmal infizierten Vertebraten aus. Selbst wenn die von BENDA [20] im Experiment gefundene, aber sonst nicht bestätigte Beobachtung der Neutralisation eines Virus in einem Arthropoden anläßlich einer neuerlichen Blutaufnahme mit neutralisierenden Antikörpern außer Betracht gelassen wird, wird doch bei Befall mit einem infektiösen Arthropoden in einem bereits immunisierten Vertebraten die Infektionskette zunächst einmal unterbrochen. $\mathrm{Da}$ die Virämie nur kurzdauernd und einmalig im Leben eines Vertebraten vorkommt, die neutralisierenden Antikörper aber zeitlebens vorhanden bleiben, wird auch mit zunehmender Lebensdauer der Vertebraten sinngemäß die Chance der Virusausbreitung verringert.

Im extremen Fall kann auch ein Fokus erlöschen, wenn er nicht neuerdings von außen reinfiziert wird. So findet man auch Hinweise im Zusammenhang mit menschlichen Erkrankungen, wie dem Verschwinden der „Australian X Disease“, die derartige Überlegungen unterstützen.

\section{Natürliche Zyklen}

Vom epidemiologischen Standpunkt aus kann man drei verschiedene Zyklusarten in der Natur unterscheiden:

a) Der primitive Zyklus einer germinalen Infektkette

$\rightarrow$ Zecke $($ P-Gen. $) \rightarrow$ transovariell $\rightarrow$ Zecke $\left(\mathrm{F}_{1}-\right.$ Gen. $) \rightarrow$ transovariell $\rightarrow$ 
Dieser Zyklus muß von theoretischer Seite aus als möglich postuliert werden, da die transovarielle Übertragung von Arbo-Viren bei Zecken im Experiment und unter natürlichen Bedingungen nachgewiesen wurde. Ob dieser Zyklus je für sich allein bestanden haben mag [181], ist umstritten; heute kann er jedenfalls bei den uns bekannten Arbo-Virosen nur als Nebenzyklus gewertet werden. Die Existenz eines derartigen Zyklus gibt uns aber jedenfalls die Möglichkeit, die ursprüngliche Entstehung zumindest der heute durch Zecken übertragenen ArboViren davon abzuleiten.

Wenn man davon ausgeht, daß die Arbo-Viren in den Zellen der Zecken sich zwar vermehren, aber keine pathologischen Veränderungen verursachen, darf man auf eine enge Beziehung zwischen diesen Zellen und den Viren schließen; sie muß jedenfalls enger sein als zu den Zellen der Vertebraten, die daran zugrundegehen bzw. mit einer Antikörperproduktion reagieren. Man könnte daher denken, daß zu irgendeinem Zeitpunkt der Evolution aus einer Zelle einer Zecke ein Teil der zelleigenen NS sich abgespaltet und selbständig gemacht hat, zunächst transovariell weitergegeben und erhalten wurde und im Laufe der Zeit durch die Passagen auch in Vertebraten adaptiert und die Form der uns heute bekannten Arbo-Viren angenommen hat [181].

\section{b) Der Zyklus einer homogenen Infektkette}

\section{$\rightarrow$ Arthropode A $\rightarrow$ Vertebrat $1 \rightarrow$ Arthropode A $\rightarrow$ Vertebrat $1 \rightarrow$ Arthropode A $\rightarrow$}

Diese homogene Infektkette stellt die Basis jedes Fokus dar, wobei der Vertebrat schon für die Erhaltung des Zyklus im Fokus unbedingt benötigt wird. Eine Sonderform unter Einschub des Menschen stellt dieser Zyklus beim urbanen Gelbfieber dar.

$$
\rightarrow \text { Aedes } \rightarrow \text { Mensch } \rightarrow \text { Aedes } \rightarrow \text { Mensch } \rightarrow
$$

Einem Zyklus unter Einbeziehung des Menschen als Reservoir kommt aber keine Priorität $\mathrm{zu}$, sondern er stellt auch im vorliegenden Fall infolge Änderung der Umweltbedingungen eine sekundä:e Verwandlung des natürlichen Infektionsspektrums ( $\rightarrow$ Affe $\rightarrow$ Haemagogus $\rightarrow$ Affe $\rightarrow$ Haemagogus $\rightarrow$ ) dar.

\section{c) Der Zyklus mit heterogener Infektkette}

$$
\rightarrow \text { Arthropode A } \rightarrow \text { Vertebrat } 1 \rightarrow \text { Arthropode B } \rightarrow \text { Vertebrat } 2 \rightarrow
$$

Diese heterogenen Infektketten werden in der Natur am häufigsten vorgefunden, weil innerhalb eines Fokus meist verschiedene Vertebraten durch Stich infiziert werden, wobei auch verschiedene gleichzeitig vorhandene ArthropodenSpezies, vor allem was die durch Mücken übertragenen Virosen betrifft, das 
Virus übertragen können. Hier ist die Entscheidung sehr schwierig, oft sogar unmöglich, festzustellen, welche Vertebraten und Arthropoden für die Erhaltung des Fokus unbedingt notwendig sind. Dabei können einerseits durch Arthropoden diverse Vertebraten infiziert werden, die für den Zyklus ohne Bedeutung sind und nur als blinde Endglieder bzw. Nebenglieder einer Infektkette fungieren, wie es beispielsweise bei den meisten Arbo-Virosen dem Menschen zukommt, andererseits auch blutsaugende Arthropoden an virämischen Vertebraten infiziert werden, ohne das Virus weiter verbreiten zu können (Flöhe, Läuse).

Man darf sich daher grundsätzlich bei einer Felduntersuchung auf Grund einer Virusisolierung bzw. eines Nachweises von Antikörpern nicht zu voreiligen Schlüssen verleiten lassen.

\section{Endemie - Epidemie}

In den meisten Fällen treten die Arbo-Virosen endemisch auf. Das Virus kreist in seinem natürlichen Zyklus und die Infektion des Menschen (oder des anfälligen Tieres) spielt dabei eine inferiore Rolle.

Die Durchseuchung der Vertebraten hängt von deren Lebensgewohnheiten und vom Verhalten der Vektoren ab. Bei den durch Stechmücken übertragenen Infektionen ist die Durchseuchung vor allem in den tropischen Zonen sehr hoch und setzt schon bei den Kleinkindern ein, während bei den durch Zecken übertragenen Viren es im wesentlichen davon abhängt, in welchem Ausmaß und von welchem Zeitpunkt an der Mensch mit den standortgebundenen Zecken in Kontakt kommt; i. a. setzt die Durchseuchung viel später ein, so daß auch die Rate wesentlich niedriger liegt. In beiden Fällen aber bleibt der prinzipiell endemische Charakter der Infektion gewahrt. Andert man jedoch diese Situation eines endemischen Fokus, so kann sich das Virus auch epidemisch verbreiten:

a) Verschleppung des Virus aus dem Fokus in eine nicht immunisierte Population: Buschgelbfieber $\rightarrow$ Stadtgelbfieber.

b) Massive Einwanderung von nicht immunisierten Vertebraten in einen Fokus: epidemische Ausbrüche von Gelbfieber bei Kolonisten, Arbeiten beim Bau des Panamakanals usw.

c) Genuß ungekochter und nicht pasteurisierter Milch virämischer Vertebraten: Epidemie von FSME in Roznava 1951 [24].

\section{Verbreitung der Viren in fremde Territorien}

Dieser besonderen Frage wird nicht nur aus seuchenhygienischen, sondern auch aus prinzipiellen Überlegungen über die potentielle Entstehung eines 
neuen Fokus heraus große Aufmerksamkeit beigemessen. Eine Verschleppung des Virus selbst ist auch auf weite Entfernungen möglich durch

a) Zugvögel

b) infizierte reisende Menschen

c) Arthropoden in Transportmitteln (Schiff, Flugzeug).

Damit aber ein derartig verschlepptes Virus einen neuen Fokus bilden kann, sind einerseits die schon zuvor beschriebenen Prämissen an Vertebraten und Vektoren erforderlich. Andererseits darf auch nicht unberücksichtigt bleiben, daß möglicherweise an diesem neuen Ort schon andere antigenverwandte Viren dominieren, die bereits zu einer Immunisierung der Vertebraten geführt haben. Dadurch könnte auch die weitere Verbreitung einer neu eingeschleppten Infektion blockiert werden.

Dieses Phänomen wird auch immer wieder als Erklärung herangezogen, warum die in Ägypten mit West Nile durchseuchte autochthone Population nicht anfällig ist für Gelbfieber, obwohl alle anderen Voraussetzungen (Klima, Vektor) für einen Gelbfieberfokus gegeben wären.

Es muß schließlich noch in Betracht gezogen werden, daß möglicherweise den Zugvögeln auch die Aufgabe zukommt, die in der gemäßigten Zone saisonmäßig ablaufenden Arbo-Virosen jedes Frühjahr neu mit Virus bzw. mitgeschleppten infizierten Arthropoden zu versorgen. Dies wird bei den Foci von WEE und EEE in USA mit großer Wahrscheinlichkeit angenommen.

Auch der Verschleppung des Virus durch Personen während der Inkubationszeit und durch Arthropoden, die im Flugzeug mitgenommen wurden, kommt eine gewisse Bedeutung zu. So stellt man sich auch vor, daß das in Afrika ursprünglich beheimatete Gelbfieber-Virus in infizierten Mücken auf Schiffen nach Amerika verschleppt wurde. Da durch den modernen Verkehr im Flugzeug diese Verbreitungsmöglichkeit weitaus größere Chancen hat, wurden auch von der WHO geeignete Empfehlungen zur Desinfektion von Flugzeugen ausgegeben, die im internationalen Flugverkehr Anwendung finden [211].

\section{G. Prophylaxe}

Prophylaktische Maßnahmen gegen die Ausbreitung einer Arbo-Virusinfektion können einerseits gegen den Vertebraten als Wirt des Reservoirs, andererseits gegen den Arthropoden als Vektor gerichtet sein. Darüber hinaus ist auch noch eine spezifische Prophylaxe des Menschen und gefährdeter Tiere durch aktive und passive Immunisierung möglich.

Alle Versuche, das Virusreservoir - wenn schon nicht völlig auszurotten so doch zumindest so zu reduzieren, daß ein natürlicher Zyklus nicht mehr aufrecht erhalten bleiben kann, scheitern meist schon an dem mangelnden Wissen, welche Tierart als Reservoir anzusehen ist. Darüber hinaus dürfte es auch heutzutage sehr schwierig, wenn nicht unmöglich sein, beispielsweise bestimmte Vögel oder Nager in einem Herd mit Erfolg zu bekämpfen. 
Eine Beeinflussung eines Herdes scheint vielmehr durch menschliche Eingriffe eher im gegenteiligen Sinn gegeben zu sein, wenn beispielsweise die natürlichen „Feinde“ (Raubvögel, Raubtiere) in einem Fokus eliminiert werden und infolgedessen die Tiere des Virusreservoirs sich über das sonst natürliche Maß hinaus vermehren können.

Im Gegensatz hierzu ist die Bekämpfung der Arthropoden zum Zweck der Elimination eines Fokus schon seit langer Zeit gepflogene Methode, die sich insbesondere bei der Ausrottung des Gelbfiebers in den amerikanischen Hafenstädten ausgezeichnet bewährt hatte. Mit der Entwicklung moderner Insektizide und Akarizide haben diese Bekämpfungsmaßnahmen neuen Auftrieb erhalten und insbesondere auch den Menschen in die Lage versetzt, größere Territorien zu behandeln. Hier waren es vor allem auch russisch€ Autoren, die in zahlreichen Felduntersuchungen die so diffus verbreiteten Zecken bekämpften. Inwieweit man damit auch dauernde Erfolge wird erzielen können, ist problematisch, weil im Gegensatz zu den an den Menschen und seine Haustiere adaptierten Arthropoden, die auch in seiner unmittelbaren Nähe leben, die in der freien Natur vorkommenden Arthropoden, insbesondere die Zecken, bei weitem schwieriger als Moskitos zu erreichen sind, abgesehen von dem nahezu unbegrenzten Territorium ihrer Verbreitung.

Neben diesen allgemeinen Bekämpfungsmaßnahmen ist für den Menschen und seine Haustiere die gezielte Immunprophylaxe von wesentlicher individueller Bedeutung.

Die aktive Immunisierung wird dabei schon seit vielen Jahren mit großem Erfolg angewandt, wobei einerseits Vakzinen mit nicht vermehrungsfähigen Keimen (meist durch Formalinzusatz inaktivierte Viren) und Vakzinen mit attenuierten Stämmen zur Verfügung stehen.

Die passive Immunisierung hat im wesentlichen die Aufgabe, bei Laborinfektionen dem Betroffenen einen Sofortschutz zu vermitteln, während sie für die allgemeine Verwendung wohl kaum in Frage kommt. Hyperimmunsera bzw. Hyperimmunglobuline gegen TBE-Virus wurden zu diesem Zweck hergestellt und auch entsprechend ausgetestet.

\section{Spezieller Teil}

\section{Der Tick Borne Encephalitis-(TBE-)Komplex}

Der TBE-Komplex setzt sich aus Virusstämmen der Gruppe B zusammen (siehe Tabelle), die durch Zecken übertragen werden und in ihrem Antigenaufbau so eng verwandt sind, daß man sie untereinander nur mit Hilfe von absorbierten Sera oder Kreuzpräzipitationen im Agar-Gel unterscheiden kann [41]. Die Bezeichnung „Enzephalitis“ soll dabei andeuten, daß die meisten Virusstämme dieses Komplexes eine Erkrankung des Zentralnervensystems (ZNS) beim Menschen und beim Tier auslösen können. Als typische Krankbeiten sind davon bekannt: 
1. TBE-Virus

a) Subtyp RSSE: Russische Fern-Ost-Enzephalitis

b) Subtyp CEE: Frühsommer-Meningo-Enzephalitis

2. Virus Typ LI: „Louping ill“ der Schafe.

Außerdem gehören noch hiezu 2 Virusstämme, die zwar aus Gehirnen von an Meningo-Enzephalitis verstorbenen Menschen isoliert wurden, ohne aber für eine in dieser Region endemisch auftretende Erkrankung des ZNS (bisher) verantwortlich gemacht werden zu können.

3. Virus Typ Powassan (Kanada) [101]

4. Virus Typ Negishi (Japan) [127].

Schließlich gehört in diese Gruppe noch der

5. Virus Typ Langat TP 21,

der 1956 aus Ixodes granulatus in Malaya isoliert worden ist [57].

Ixodes granulatus befällt normalerweise den Menschen nicht, jedoch sind bisher vereinzelt neutralisierende Antikörper gegen dieses Virus unter der einheimischen Bevölkerung in Malaya gefunden worden [59a]. Der Verbreitungsmodus ist noch unklar. Der Virusstamm selbst zeichnet sich durch seine geringe Neurovirulenz bei Tier und Mensch aus und wird als attenuierter Impfstamm beim Tier verwendet (siehe Louping ill).

Die restlichen 2 Typen rufen beim Menschen das klinische Bild eines Hämorrhagischen Fiebers hervor:

6. Virus Typ Omsk (mit Subtyp I und II): Omsker Hämorrhagisches Fieber (Zentral-Sibirien)*

7. Virus Typ KFD: Kyasanur Forest Disease (Indien)*

\section{Die Russische Fernost-Enzephalitis}

Synonyma: Russian spring summer encephalitis, Russ. Frühling-SommerEnzephalitis, Fernöstliche Wald-Enzephalitis, Taiga-Enzephalitis

Nach russischen Angaben [130] wurde schon seit 1932 im Fernen Osten eine Häufung von Meningo-Enzephalitiden des Menschen beobachtet. Unter Leitung von SILBER wurde 1937 eine groß angelegte Feld-Untersuchungsaktion gestartet, die von 1937 bis 1939 nicht nur zur Isolierung von verschiedenèn Virusstämmen aus Menschen, Zecken und Nagern, sondern auch schon zur Aufklärung des Infektionszyklus geführt hatte [213].

1941 konnten dann SMORODINTSEv et al. [175a] auch schon über gelungene Versuche einer aktiven Immunisierung des Menschen mit Hilfe von formolisierten

* Wird unter 5. „Die Hämorrhagischen Fieber (HF)“ S. 468 behandelt. 
Vakzinen aus Überständen von infizierten Mäusegehirnen berichten. CASALS und Webster [34, 35] wiesen schließlich 1943 und 1944 die Antigenverwandtschaft mit Louping ill nach.

Nach Pawlowsky wird dieses Virus in erster Linie durch Ixodes persulcatus, möglicherweise aber auch durch Haemaphysalis concinna und Dermacentor silvarum übertragen. In allen drei Fällen handelt es sich um dreiwirtige Zecken, bei denen das Virus nicht nur die Metamorphose überlebt, sondern auch transovariell übertragen wird [130].

Ixodes persulcatus weist eine Aktivitätsspitze im Frühsommer auf, die mit der jahreszeitlichen Verteilung der menschlichen Erkrankungen gut korreliert [174], während die auch im Fernen Osten auftretende „Herbst-Enzephalitis“ durch JBE-Viren hervorgerufen und durch Stechmücken übertragen wird [176].

Die tatsächliche geographische Verbreitung der Erkrankung im Fernen Osten und in Sibirien wird von den russischen Autoren nirgends genau angegeben; sie scheint jedoch entsprechend der Verbreitung von Ixodes persulcatus zumindest gegen Norden zu i. a. den 60. Breitengrad nicht wesentlich zu überschreiten [124, 175].

Das auffallendste Merkmal der Erkrankung aber ist die von den russischen Autoren zitierte klinisch schwere Verlaufsform mit einer hohen Paralyserate und einer auch hohen Letalität von 30 bis $40 \%$. Ob letzteres mit einer Neurovirulenzsteigerung des Virus in Ixodes persulcatus bzw. einer besonderen Empfindlichkeit der autochthonen Bevölkerung in Zusammenhang gebracht werden darf oder ob für diese statistischen Angaben nicht alle (insbesondere die leichten) Krankheitsfälle zugrunde gelegen haben, ist nicht bekannt.

Untersuchungen über die Pathogenität dieses Virus haben hierzu nur ergeben, daß diese Fernost-Stämme in höherem Ausmaß zu Paresen- und Paralysenbildung bei Schaf und Affe neigen als die Virusstämme vom Subtyp CEE [214, 215$]$. Jedenfalls scheint diese besonders schwere Verlaufsform beim Menschen auch mit dazu beigetragen zu haben, den Versuch einer aktiven Immunisierung der exponierten Bevölkerung besonders zu forcieren, was trotz der nicht komplikationslosen Vakzinen, die anfänglich aus Mäusegehirnen (heute aus Gewebekulturen [937) gewonnen wurden, doch mit gutem Erfolg gelungen scheint $[37,79]$.

Im Hinblick auf großzügige Anwendung akarizid wirkender Mittel zur Bekämpfung der Zecken im Gelände konnte man zahlreiche gute Erfahrungen sammeln und laut Angaben auch die Morbiditätsrate senken [30, 60, 114, 122].

\section{Louping Ill}

Synonyma: Spring- oder Drehkrankheit der Schafe

Die Erkrankung wird im Kapitel von M. Mussgay, Menschliche Infektionen durch tierpathogene Viren, näher beschrieben. 


\section{Die Frühsommer-Meningo-Enzephalitis (FSME)}

Synonyma: Centraleuropean Encephalitis (CEE), Zecken-Enzephalitis, Kumlinge Disease (Finnland), Biphasische Meningo-Enzephalitis [116]

Die ersten klinischen und epidemiologischen Beobachtungen über die Verbreitung der FSME in Europa gehen auf SCHNEIDER zurück, dem schon seit 1927 in Neunkirchen (Niederösterreich) eine Häufung gutartiger, vor allem meningitischer Formen von Erkrankungen des Zentrainervensystems (ZNS) aufgefallen war [183].

In einer Monographie publizierte er schon 1931 seine ersten Beobachtungen und Erfahrungen bei 66 Patienten, deren Erkrankung er für eine neuartige, damals noch unbekannte Infektion, aber sui generis, hielt [184]. In Anlehnung an WallgreEn benannte er seine Fälle als "Meningitis serosa“, wobei aber nach heutiger Auffassung diese Fälle zum großen Teil als Meningo-Enzephalitiden zu diagnostizieren gewesen wären. Damals traten zwar auch schwer verlaufende, insbesondere mit Paralysen einhergehende Fälle auf, jedoch wurden sie ätiologisch nicht richtig erkannt, da man im Fall einer Obduktion bei der histologischen Untersuchung des ZNS immer nur die damals nur für Poliomyelitis bekannten typischen Läsionen im Bereich des Vorderhorns des Rückenmarks gefunden hatte und somit alle diese Fälle als Poliomyelitis oder - bei abweichendem klinischem Verlauf - als atypische Poliomyelitis deutete. Alle Isolierungsversuche schlugen damals noch fehl.

Es liegen aber aus dieser Zeit noch einige Beobachtungen über derartige gehäufte Erkrankungen des ZNS von Erwachsenen vor, die möglicherweise auch in diesen Formenkreis gehören, wie z. B. die im Raum von Szeged [23] und Kaschau [50] beobachteten Fälle.

Atiologisch richtig erkannt wurde diese Infektion in Mitteleuropa in der Nachkriegszeit, als es 1948 in der CSR gelang, den Erreger erstmalig zu isolieren und gezielte serologische Untersuchungen über die Verbreitung dieser Infektion anzustellen [72]. In den nächsten zehn Jahren wurde diese Infektion auch in Finnland [126], Schweden [180], Bornholm/Dänemark [52a], OstPreußen [175], Polen [142], Ost-Deutschland [171], Ungarn [51, 114a] und in Jugoslawien [82] bestätigt. In Österreich wurde das Virus in der Steiermark [194] und auch im Bezirk Neunkirchen [117] isoliert. Dabei gelang es auch, durch serologische Untersuchungen zahlreicher Patienten der vergangenen 30 Jahre nachzuweisen, daß die von SCHNEIDER beobachteten und als Infektion sui generis gedeuteten Fälle tatsächlich als FSME zu diagnostizieren sind; dadurch wurde auch der sichere Beweis erbracht, daß diese Erkrankung nicht erst während des Krieges aus dem Osten eingeschleppt wurde, sondern schon zuvor - zumindest im Raum von Neunkirchen - bestanden hat $[118,119]$.

In der Nachkriegszeit (1949-1953) wurde außerdem im europäischen Rußland eine besondere Form der Erkrankung als "Biphasische Meningo-Enzephalitis“ (nach SMORODINTSEv) bezeichnet. Bei dieser sehr benigne verlaufenden Erkrankung wird das Virus durch Genuß roher Ziegenmilch (daher auch „Biphasisches Milchfieber“, nach Chumakov) auf den Menschen übertragen. Es handelt 
sich dabei aber nicht um einen grundsätzlich andersartigen Zyklus des Virus in der Natur, sondern nur um Einbeziehung der durch Zecken infizierten laktierenden Ziege, die das Virus mit der Milch ausscheiden kann. Bei einem dichten Ziegenbestand und hohem Ziegenmilchkonsum kann dies von besonderer Bedeutung für die Übertragung des Virus auf den Menschen sein. Auf Grund der Untersuchungsergebnisse von Clarke [40] ist dieses Virus aber im Antigenaufbau nicht unterscheidbar von TBE-Virus Typ CEE, das auch im europäischen Rußland vorkommt und dort durch Zecken auf den Menschen übertragen wird.

\section{a) Physikalische, chemische und biologische Eigenschaften}

Nach elektronenoptischen Untersuchungen haben die Viren in HeLa-Zellen eine regelmäßige Größe von $25 \mathrm{~m} \mu$, sind rund und bestehen aus einem dichten Innenkörper und einer hellen Außenzone [86]. Das Partikelgewicht wird auf 10 Millionen geschätzt [177].

Gereinigtes extrazelluläres Virus zeigt im Elektronenmikroskop einen Durchmesser von etwa $30 \mathrm{~m} \mu$. Abschätzungen der Sedimentationskonstante in der Ultrazentrifuge lassen dagegen auf ein Partikelgewicht von 20-25 Mill. schließen. Es erscheint somit denkbar, daß das Virus durch den Exkretionsvorgang an Größe zunimmt.

Das infektiöse Virusteilchen ist bei $4^{\circ} \mathrm{C}$, insbesondere in Gegenwart von mindestens $10 \%$ Serum, relativ stabil und hält sich auch in der Milch und in der Butter bis zu 2 Monaten [64]. Dagegen wird bei $85^{\circ} \mathrm{C}$ (Hochpasteurisieren) das Virus schon in 10 Sekunden inaktiviert [65]. Nach Gresikova-Kohutova [63] ist das Virus auch in einem $\mathrm{pH}$-Bereich von 2,75-11,55 mit einem Op-

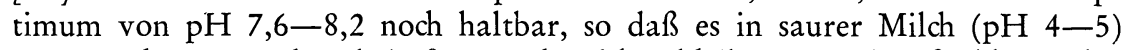
sogar noch 24 Stunden (bei $4^{\circ} \mathrm{C}$ ) nachweisbar bleibt. Von Eiweiß abbauenden Fermenten (Trypsin, Chymotrypsin, Papain) wird das Virus (wie auch die anderen Viren der Gruppe B) im Gegensatz zu den Viren der Gruppe A angegriffen [36] und inaktiviert. Das Virus verliert auch durch die üblichen chemischen Inaktivierungsverfahren (Formalin, $\beta$-Propiolakton) seine Infektiosität. Die Reinigung einer Virusaufschwemmung ist mit Hilfe von HalogenKohlenwasserstoffen [177], durch Adsorption an Ca-Phosphat [58] sowie mittels Protaminsulfat [39] gelungen und ist vielleicht auch durch Adsorption an Erythrozyten und nachfolgende Elution möglich [153].

Die Fähigkeit, Erythrozyten von Gänsen und Hähnen zu agglutinieren, kommt dem nach Clarke und Casals [39] hergestellten HA, aber auch dem infektiösen Virusteilchen bei einem $\mathrm{pH}$ von 6,2-6,8 zu, wobei es SALMINEN [153] gelang, das Virus bei einem pH 9,0 wieder von den Erythrozyten zu eluieren. Diese Hämagglutination ist aber sehr empfindlich und kann nicht nur in spezifischer Weise durch hämagglutinationshemmende Antikörper, sondern auch durch normalerweise im Serum vorkommende Lipide inhibiert werden, die man aus dem Serum durch Adsorption an Kaolin und am besten durch Behandlung mit 
Azeton entfernen kann [39]. Dabei scheint es sich um Komplexe von freiem Cholesterin mit den wichtigsten Serumphosphatiden bzw. freiem Cholesterin mit freien Fettsäuren zu handeln, die vermutlich ähnlich wie die Lipide an der Oberfläche eines Erythrozyten das Virus in Form einer elektrostatischen Bindung adsorbieren $[154,159,160]$. Die von Porterfield und Rowe [137] unterschiedene Inhibition der Hämagglutination von Viren der Gruppe A und B konnte dagegen von SALminen [157] im Detail nicht bestätigt werden.

Die intrazelluläre Virusvermehrung kann in zahlreichen Gewebekulturen vor sich gehen, wobei aber ein CPE nicht immer beobachtet wird; dies kann einerseits auf die Eigenheit des einzelnen Virusstammes, andererseits auch auf die besondere Haltung der Gewebekultur, insbesondere der permanenten Stämme Detroit-6 und HeLa [91], zurückgeführt werden. Der Virus-Synthesevorgang kann durch Zugabe von fluoreszeinmarkierten Antikörpern [89] zeitlich und örtlich verfolgt werden, wobei schon 8 Stunden p. i. im Bereich des Golgifeldes der HeLa-Zelle [87] das Virusantigen und die Elementarkörperchen nachzuweisen sind.

Als empfindliche Versuchstiere werden im Labor Saugmäuse (eventuell auch größere Mäuse bis zu $20 \mathrm{~g}$ ) verwendet, während Hühnerembryonen, Küken, Saugratten, Hamster und Affen kaum mehr beansprucht werden. Bei den Haustieren, wie Kuh, Schaf und Ziege, geht das Virus zwar an, sie bekommen eine Virämie und scheiden auch das Virus mit der Milch aus; eine Enzephalitis nach peripherer Inokulation kommt dagegen nicht zustande.

Unter den Arthropoden gelang es wohl, Culiciden durch Saugakte an virämischen Mäusen zu infizieren, wobei das Virus i. a. nach 1-2 Tagen in den Culiciden nachweisbar blieb [129,130,139, 173], ohne aber von den Culiciden ausgeschieden $\mathrm{zu}$ werden. Dagegen lassen sich im Experiment Ixodes ricinus [20, $21,99]$ und Ixodes hexagonus $[186,193]$ auf natürliche Weise infizieren, wobei es möglich war, das Virus unmittelbar nach der Blutmahlzeit aus den Fäzes und auch aus dem nächsthöheren Stadium (durch Zerreiben der Nymphe bzw. Adulte) rückzuisolieren, während die transovarielle Übertragung nur BENDA [21], Streissle [188], und Rehacek [146] gelungen war. Die Virusvermehrung in Zecken scheint auf Ixodidae beschränkt zu sein. Sie konnte in Argasidae nicht reproduziert werden [83, 187].

Auch andere Arthropoden, wie z. B. Flöhe, lassen sich durch den Saugakt infizieren, ohne daß es aber in diesen zu einer Virusvermehrung kommt [145]; dagegen konnte JeTTMAR [80] an natürlich infizierten Triatomen zeigen, daß sie das Virus zwar lebenslänglich behielten, nie aber mit dem Speichel ausschieden, so daß sie als Vektoren wohl nicht in Frage kommen.

\section{b) Klinik, Patho-Histologie, Immunologie}

Nach einer Inkubationszeit von 7-14 Tagen setzt die erste Phase der Erkrankung (= Virämie) ein, die i. a. mit Fieber bis zu $38^{\circ} \mathrm{C}$, unklaren Schmerzen 
in Kopf, Wirbelsäule, Gelenken und Muskeln sowie entzündlichen Veränderungen im Bereich des Augen-, Nasen-Rachenraumes einhergeht. Diese nur wenige Tage anhaltenden Beschwerden klingen ab, worauf sich ein symptomloses Intervall bis zum Beginn der Phase 2 anschließt.

Diese erste Phase wird von den Patienten in etwa 60\% retrospektiv zugegeben, wenn sie sich in der Phase 2 in ärztliche Behandlung begeben und danach befragt werden. Vielfach waren aber die angegebenen Beschwerden so geringfügig, daß weder die Arbeit unterbrochen, noch ein Arzt konsultiert wurde. Genaue Beobachtungen über den Verlauf der Phase 1 gewinnt man nur, wenn bei besonders starken Beschwerden die Patienten in ein Krankenhaus aufgenommen werden und somit zufällig beide Phasen genau verfolgt werden können, oder bei Laborinfektionen, bei denen die Phase 1 von allem Anfang an ätiologisch richtig gedeutet werden kann (siche Abbildung 2). Ansonsten ist es auch in einem Endemiegebiet zur Saison im Frühjahr praktisch unmöglich, alle derartigen banalen Infekte nicht nur zu erfassen, sondern auch so gewissenhaft klinisch und virologisch (Virusisolierung aus Blut) zu verfolgen, daß man sie epidemiologisch verwerten kann. Dazu ist die Morbidität und auch die Durchseuchungsrate der Bevölkerung in einem Endemiebezirk zu gering.

Nach einem symptomlosen Intervall von ca. 8 Tagen (das entspricht ca. 12 Tagen nach Beginn der Phase 1) setzt akut die Phase 2 ein. Dabei fällt auf, daß der klinische Verlauf eine merkliche Altersabhängigkeit aufweist (siehe Tabelle). Während bis zum 40. Lebensjahr das meningitische Bild überwiegt, dominiert vom 40. bis zum 60. Lebensjahr die Enzephalitis und nach dem 60. Lebensjahr die paralytische Komponente.

Die meningeale Form der Erkrankung geht scheinbar ohne Beteiligung des Parenchyms des ZNS einher und bietet keine Auffälligkeiten, sondern klingt wie alle diese "serösen“ virusbedingten Meningitiden nach 3-5 Tagen ab und heilt mit einer völligen restitutio ad integrum aus. Die klinische Diagnose „seröse Meningitis“ kann aus dem Verlauf (Nackensteifigkeit, Fieber bis über $39^{\circ} \mathrm{C}$ ) und den Liquorbefunden (Zellzahl bis $\mathrm{zu} 500 / 3$ mit überwiegend Lymphozyten, mit Dauer der Erkrankung zunehmenden Eiweißwerten) gestellt werden; dieses Bild ist zwar charakteristisch, aber nicht spezifisch für FSME.

Die enzephalitische Form (Meningo-Enzephalitis) ist in ihrer Verlaufsform sehr vielgestaltig; am häufigsten findet man sie zusammen mit einer Meningitis, wobei neben der Nackensteifigkeit manchmal nur Zucken der Gesichts- oder Zungen- und Extremitätenmuskulatur, Benommenheit, Sensibilitätsstörungen, Schlafbedürfnis, Reflexstörungen und ähnliches einen Hinweis auf die pathologischen Veränderungen des Enzephalon vermitteln. Daneben gibt es aber ausgesprochen bösartige, bisweilen letal endende Enzephalitiden, bei denen Symptome wie Lähmungen der Augenmuskeln, Sprachstörungen, Fazialis- und andere Hirnnervenparesen, Bewußtlosigkeit und Psychosen im akuten Stadium dominieren. Dementsprechend variieren auch die Länge des akuten Stadiums und die möglichen Folgezustände nach einer Enzephalitis. 


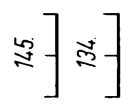

$\left[\begin{array}{c}\mathbb{6} \\ -\underset{2}{2}\end{array}\right.$

$\infty$

$\Re] \curvearrowright-$

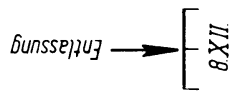

$\approx] \approx-$

$\left[\begin{array}{l}x \\ \infty\end{array}\right.$

$\approx$

กั

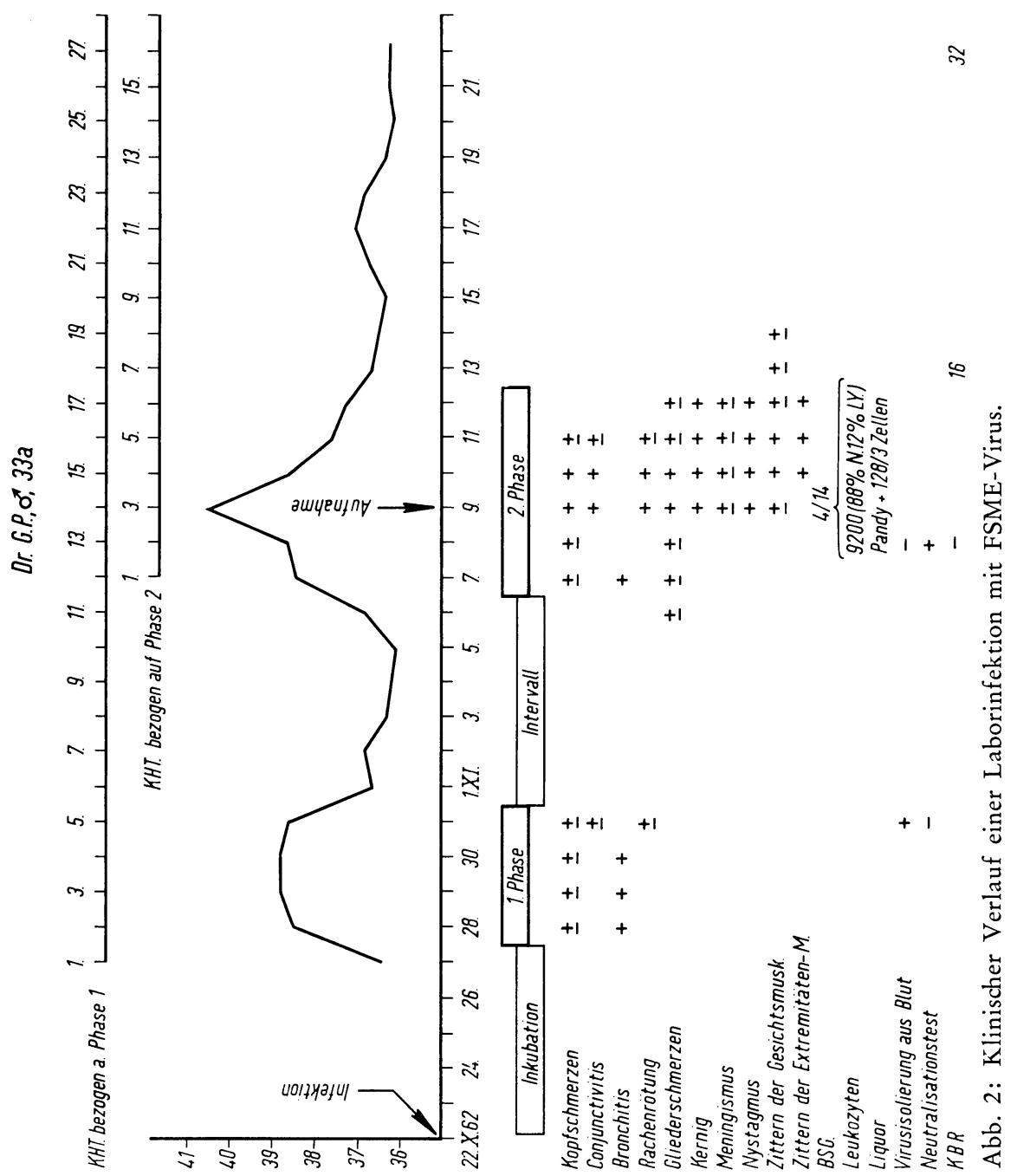


Auffallend ist hier das Einsetzen sogenannter „Spätlähmungen“, die 8-10 Tage nach der Entfieberung meist im Bereich der oberen Extremitäten auftreten, wobei vielfach Sensibilitätsstörungen in den betroffenen Partien vorangehen; diese Lähmungen gehen ohne Temperaturerhöhung einher und heilen dann rasch ohne Atrophie oder Restlähmung aus. Vermutlich handelt es sich hierbei um eine neuroallergische Reaktion als Folge eines akuten Infektes des ZNS.

Auf Grund der Vielseitigkeit des klinischen Bildes kann man eine ätiologische Diagnose nicht stellen.

Die paralytische Verlaufsform zeichnet sich (wie bei einer Poliomyelitis) durch schlaffe Lähmungen aus, die aber in typischer Weise für alle TBE-Viren eine Bevorzugung der Muskulatur des Schultergürtels und der oberen Extremität (proximale Anteile) erkennen lassen. Neben dieser spinalen Lokalisation gibt es aber auch bulbär lokalisierte Paralysen sowie auch aszendierende Formen vom Landry'schen Typ. Bei dieser paralytischen Verlaufsform hat man zwar gewisse klinische Hinweise wie die Lokalisation, die für eine FSME sprechen; aber selbst für den erfahrenen Kliniker ist es nicht möglich, in jedem Einzelfall eine Poliomyelitis mit Sicherheit auszuschließen. Wenn nicht gerade lebenswichtige Gehirnzentren befallen werden, ist die Rückbildungstendenz der $\mathrm{Pa}$ resen sehr gut, wie i. a. die Nachuntersuchungen auch nach einem halben Jahr schon zeigen.

Abgesehen von Restlähmungen und Atrophien nach einer paralytischen Ver-

\begin{tabular}{c|c|c|c|c|c|c}
\hline \multicolumn{4}{c}{ FSME } \\
\hline $\begin{array}{c}\text { Alters- } \\
\text { stufen }\end{array}$ & $\begin{array}{c}\text { menin- } \\
\text { gitisch }\end{array}$ & $\begin{array}{c}\text { enzepha- } \\
\text { litisch }\end{array}$ & $\begin{array}{c}\text { para- } \\
\text { lytisch }\end{array}$ & $\begin{array}{c}\text { menin- } \\
\text { gitisch }\end{array}$ & $\begin{array}{c}\text { enzepha- } \\
\text { lytisch }\end{array}$ & $\begin{array}{c}\text { para- } \\
\text { lytisch }\end{array}$ \\
\hline & 11 & 4 & - & 18 & 8 & 9 \\
$11-10$ & 11 & 15 & - & 23 & 8 & 10 \\
$21-30$ & 9 & 15 & 2 & 15 & 8 & 3 \\
$31-40$ & 9 & 16 & - & 10 & 5 & 3 \\
$41-50$ & 11 & 32 & 6 & - & 4 & - \\
$51-60$ & 5 & 19 & 3 & 5 & 5 & 1 \\
$61-70$ & 2 & 8 & 4 & - & 4 & 1 \\
$71-80$ & - & 3 & 1 & - & - & - \\
$81-90$ & - & - & 1 & - & - & - \\
\hline
\end{tabular}

Gemäß dieser Aufstellung beträgt das Durchschnittsalter für FSME 37,3 Jahre und für alle anderen Infektionen des ZNS 23,1 Jahre; der Altersunterschied ist statistisch sehr signifikant $(\mathrm{t}=7,0, \mathrm{p}<0,01)$.

Tab. 1: Altersverteilung aller Infektionen des ZNS in einem Endemiebezirk der FSME 1956-1962 (Neunkirchen/N.Ö.) (nach KrausLer). 
laufsform wird aber nach einer FSME von ca. 10\% der Patienten auch über vegetative Dystonie, insbesondere mit langdauernden Kopfschmerzen, geklagt. Vereinzelt kann man dann auch Bilder wie Parkinsonismus, Diabetes insipidus, schizophrenieartige Psychosen und auch epileptiforme Zustände registrieren. Letztere Bilder wurden schon 1880 von KoJEvnikov als Folgezustand einer Enzephalitis im Fernen Osten beschrieben, wobei dies möglicherweise einen Hinweis für die Existenz dieser Infektion bedeuten könnte.

Eine spezifische Therapie der Erkrankten gibt es nicht, ebenso hat sich auch die zusätzliche Zufuhr von Antikörpern bei manifester Phase 2 therapeutisch als erfolglos erwiesen. Die Grundlage für alle klinischen Symptome stellen die Organveränderungen dar, die man mit Hilfe von pathologisch-histologischen Untersuchungen objektivieren kann.

Dabei kommt es vor allem darauf an, daß nicht nur einzelne Teile des ZNS untersucht werden, sondern daß das ZNS in toto fixiert wird und durch entsprechende Aufarbeitung die topische Verteilung der Läsionen erhalten wird.

Seitelberger und Jellinger [163], Jellinger und Kovac [76] bzw. Grinschgl, Kovac und Seitelberger [67] berichteten über derartige systematische Untersuchungen, die kürzlich von Seitelberger [164] sowie Jellinger und SeitelBERGER [77] zusammengefaßt wurden. Auf Grund des an einer Serie von verifizierten heimischen Letalfällen erhobenen Läsionsschemas sowie unter Berücksichtigung der histologischen Merkmale des enzephalitischen Syndroms gelang es, auch die morphologische Abgrenzbarkeit gegenüber der Poliomyelitis $\mathrm{zu}$ bestätigen, die bereits von Bednar [19], Környey [84] und Juba [81] wegen des unterschiedlichen Kleinhirnbefalls vermutet worden war. Hingegen ergeben sich aus der Art und Topik des zentral-nervösen Entzündungsprozesses keine prinzipiellen Unterschiede gegenüber anderen Arbo-Virusinfektionen des ZNS. Das ist von wesentlicher Bedeutung, weil trotz gewisser qualitativer Unterschiede der enzephalitischen Gewebsreaktion zwischen der FSME und der Poliomyelitis - sie beschränkt sich bei jener vorwiegend auf das Gefäßmesenchym mit relativ geringer Gliabeteiligung, während bei dieser gliöse Proliferations- und Abräumvorgänge im Vordergrund stehen - bei der Beurteilung von Einzelpräparaten aus isolierten Regionen des ZNS eine eindeutige Differentialdiagnose oft nicht möglich ist. So gestattet gerade das topische Befallsmuster von Rückenmark und Hirnstamm allein noch keine Abgrenzung der beiden Erkrankungen. Das ist auch die Erklärung, warum in den vergangenen Jahrzehnten derartige Fälle nicht richtig, sondern als Poliomyelitis (evtl. mit klinisch atypischem Verlauf) diagnostiziert wurden, weil man in Ermangelung unterstützender bzw. beweisender Untersuchungen diese Fälle nicht richtig erkannt hatte.

Das histo-pathologische Bild der FSME entspricht dem einer voll entwickelten primären Virus-Enzephalitis vom Ausbreitungstyp der „fleckförmigen Polio-Enzephalitiden mit meningealer Beteiligung " [163]. Es ist durch diskontinuierlichen Befall weit auseinander liegender Teile des ZNS mit deutlicher Bevorzugung der grauen Formationen gekennzeichnet und weist eine auffal- 

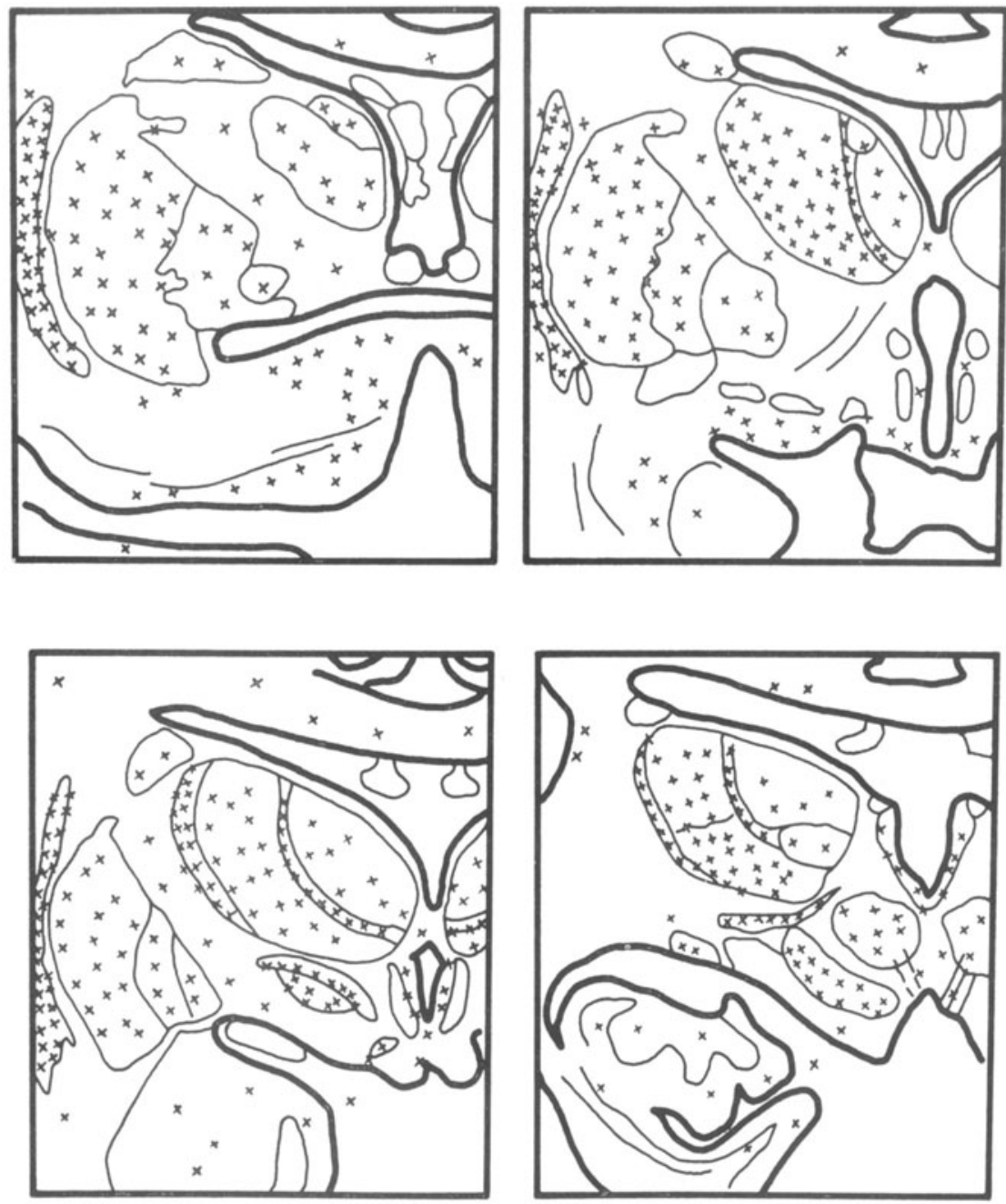

Abb. 3a: Stammganglien: Schwerer Befall des Thalamus mit Bevorzugung der retikulären Kerne, des Subthalamus, des Klaustrums und des Linsenkerns mit Akzentuierung im Putamen. Affektion des basalen Riechhirngraus und des zentralen Höhlengraus unter Verschonung des vorderen Hypothalamus. Einzelne Entzündungsknötchen in den tiefen Markformationen. 
lende Konstanz des entzündlichen Befalls von Rückenmark, Hirnstamm, Kleinhirn und $Z$ wischenhirn auf (siehe Abb. 3). Innerhalb dieses obligaten Verteilungsmusters tritt nur eine individuelle Variation hinsichtlich Intensität und Ausdehnung des enzephalitischen Syndroms in den einzelnen Grisea auf, während der Endhirnbefall als ein inkonstantes und fakultatives morphologisches Charakteristikum der FSME und verwandter Arbo-Enzephalitiden gelten muß [77, 163]. Die massivsten Parenchymausfälle finden sich in den Vorderhörnern des Zerviko-Dorsalmarks, in N. dentatus und Rinde des Kleinhirns, in der Substantia nigra und in den retikulären Hirnstamm- und Thalamusformationen.

Im einzelnen bietet das Rückenmarksgrau die typischen Läsionen mit Prädilektion der motorischen Vorderhörner, die sich histologisch nicht sicher von jenen der Poliomyelitis acuta anterior abgrenzen lassen (Abb. $4 \mathrm{a}$ ). Im Hirnstamm besteht neben

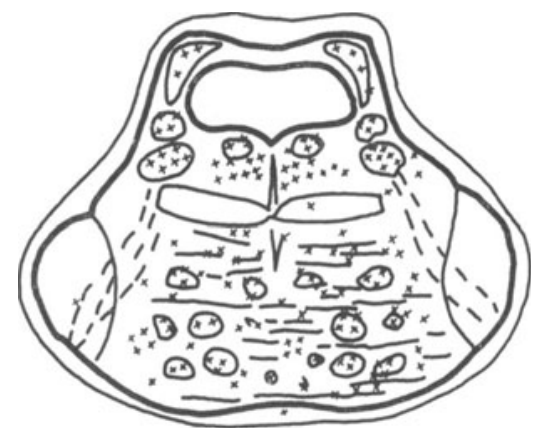

Abb. 3b: Brücke: Fleckförmig-konfluierende Affektion des Brückenfußgraus. Schwerer Befall der Haubenkerne.

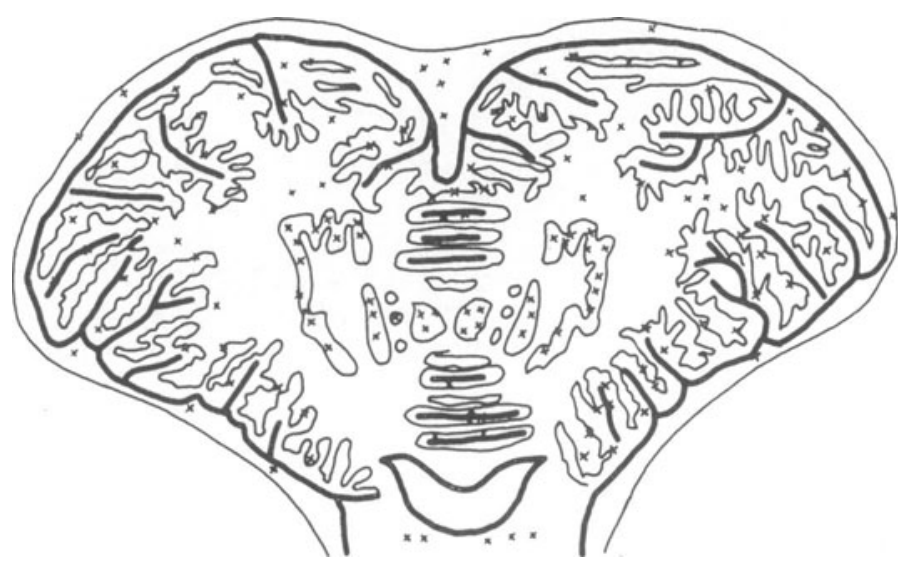

Abb. 3c: Kleinhirn: Diffuse Aussaat entzündlicher Läsionen im gesamten Kortex. Knötchenförmiger Befall von Zentralkernen und Mark. 
schwerem fleckförmigem Befall der Haubenkerne eine konstante Beteiligung der unteren Olive und des Brückenfußgraus, die bei der Poliomyelitis nur ausnahmsweise und in sehr geringem Grad auftreten kann. Charakteristische Unterschiede ergeben
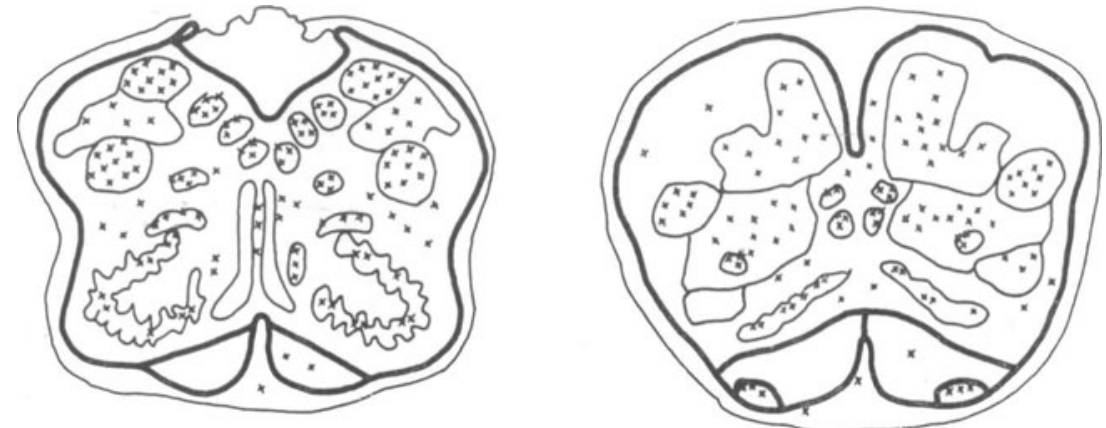

Abb. 3d: Oblongata: Schwerer Befall der retikulären, der motorischen und sensiblen Haubenkerne. Knötchenbefall der Oliven.

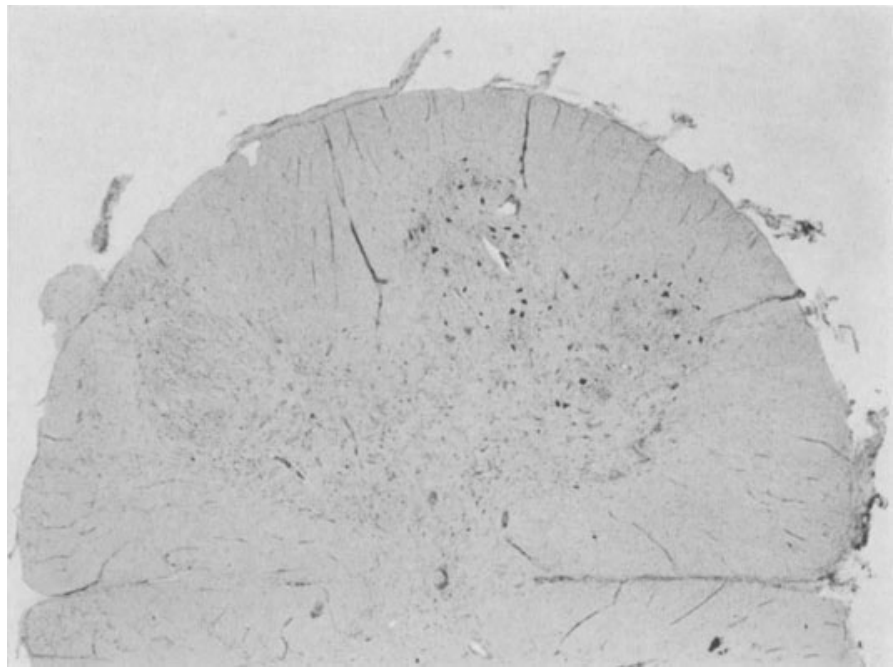

Abb. 4: Histologie des ZNS bei FSME [77].

a) N. I. 75/58. Rückenmark, Lumbalanschwellung. Fleck- und knötchenförmige Infiltration im Vorderhorn mit inkomplettem Ausfall der motorischen Wurzelzellen. Geringe Gewebsinfiltration im Hinterhorn. Rundzellsäume um die radiären Markgefäße. Leichte fleckförmige Meningitis. - Paraffin, Kresylviolett, $12 \times$. 


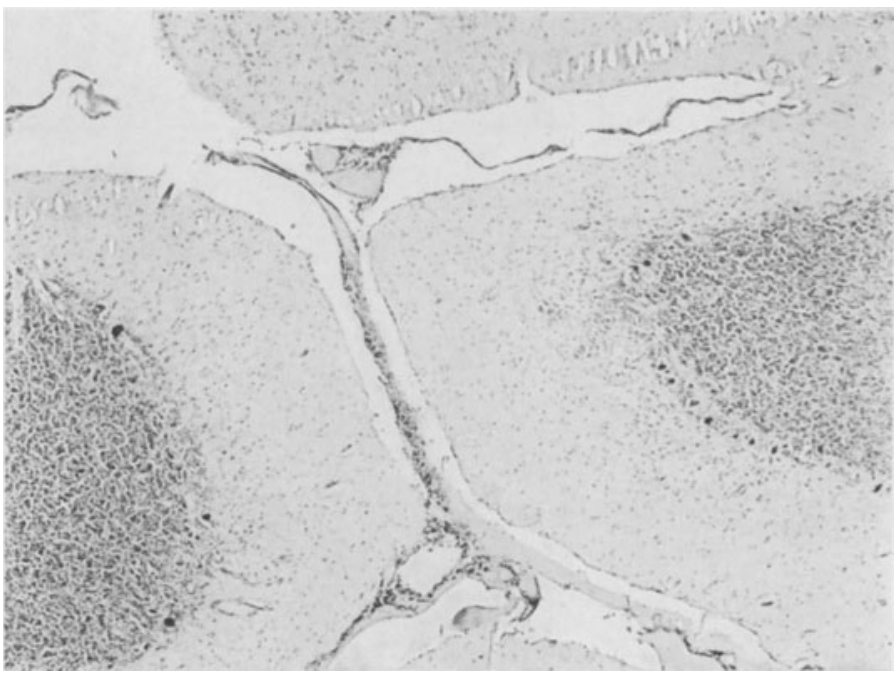

b) N. I. 75/58. Kleinhirnrinde. Entzündliche Reaktionen in den Meningen. Zusammenhängende, schwadenförmige Infiltrate, die von der Purkinjezellschicht gegen die Molekularschicht vordringen. Partieller Ausfall der Purkinjezellen. Paraffin, Kresylviolett, $40 \times$.

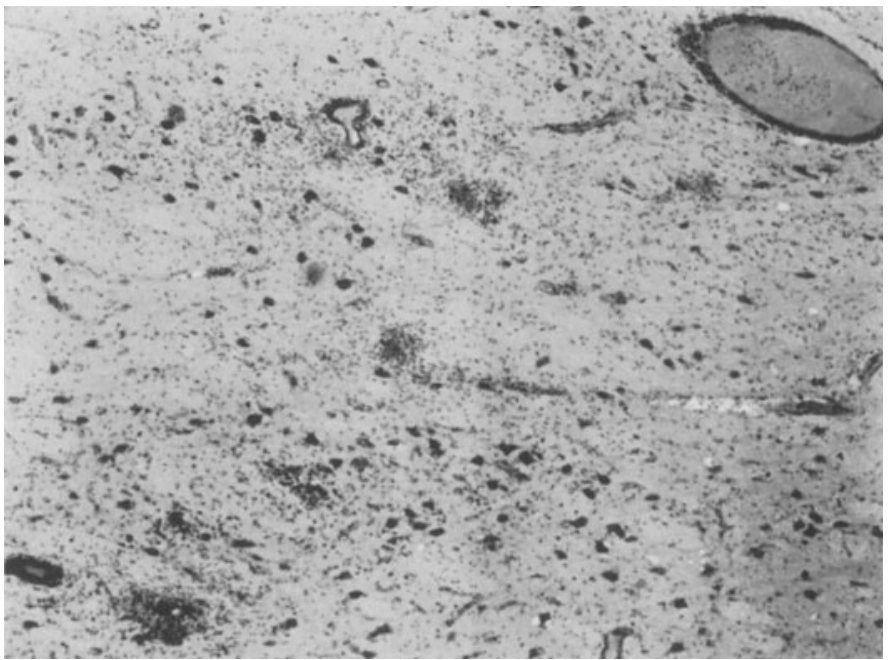

c) N. I. 119/61. Nucleus reticulatus thalami. Zahlreiche Infiltratknötchen und lymphozytäre Gefäßinfiltrate mit fleckförmigem Nervenzellausfall. Paraffin, Kresylviolett, $45 \times$. 
sich in der Kleinhirnaffektion: während bei der Poliomyelitis nur die Zentralkerne und mit gewisser Regelmäßigkeit die Wurmrinde von entzündlichen Läsionen mit Parenchymausfall betroffen sind, dürfen die gleichförmigen enzephalitischen Läsionen der Kleinhirnrinde mit Ausfall und Neuronophagie der Purkinjezellen (Abb. 4b), der zentralen Kerne und des Marks geradezu als morphologisches Kennzeichen der ArboEnzephalitiden gelten. In den Stammganglien ist der enzephalitische Prozeß zwar oft weniger intensiv, aber ausgebreiteter als bei der Poliomyelitis, wo sich die schweren Läsionen auf das tiefe Grau, Thalamus und Pallidum beschränken. Bei der FSME findet sich ein konstanter Befall der Stammkerne mit Bevorzugung des Thalamus (Abb. 4c) sowie des Putamen, geringer auch des N. caudatum, die bei der Poliomyelitis fast immer verschont bleiben. Hingegen fällt die völlige Verschonung des vorderen Hypothalamus (Nucl. paraventricularis und supraopticus) bei FSME gegenüber deren bevorzugter Affektion bei Poliomyelitis auf [77, 164]. Der fakultative Endhirnbefall besteht in einer diffusen Knötchenaussaat über die gesamte Rinde ohne die für die Poliomyelitis typische Beschränkung auf die motorische Zentralregion, ferner über das besonders schwer betroffene Klaustrum, das basale Riechhirngrau und das subkortikale Mark, die bei der Poliomyelitis im allgemeinen frei sind.

Bei protrahierten Fällen kann es zu disseminierten spongiösen Fokalnekrosen in Großhirnrinde und -mark, Stammganglien und Kleinhirnrinde (Abb. 4d) kommen, die analog bei RSSE, Encephalitis japonica B [165], den amerikanischen Pferde-Enzephalitiden und anderen Arbo-Enzephalitiden beschrieben wurden. Sie werden als fakultative Folgen des Entzündungsgeschehens durch eine schwere Schädigung der perivasalen Glia aufgefaßt [77].

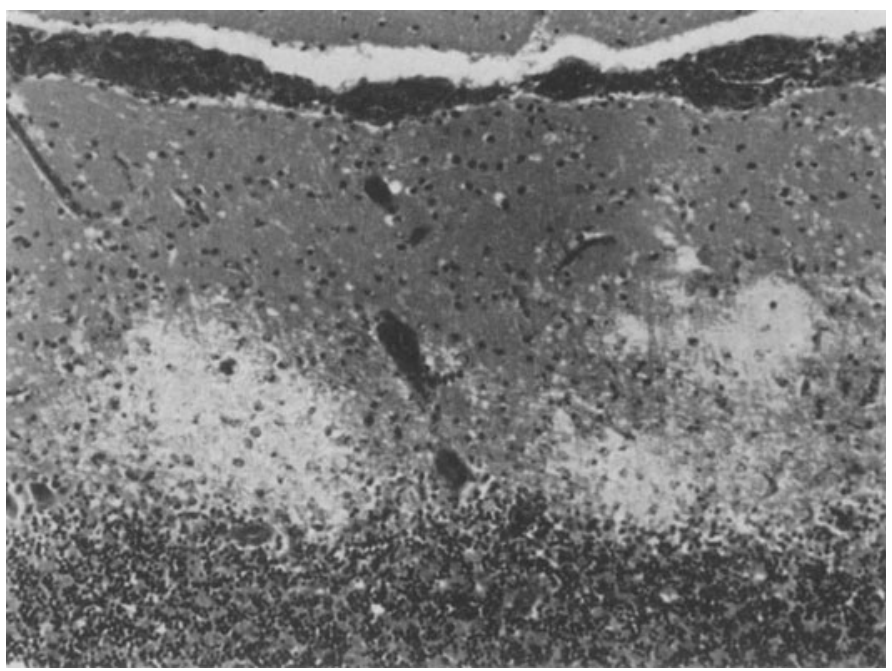

d) N. I. 119/61. Kleinhirnrinde. Zellarme spongiöse Fokalnekrosen. Fast kompletter Ausfall der Purkinjezellen. Restinfiltrate in den Meningen. Paraffin, Kresylviolett, $90 \times$. 
Diese histologischen Befunde zeigen zwar an, welches Ausmaß die Läsionen im ungünstigsten Fall annehmen können, jedoch können sie nur als Hinweis für ein Läsionsschema bei den meisten benignen Formen der Erkrankung, insbesondere der serösen Meningitis, gewertet werden. Hier findet zwar der Kliniker oft keine Zeichen von einer Beteiligung des ZNS und dennoch dürften auch hier entzündliche Veränderungen im Parenchym vorliegen [162], zumal auch auf Grund der Tierversuche anzunehmen ist, daß das neurotrope Virus zunächst das Parenchym befällt und erst konsekutiv die Hirnhäute geschädigt werden [85].

Jede Infektion mit FSME-Virus bewirkt beim Menschen die Bildung von spezifischen Antikörpern, die zuerst im NT und HT und später in der KBR nachweisbar sind. Erstere findet man immer schon am Beginn der Phase 2 [91], während die KB-Antikörper mit guten Antigenen erst um den 4. bis 7. Krankheitstag der zweiten Phase erfaßt werden können [90]. Alle diese Antikörper treten auch nach klinisch inapparenten Infektionen, also Infektionen ohne Phase 2 (vielleicht auch ohne Phase 1), auf. Während die NT-Antikörper und hämagglutinationshemmenden Antikörper vermutlich lebenslänglich im Serum nachweisbar bleiben, wobei die Titer nur allmählich absinken, findet man in der KBR innerhalb eines Jahres nach der Infektion ein schnelles Absinken des Ak-Titers, meist um 4-8 Stufen; in den folgenden Jahren dagegen sinkt dann der Titer nur noch langsam in der KBR ab, so daß sogar nach 4 Jahren ein Resttiter noch nachgewiesen werden kann. Während die Höhe des Titers im NT und HHT keinen unbedingten Hinweis für eine frische Infektion vermittelt, findet man in der KBR meist einen Titer von über $1: 64$, während im Rahmen von Durchseuchungsuntersuchungen in Sera von Personen, die eine Infektion des ZNS negieren, nur Titerwerte bis einschließlich 1:32 beobachtet wurden. Auf Grund dieser Untersuchungen bieten sich für die Praxis folgende Möglichkeiten der serologischen Untersuchung an:

Erstes Serum aus der Phase 2 im qualitativen NT (Serumverdünnung $1: 5$ ) oder HHT: bei negativem Ausfall kann FSME ausgeschlossen werden, bei positivem Ausfall: verdächtig für FSME (in Abhängigkeit von der Durchseuchungsrate), weitere Untersuchungen mit allen Sera in der KBR notwendig.

Erste und alle folgenden Sera in der KBR.: beweisend für FSME ist:

a) Konversion

b) ansteigender (mindestens $4 \mathrm{fach}$ !) Titer

c) Titer von 1:64; kommt vor allem dann in Frage, wenn infolge verspäteter Blutabnahmen oder bei Einsendung von nur einer Blutprobe keine AK-Bewegung erfaßt werden kann.

\section{c) Epidemiologie}

Die FSME kommt in Nordeuropa, vor allem im südlichen Teil von Schweden, auf der dänischen Insel Bornholm und im Süden Finnlands, insbesondere 
auch auf den Ålandsinseln (als Kumlinge Disease) vor. In Mitteleuropa reicht die westliche Grenze der Verbreitung bis ungefähr an eine gedachte Nord-Südlinie von der Ostsee bis zur Adria; östlich von dieser Linie wurde überall diese Erkrankung nachgewiesen, wenn auch die Ausdehnung nach dem Osten unbekannt ist. Im Südosten kennt man in Slowenien und auch im nördlichen Anteil von Kroatien diese Erkrankung; wieweit sich das Verbreitungsgebiet bis nach Südosten erstreckt, ist noch nicht genau ermittelt worden.

In Westdeutschland wurde diese Infektion nur an der österreichischen Grenze und in Oldenburg vereinzelt nachgewiesen. In Österreich findet man die FSME endemisch im östlichen Anteil von Niederösterreich (= pannonische Tiefebene), im Burgenland, in der Steiermark und in Kärnten, während in Oberösterreich nur mehr vereinzelt derartige Infektionen beobachtet werden. In all diesen Gegenden kommt Ixodes ricinus in hohen Populationsdichten vor, während in den anderen Teilen Europas, in welchen die FSME noch nicht beobachtet wurde, diese Dichte an Zecken nicht erreicht wird. Das Virusreservoir vermutet man in den kleinen Nagern, insbesondere in Wald- und Feldmaus, wobei das Virus bei entsprechender Dichte der Vektoren und Vertebraten in einem natürlichen Zyklus zwischen Maus und Zecke zirkulieren und einen echten Fokus bilden kann $[100,140,143]$. Im Rahmen dieses Fokus werden auch noch eine ganze Reihe von Wild- und domestizierten Tieren sowie der Mensch infiziert, die aber für die Erhaltung des Fokus nicht von tragender Bedeutung sind. Als Ausdruck dieser Durchseuchung kann man das Virus aus den Vertebraten isolieren oder Antikörper in deren Seren nachweisen. Dabei findet man eine Durchseuchungsrate des Menschen von 14\% in Finnland [158] und 14\% (standardisiert auf Bevölkerungszahl 1961) in Niederösterreich [67a].

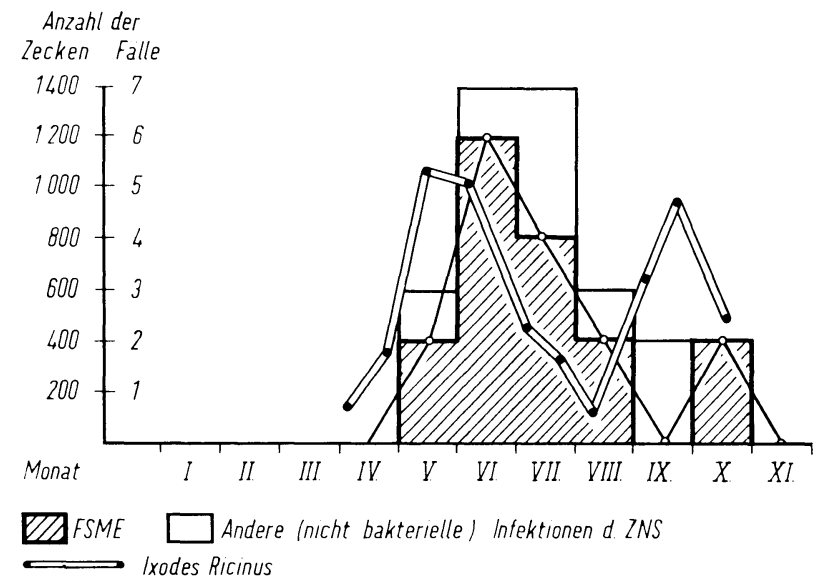

Abb. 5: Zusammenhang zwischen Anzahl gesammelter Zecken und den Erkrankungen des ZNS im FSME-Endemiebezirk Neunkirchen (N.OO.) im Ablauf des Jahres 1962. 
Entsprechend den klimatischen Verhältnissen in Europa beobachtet man auch eine saisonbedingte Häufung der Zecken in der Natur, die mit dem Auftreten der menschlichen Erkrankung gut korreliert.

So fanden RADDA et al. bei systematischen Kollektionen von Zecken in einem Fokus wie die Zahl der frisch Erkrankten um ca. 4 Wochen (entspricht ungefähr Inkubation, Phase 1 und Intervall) den ermittelten Zahlen der aufgelesenen Zecken nachhinkt (siehe Abb. 5).

Auffallend ist vor allem in Mitteleuropa die jahreszeitliche Häufung der Fälle in den Frühjahrsmonaten Mai, Juni, mit einem Maximum im Juli sowie mit einem zweiten kleineren Gipfel im Oktober. Dies steht im Gegensatz zur Verbreitung anderer Viren, insbesondere der Enteroviren (siehe Abb.6).

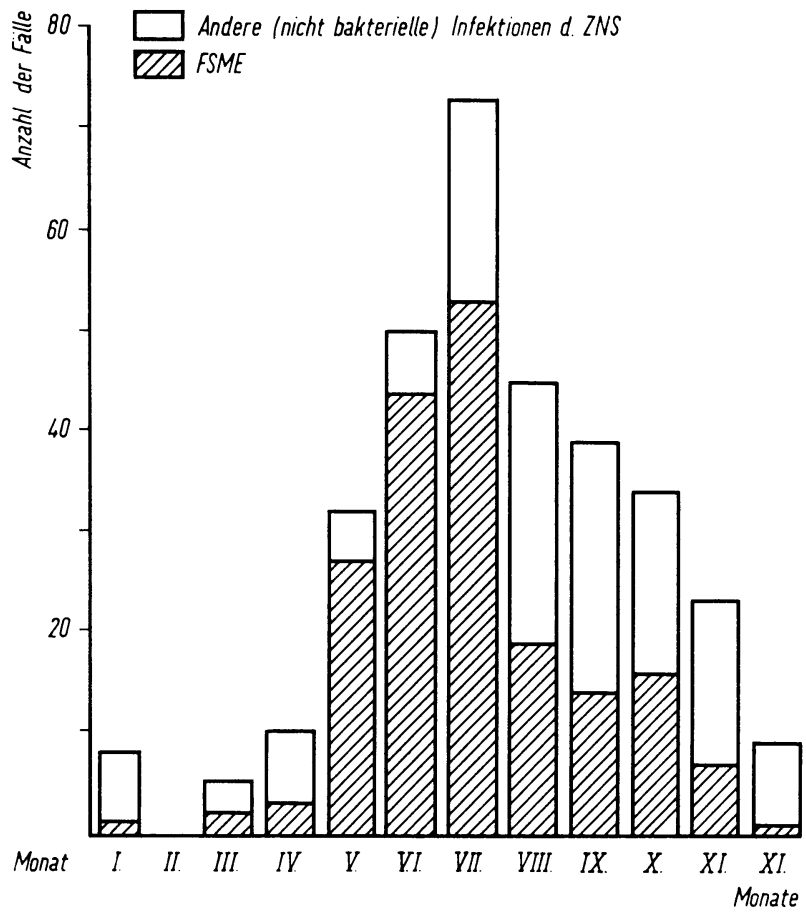

Abb. 6: Monatliche Verteilung der Infektionen des ZNS im FSME-Endemiebezirk Neunkirchen (N.OO.) 1956-1962.

Im Gegensatz dazu wird dieser frühe Gipfel im Juli im Norden nicht beobachtet; hier verschiebt sich die Morbiditätskurve ganz in die kurze, warme Zeit des Sommers mit einem Maximum im August [180].

Entsprechend der natürlichen Verbreitung dieses Virus im Gelände und dem geringen Aktionsradius der Zecken sind vor allem nur jene Menschen exponiert, 
die sich zu diesem Fokus begeben. Demzufolge ist auch das Durchschnittsalter der Erkrankten (siehe Tabelle) relativ hoch, nämlich 37,3 Jahre. Auch die berufliche Exposition spielt hier eine große Rolle. Forstarbeiter in Endemiebezirken haben beispielsweise im Vergleich mit den anderen Bewohnern einen dreifach höheren Durchseuchungsgrad. Ebenso überwiegt die Zahl der erkrankten Männer die der Frauen (105:82). Bei der Befragung der Patienten nach Zeckenstich und Genuß roher Milch wurde nur in ca. einem Drittel aller Fälle der Zeckenstich zugegeben. Dies schließt zwar die Zeckengenese nicht aus, weist aber doch auch auf andere Möglichkeiten der Infektion hin. Der Genuß roher Milch von virämischen Tieren ist nicht nur im europäischen Teil Rußlands (zweiwelliges Milchfieber) eine wesentliche Infektionsquelle, sondern muß auch in Mitteleuropa gelegentlich in Betracht gezogen werden. Immerhin hat eine mangelhafte Pasteurisierung eines Gemisches von Kuh- und Ziegenmilch in Roznava (Slowakei) im Jahr $1951 \mathrm{zu}$ einer Epidemie mit 660 erkrankten Personen geführt [24]. Darüber hinaus wird man auch mit Kontaktinfektionen, vor allem im Schlachthof, zu rechnen haben [117], wie dies vor allem auch für die Übertragung von Louping ill-Virus angenommen wird [206].

\section{d) Prophylaxe}

Im Rahmen der Prophylaxe muß zwischen einer Individualprophylaxe und Sanierungsmaßnahmen in einem Herd unterschieden werden.

Die Individualprophylaxe bezieht sich auf die passive und aktive Immunisierung des Menschen. Eine passive Immunisierung wird man in der Praxis nur bei Laborzwischenfällen vornehmen können, wenn eine Infektion konstatiert und dem Betroffenen durch Zufuhr von Hyperimmunglobulinen ein Sofortschutz vermittelt werden soll. Wesentlich ist dabei die rechtzeitige Applikation; eine Behandlung einer manifesten Erkrankung des ZNS (2. Phase) bleibt dagegen ohne Erfolg.

Für die aktive Immunisierung bemüht man sich einerseits, aus Gewebekulturen Vakzinen mit nicht vermehrungsfähigen Viren (formalin- und hitzeinaktiviert) herzustellen [22, 44, 45], ähnlich den in Rußland verwendeten Vakzinen [93], nachdem man mit den Vakzinen, die aus Gehirnen von Mäusen und Saugmäusen gewonnen wurden, Komplikationen beobachtet hatte [73]. Möglicherweise wird man aber in Zukunft auch andererseits mit attenuierten Lebendvakzinen rechnen können, nachdem man schon in Feldversuchen an Schafen (siehe Louping ill) und im Experiment an Affen [141] sowohl mit dem Stamm Langat TP 21 allein, als auch in Kombination mit Gelbfieber-17-D-Vakzine und einem attenuierten West Nile-Stamm vielversprechende Resultate erhalten hat. Für eine allfällige spätere Vakzination kämen in Mitteleuropa, abgesehen von Personen, die in einschlägigen Laboratorien beschäftigt sind, besonders exponierte Personen, wie Land- und Forstarbeiter, in Frage. 
Allgemeine Sanierungsmaßnabmen in einem Herd richten sich gegen den Vektor (Zecke), dessen Reservoir (Nager) und allfällige Virusausscheider (laktierende Großtiere). Eine wirksame Bekämpfung der Zecken wurde in Mitteleuropa nur von SinNeCKer mit gutem Erfolg beschrieben [172].

Eine Ausrottung der Nager selbst in einem kleinen Versuchsgelände erscheint noch unrealistisch. Dagegen ist es ohne Schwierigkeiten möglich, eine alimentäre Infektion des Menschen zu verhindern, wenn entweder die Milch in der üblichen Weise bei $85^{\circ} \mathrm{C}$,hoch“ pasteurisiert wird oder die Großtiere aktiv immunisiert werden, da immunisierte Tiere das Virus mit der Milch nicht mehr ausscheiden [92].

\section{Die Hämorrhagischen Fieber (HF)}

Unter HF versteht man eine akute fieberhafte Arbo-Virusinfektion mit hämorrhagischer Diathese, die durch eine charakteristische Schädigung der Kapillaren in den verschiedensten Organen ausgelöst wird.

Diese hämorrhagische Diathese stellt ein eigentüniliches Phänomen einer ArboVirose dar, das für sich allein, nur begleitet von Fieber, aber auch als erschwerende Komplikation im Gefolge anderer Arbo-Virusinfektionen, wie z. B. bei Gelbfieber, EEE, auftreten kann.

Derartige Krankheitsbilder wurden an den verschiedensten Stellen der Welt z. T. schon seit vielen Jahren beobachtet, wobei diese Erkrankungen meist nach ihrem geographischen Vorkommen bezeichnet werden. $\mathrm{Ob}$ es sich dabei in allen bisher beschriebenen (ätiologisch aber nicht identifizierten) HF immer auch um eine Arbo-Virusinfektion gehandelt hat, ist sehr zweifelhaft; so ist es bisher auch - trotz intensiven Einsatzes - nur an wenigen Stellen gelungen, ArboViren als verantwortliche Agentien zu isolieren (siehe Tabelle).

\section{a) Kyasanur Forest Disease (KFD)}

Im Frühjahr 1957 fiel ein gehäuftes Affensterben im Kyasanur Forest von Shimoga (District Mysore) auf, das auch in Zusammenhang mit Erkrankungen der Menschen gebracht wurde, die in diesen Waldbezirken gearbeitet hatten. Im Verlauf systematischer Untersuchungen gelang es dann, das verantwortliche Agens (KFD-Virus) aus Organen verstorbener Affen, aus dem Blut von akut erkrankten Menschen und aus Zecken verschiedener Genera, vor allem aus Haemaphysalis spinigera, zu isolieren [210].

Das Virus gehört zur Gruppe B und ist ein Mitglied des TBE-Komplexes; es unterscheidet sich aber von dem Virus des sibirischen HF (Typ Omsk) im Antigenaufbau [36]. Das natürliche Wirtsreservoir stellen Affen (Macaca radiata und Presbytis entellus) dar, die durch Zecken mit dem Virus infiziert werden. Entsprechend der saisonbedingten Entwicklung der Zecken ist die Infektion 


\begin{tabular}{|c|c|c|c|}
\hline Geograph. Verbreitung & Klinische Bezeichnung & Atiologie & Vektor \\
\hline $\begin{array}{l}\text { Nord-Skandinavien } \\
{[54]}\end{array}$ & Nephropathia epidemica & unbekannt & unbekannt \\
\hline $\begin{array}{l}\text { Ungarn [128], Jugo- } \\
\text { slawien, Bulgarien [4], } \\
\text { Transkarpathien } \\
\text { (Bukowinien) [5,54] }\end{array}$ & $\begin{array}{l}\text { Hämorrhagische } \\
\text { Nephroso-Nephritis } \\
\text { Bukowinisches Hämor- } \\
\text { rhagisches Fieber }\end{array}$ & unbekannt & Acarina (?) \\
\hline Krim [54], Astrachan & $\begin{array}{l}\text { Hämorrhagisches Krim- } \\
\text { fieber }\end{array}$ & unbekannt & Acarina (?) \\
\hline $\begin{array}{l}\text { Uzbekistan }[54,55] \\
\text { (Zentralsibirien) }\end{array}$ & $\begin{array}{l}\text { Uzbekistan Hämorrhagi- } \\
\text { sches Fieber }\end{array}$ & unbekannt & Acarina (?) \\
\hline Baraba-Steppe & $\begin{array}{l}\text { Omsker Hämorrhagisches } \\
\text { Fieber }\end{array}$ & $\begin{array}{l}\text { TBE-Virus } \\
\text { Typ Omsk }\end{array}$ & Ixodidae \\
\hline $\begin{array}{l}\text { Indien } \\
\text { (Distrikt Shimoga) }\end{array}$ & Kyasanur Forest Disease & $\begin{array}{l}\text { TBE-Virus } \\
\text { Typ KFD }\end{array}$ & Ixodidae \\
\hline $\begin{array}{l}\text { Malaya, Thailand, } \\
\text { Philippinen }\end{array}$ & $\begin{array}{l}\text { Singapur-thailändisches- } \\
\text { philippinisches Hämor- } \\
\text { rhagisches Fieber }\end{array}$ & $\begin{array}{r}\text { Dengue-Virus } \\
\text { Typ 2, 3, } 4 \\
\text { Chikungunya- } \\
\text { Virus }\end{array}$ & Culicidae \\
\hline $\begin{array}{l}\text { Fern-Ost-Sibirien } \\
{[54,55] \text {, }} \\
\text { Mandschurei, Korea }\end{array}$ & $\begin{array}{l}\text { Fern-Oistliche Hämor- } \\
\text { rhagische Nephroso- } \\
\text { Nephritis }\end{array}$ & unbekannt & Acarina (?) \\
\hline Argentinien & $\begin{array}{l}\text { Argentinisches Hämor- } \\
\text { rhagisches Fieber }\end{array}$ & Junin-Virus & Acarina \\
\hline Bolivien & $\begin{array}{l}\text { Bolivianisches Hämor- } \\
\text { rhagische Fieber }\end{array}$ & $\begin{array}{l}\text { verwandt mit } \\
\text { Junin-Virus }\end{array}$ & unbekannt \\
\hline USA $[112,166]$ & $\begin{array}{l}\text { Hämorrhagisches Fieber } \\
\text { von Odocoileus virginia- } \\
\text { nus (Epizootie) }\end{array}$ & $\begin{array}{l}\text { Epizootic } \\
\text { Hemorrhagic } \\
\text { Disease (EHD) } \\
\text { virus }\end{array}$ & unbekannt \\
\hline
\end{tabular}

während der regenfreien Monate von Januar bis Juni verbreitet. Die Affen erkranken auch mit den klinischen Symptomen einer hämorrhagischen Diathese und können auch daran zugrunde gehen. Bisher wurde diese Infektion nur an dieser einen Stelle in Indien beobachtet.

Die Erkrankung des Menschen setzt nach einer Inkubationszeit von 5-8 Tagen akut ein. Hohes Fieber, Kopfschmerzen, Albuminurie sowie eine hochgradige Leukopenie und Thrombozytopenie, die für diverse Blutungen in der Haut, 
Schleimhaut und in den Organen neben dem direkten Gefäßwandschaden mit verantwortlich sind, können bis zu 9-10 Tagen andauern.

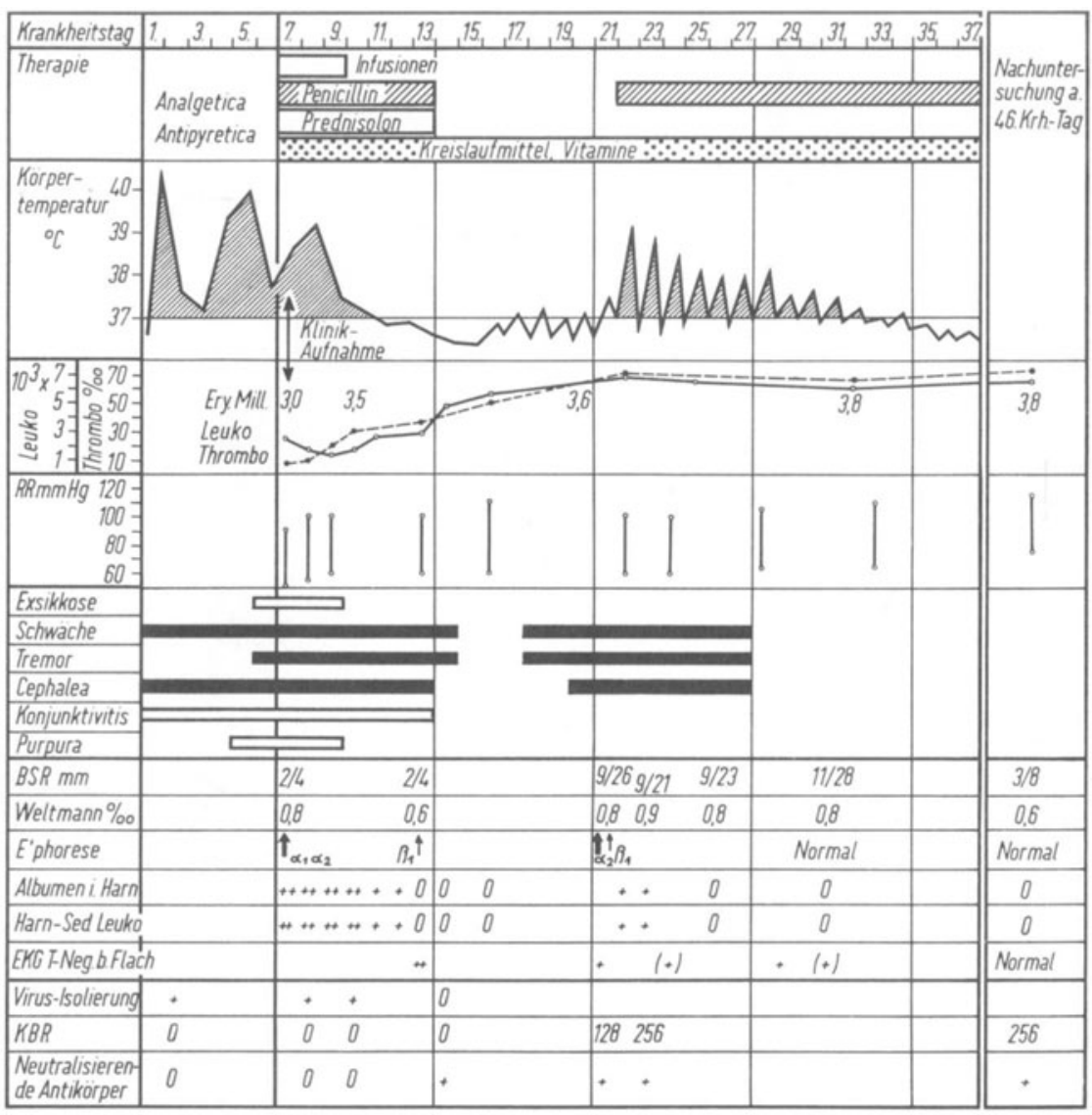

Abb. 7: Laboratoriumsinfektion mit KFD-Virus.

Während dieser ersten Fieberphase ist das Virus regelmäßig aus dem Blut isolierbar (siehe Abbildung 7 [787); mit dem Abklingen des Fiebers beginnen sich langsam die Blutbefunde wieder zu normalisieren. Nach einem fieberfreien Intervall von $1-3$ Wochen kann eine zweite Fieberphase auftreten, welche die gleichen Symptome wie in der ersten Phase (siehe Abbildung 7) bieten, gelegentlich aber auch unter dem Bild einer Meningo-Enzephalitis ablaufen 
kann. Antikörper lassen sich im Neutralisationstest (NT) im Anschluß an das virämische Stadium in der zweiten Krankheitswoche und in der Komplementbindungsreaktion (KBR) nachweisen. Die Letalität ist mit 10\% angegeben.

\section{b) Omsker Hämorrhagisches Fieber}

In der Baraba-Steppe im Bereich von Omsk (Westsibirien) wurde schon seit 1944 eine Erkrankung des Menschen mit hämorrhagischer Diathese beobachtet, deren Erreger 1947 von Chumakov isoliert werden konnte. Das Virus gehört wie KFD-Virus zum TBE-Komplex und wird von Dermacentor pictus und Dermacentor marginatus übertragen; das Wirtsreservoir des Virus ist noch ungeklärt [54].

Dermacentor pictus ist vor allem im nördlichen Teil, Dermacentor marginatus im südlichen Teil der Waldsteppe verbreitet und kommt i. a. nicht gemeinsam mit Ixodes persulcatus vor, so daß auch Omsker HF und Frühsommer-Meningoenzephalitiden nicht nebeneinander beobachtet werden [124].

\section{c) Thai-Philippinisches Hämorrhagisches Fieber}

Seit 1954 werden in Südost-Asien epidemieartige Ausbrüche von Hämorrhagischem Fieber beobachtet, die 1956 im Rahmen einer schweren Epidemie in Manila mit über 1200 Patienten zur Isolierung von Dengue-Virus Typ 3 und 4, und 1958 in Bangkok zu Dengue-Virus Typ 2 und 4 sowie auch ChikungunyaVirus geführt hatten [182].

Auffallend an diesem Hämorrhagischen Fieber ist der ausschließliche Befall von Kindern, die mit Fieber und hämorrhagischer Diathese und Kreislaufkollaps und in Bangkok auch mit Hepatomegalie erkrankten. Die Letalität betrug ca. 10\%. Die verantwortlichen Viren werden vermutlich in erster Linie durch Aedes aegypti übertragen, wobei Epidemien in Manila im April und Mai (vor der Regenzeit) und in Bangkok von Juli bis Oktober (während der Regenzeit) beobachtet wurden.

Eigenartig ist in diesem Zusammenhang, daß einerseits ein relativ einheitliches und charakteristisches Krankheitsbild, nämlich das HF, durch verschiedene Arbo-Viren sogar verschiedener Gruppen (A und B) verursacht werden kann, andererseits aber auch Dengue-Typ-2- und Chikungunya-Virus an anderer Stelle ein typisches Dengue-Fieber auslösen können (siehe Dengue-Fieber).

\section{d) Argentinisches Hämorrbagisches Fieber}

Greenway u. Mitarb. [61] gelang es erstmalig 1958, aus Organen von Patienten mit HF, das seit einigen Jahren im Nordwesten von Buenos Aires beobachtet 
und auch als „Mal de los Rastrojos“ bezeichnet wird, Viren zu isolieren. Später wurde dieses "Junin-Virus" aus Nagern gewonnen. Das Virus gehört entgegen anfänglichen Untersuchungsergebnissen nicht zum TBE-Komplex, sondern bildet mit dem Tacaribe-Virus eine Gruppe (Tacaribe-Gruppe). Vermutlich wird das Virus von Milben übertragen. Ob die Vektoren tatsächlich Milben aus der Gruppe der Gamasina darstellen, kann aus der Isolierung des Virus aus Echinolaelaps echidninus vorläufig nicht geschlossen werden. Ein Häufigkeitsgipfel an menschlichen Erkrankungen, insbesondere unter Landarbeitern, wurde im Mai' Juni (Winter!) beobachtet [131].

Die Schwere der Erkrankung nimmt mit steigendem Alter zu, wobei ein letaler Ausgang durch Hämorrhagien in Niere und Gehirn verursacht werden kann.

\section{Das Dengue-Fieber}

Unter Dengue-Fieber versteht man eine durch Stechmücken übertragbare virusbedingte, fieberhafte Erkrankung des Menschen, welche mit Schmerzen in den verschiedensten Körperregionen, insbesondere Gliedern und Gelenken, Exanthem und Lymphadenopathie einhergeht.

Das klinische Bild der Erkrankung ist zwar schon seit einigen Jahrhunderten im Fernen Osten bekannt, jedoch wies erstmalig BANCrOFT (1906) auf die Ubertragung durch Aedes aegypti hin. CraIg und AshBuRn (1907) identifizierten den Erreger als ein Virus, während die Isolierung und Züchtung dieses Virus in der Maus sowie die Entdeckung von verschiedenen Antigentypen aber erst in ausgedehnten Untersuchungen während des Zweiten Weltkrieges [151] gelang.

Heute muß man zwischen dem klinischen Begriff "Dengue-Fieber" und dem mikrobiologischen Terminus „Dengue-Komplex“ unterscheiden: Im ersteren Fall handelt es sich um ein bestimmtes, beim Menschen zu diagnostizierendes Krankheitsbild, das aber durch verschiedene Arbo-Viren hervorgerufen werden kann, während der virologische Begriff „Dengue-Komplex“ dagegen vier im Antigenaufbau verwandte Viren der Gruppe B umfaßt, die als Dengue-Virus Typ $1-4$ bezeichnet werden. Während Typ 1 und 2 im wesentlichen für das klinische Bild des „Dengue-Fiebers" verantwortlich sind, rufen Typ 3 und 4 (manchmal auch Typ 2) ein „Hämorrhagisches Fieber“ (siehe dort) bei Kindern hervor.

Das Dengue-Virus ist $17-25 \mathrm{~m} \mu$ groß und läßt sich (abgesehen von Saugmäusen) auch in der Gewebekultur anreichern; die einzelnen Typen können mittels Immunsera in der KBR und im NT differenziert werden, jedoch geben sie untereinander beträchtliche Mitreaktionen.

Extraneurale und intrazerebrale Applikation frischer Stämme führt bei Affen nur zu klinisch inapparenten (wohl aber histologisch und serologisch manifesten) Infektionen, jedoch kann man mit mäuseadaptierten Stämmen auch bei Affen (Schimpansen) poliomyelitisähnliche Läsionen provozieren [149]. 
Die Diagnose eines „Dengue-Fiebers“ wurde auf Grund des charakteristischen Bildes (zumindest in der zweiten Fieberphase) vom Kliniker gestellt. $\mathrm{Zu}$ Beginn der Erkrankung (= erste Fieberphase) kreist das Virus im Blut und kann durch Überimpfung auf Saugmäuse isoliert werden; in der Rekonvaleszenz können als Ausdruck der homologen Virusstamm-Immunität Antikörper im NT und HHT nachgewiesen werden.

Die Erkrankung des Menschen setzt nach einer Inkubationszeit von 5-8 Tagen mit Fieber und Schmerzen im Kopf sowie Muskeln, Kreuz und Gelenken mit rheumaartigem Charakter ein. In typischer W/eise fällt das anfänglich sehr hohe Fieber $\left(40^{\circ} \mathrm{C}\right)$ am 3. und 4. Krankheitstag ab, erreicht am 5. Krankheitstag neuerlich Werte von $40^{\circ} \mathrm{C}$, so daß ein biphasischer Temperaturanstieg resultiert; um den 7. Krankheitstag fiebert der Patient dann ab.

Neben dem Fieber und den charakteristischen Schmerzen ist das Exanthem noch auffallend, das meist am 3. bis 5 . Krankheitstag auftritt und sehr flüchtig ist; die Neigung zu hämorrhagischer Diathese (wie bei Typ 3 und 4) ist bei typischem „Dengue-Fieber“ dagegen sehr gering, wenn auch manchmal petechiale Blutungen im Exanthem und im Fall eines Exitus (selten vorkommend) Blutungen im Bereich der serösen Häute und Schleimhäute beschrieben wurden.

Das eigenartige Krankheitsbild hat der Erkrankung auch den Namen „Dengue“ gegeben, der - aus dem Spanischen kommend "dengoso" oder "denguero" - soviel wie "geziert" heißen soll, weil auf Grund der schmerzbedingten eigentümlichen Körperhaltung die Patienten einen gespreizten Gang (englisch auch „Dandy fever") annehmen.

Dengue-Virus Typ 1 und 2 werden - wie Gelbfiebervirus - in erster Linie durch Aedes aegypti übertragen. Dabei scheint der Mensch das einzige Reservoir darzustellen, zumal man bisher - abgesehen von experimentellen Infektionen von Affen - noch keinen anderen natürlichen Wirt gefunden hat.

Dieser Mensch-Stechmücke-Mensch-Zyklus kann sicherlich in tropischen und subtropischen Gegenden (ohne Winter) bei genügender Dichte von Menschen und Stechmücken aufrecht erhalten bleiben, jedoch schließt dies nicht die Existenz eines anderen Grundzyklus unter Einbeziehung eines wild lebenden Vertebraten (Affen?) aus.

Die Verbreitung der beiden Dengue-Virustypen erstreckt sich auf die tropische und subtropische Zone des Mittleren und Fernen Ostens, Afrikas und Amerikas. Dabei werden diese Viren auch durch andere Culiciden-Spezies übertragen. In Europa trat Dengue-Fieber epidemieartig in Griechenland (1927-1928) auf, wobei über eine Million Menschen erkrankt g€wesen sein dürften; retrospektiv gesehen hat es sich dabei um eine Infektion mit Dengue-Virus Typ 1 gehandelt [191].

Prophylaktische Maßnahmen zielen in erster Linie auf eine Stechmückenbekämpfung hin. Die Wirksamkeit derartiger Maßnahmen geht sehr gut daraus hervor, daß beispielsweise Europäer auf Grund ihrer rigorosen Maßnahmen gegen Anophelen in ihren Siedlungen, im Gegensatz zu den Eingeborenen, nicht an 
O’Nyong-nyong erkrankten. Vakzinationen wurden mit attenuierten Stämmen bei Dengue 1 und 2 in Betracht gezogen.

Chikungunya-Virus (Subtyp Afrika) (Gruppe A) wurde erstmalig 1952 in Ostafrika aus Patientenblut und Stechmücken isoliert. Damals wurde unter den Eingeborenen eine Epidemie eines benignen dengue-artigen Krankheitsbildes, vor allem mit den charakteristischen Gelenkschmerzen und zweiphasigem Fiebertyp mit Exanthem, beobachtet; zum Unterschied von Dengue fehlt aber bei der Infektion mit Chikungunya-Virus die Adenitis.

Das Virus wird von zahlreichen Culiciden-Spezies übertragen. Das Hauptverbreitungsgebiet ist Süd- und Ostafrika, Kongo, jedoch wurde Chikungunya-Virus (Subtyp Thailand) auch in Thailand aus Blut von Kindern mit HF isoliert (siehe HF).

O'nyong-nyong-Virus (Gruppe A) ist eng verwandt mit Chikungunya-Virus und wurde erstmalig 1959 aus Patientenblut in Uganda isoliert. Damals brach eine Epidemie eines benignen dengue-artigen Fiebers unter den Eingeborenen von Uganda, Kenia, Kongo und Sudan aus und ergriff über 750000 Personen. Das klinische Bild stimmt weitgehend mit Dengue-Fieber überein, wurde aber von den Afrikanern zunächst als O'nyong-nyong bezeichnet. Das Virus wird von Anophelen verbreitet und konnte auch daraus mehrfach isoliert werden. Ein natürliches Wirtsreservoir ist noch nicht entdeckt worden $[43,69,168,208]$.

\section{Das Gelbfieber}

Die ursprüngliche Heimat des Gelbfiebers ist nicht genau eruierbar, jedoch wird heute vermutet, daß das Virus im 17. Jahrhundert von Afrika nach West-Indien verschleppt wurde. Im 18. und 19. Jahrhundert wurden jedenfalls schon schwere Gelbfieberepidemien in Mittel- und Südamerika beobachtet. Ein Zusammenhang zwischen Stechmücken sowie Verbreitung und Übertragung des Virus auf den Menschen wurde aber erst 1881 von Findlay angenommen. Den Beweis für diese These erbrachten dann die Untersuchungsergebnisse der amerikanischen Gelbfieberkommission in Kuba unter Leitung von REED (1900/1901); es gelang ihnen, damals schon zu beweisen, daß der Erreger bakteriendichte Filter passiert, während der ersten drei Fiebertage im peripheren Blut des Menschen kreist und dabei durch eine blutsaugende Aedes aegypti aufgenommen werden kann, die aber erst nach ca. 12 Tagen wieder das Virus weiter übertragen kann. Diese Erkenntnisse wurden praktisch ausgewertet, und es schien so, als ob durch die Bekämpfung dieser Stechmücken auf dem amerikanischen Kontinent das Gelbfieber in den Städten ausgerottet werden könnte, bis man erstmalig im Zusammenhang mit einer neuerlichen Epidemie in Rio de Janeiro (1928) und aus den experimentellen Untersuchungsergebnissen [185] erkennen mußte, daß noch ein weiterer Zyklus des Virus in der Natur besteht. Schließlich gelang es THeILER [189], das Virus erstmalig auf Mäuse i.c. zu übertragen und weiter zu züchten und damit auch die Voraussetzung für die Entwicklung der Impfstoffe aus attenuierten Virusstämmen zu schaffen [179].

Das Gelbfieber-Virus (Asibi-Stamm) ist auf Grund elektronenoptischer Untersuchungen 25-27 $\mathrm{m} \mu$ groß [18]; es ist in 50\% \% iger Glyzerinlösung, aber auch im lyophilisierten Zustand für längere Zeit haltbar. Frisch isolierte Stämme haben viszerotrope und neurotrope Eigenschaften, wobei im natürlichen 
Zyklus des Virus die viszerotropen dominieren. Wird ein Mensch oder auch experimentell ein Affe infiziert, kommt es nach wenigen Tagen zur Virämie und zum hämatogenen Befall der Leber; eine Enzephalitis tritt auch bei i.c. Applikation dieses Stammes nicht auf, es sei denn, daß simultan ein Hyperimmunserum verabfolgt wird, welches nur die viszerotropen Elemente neutralisiert.

TheIler gelang es ferner, durch Adaptierung des Virus an das Gehirn der Maus die neurotropen Elemente zu selektionieren, so daß derartige Stämme schon nach einer kurzen Inkubationszeit eine Enzephalitis bei der Maus und auch beim Affen hervorrufen konnten; jedoch gingen nach subkutaner Applikation noch 5-10\% der Affen an einer Enzephalitis zugrunde. Das Virus hatte aber doch durch die Mäusegehirnpassagen seine viszerotropen Eigenschaften soweit eingebüßt, daß es bei den Affen, die an einer Enzephalitis zugrunde gegangen waren, nicht mehr im Blut und in der Leber, wohl aber im ZNS und verschiedenen Drüsen nachgewiesen werden konnte.

Die Vermehrung von neurotropen Komponenten des Virus in Maitland-Kulturen wurde von HAagen und THEILER [68] beschrieben, jedoch gelang es erst Lloyd et al. [98] auch den Asibi-Stamm, welcher sowohl neurotrope als auch viszerotrope Eigenschaften besaß, in der Gewebekultur zu züchten. Dabei trat bei diesem ursprünglich pantropen Virusstamm im Lauf der Passagen eine teilweise Abschwächung der viszerotropen Komponente ein, ohne daß sich die neurotropen Eigenschaften verstärkten; eine $Z$ weiglinie dieser Passagen wurde mit $17 \mathrm{D}$ bezeichnet und wird heute noch als attenuierter Vakzinestamm verwendet. Dieser Stamm verursacht nach extraneuraler Applikation nur eine geringfügige Virämie ohne konsekutive Enzephalitis oder Hepatitis beim Affen; durch i.c. Applikation entwickelt sich aber bei Mäusen regelmäßig und bei Affen nur in etwa einem Drittel der Versuchstiere eine Enzephalitis. Zur Zeit wird dieser Stamm zur Gewinnung der Vakzinen im befruchteten Hühnerei (Infektion des Embryo) gezüchtet. Darüber hinaus lassen sich aber heute auch Laborstämme von Gelbfieber in verschiedenen Gewebekulturen unter Plaquebildung züchten. Vom serologischen Standpunkt aus kann man die zwei Subtypen Amerika und Afrika unterscheiden [41 a].

Die ersten klinischen Anzeichen eines Gelbfiebers treten nach einer Inkubationszeit von 3-6 Tagen auf. Die erste Fieberperiode (= Virämie) dauert 3-4 Tage und nach einer kurzen Remission von 1-2 Tagen tritt in typischen Fällen neuerlich Fieber als Ausdruck des Organbefalls auf.

Von Fall zu Fall ist der Verlauf sehr schwankend, wobei man von klinisch inapparenten oder nur mit leichtem Fieber und Kopfschmerzen, eventuell auch mit Nasenbluten Erkrankten über mittelschwere Fälle mit Fieber, Gelbsucht und Albuminurie bis zu schwersten Fällen mit Komplikationen durch ausgedehnte Hämorrhagien unterscheiden kann. Während die erste Phase der Virämie zwar akut mit Fieber, Leukopenie und den üblichen charakteristischen, aber unspezifischen Begleiterscheinungen einsetzt, weist die zweite Phase typische klinische Zeichen der Leber- und Nierenschädigung auf. 
In der meist normal großen Leber findet man dann vor allem in der Intermediärzone der Leberläppchen Nekrose und Verfettung, während die Zellen an der Peripherie und im Zentrum relativ gut erhalten sind. Die nekrotischen Zellen bekommen dabei ein hyalines Aussehen und werden als "Councilman bodies" bezeichnet. Die Kapillaren sind zwar stark erweitert, jedoch findet man keine Schädigung der Kupfferschen Sternzellen und auch nicht an den Gallengängen selbst. Der resultierende Ikterus tritt im Verlauf der Phase 2 auf, wobei ein frühzeitiges Auftreten desselben auf eine ungünstige Prognose hinweist.

Auch in der Niere sieht man keine entzündlichen Reaktionen, wohl aber fettige Degeneration der Tubuli. Die Albuminurie entspricht ungefähr der Schwere des Ikterus, wobei die Oligurie in eine prognostisch ungünstige Anurie übergehen kann. Eine Zunahme der Urinmenge, Abnahme der Albuminurie und Ausscheidung der Gallenfarbstoffe sind dagegen prognostisch günstige Zeichen.

Die hämorrhagische Diathese ist vermutlich ein Zeichen einer direkten Gefäßwandschädigung (vgl. Hämorrhagisches Fieber), wobei durch die Leberschädigung noch eine Verringerung der Vitamin-K-Synthese dazukommt. Blutungsneigungen bestehen überall (Haut, Innenorgane); gefürchtet ist aber dabei besonders das blutige Erbrechen.

Eine Schädigung des Kreislaufes manifestiert sich durch eine niedrige Pulszahl (bei hoher Körpertemperatur). Zu Beginn der ersten Phase zeigt das Blutbild eine Leukopenie, im weiteren Verlauf ist vor allem die Blutgerinnungszeit verlängert. Der Exitus kann als Folge der Niereninsuffizienz und des Leberkomas um den 6. und 7. Krankheitstag auftreten. Ansonsten heilt die Krankheit ohne Entwicklung chronischer Nieren- und Leberschäden und mit einer Immunität aus.

Die Verbreitung des Gelbfiebers erfolgt in der vom Menschen unbesiedelten Natur in einem Zyklus:

Subtyp America
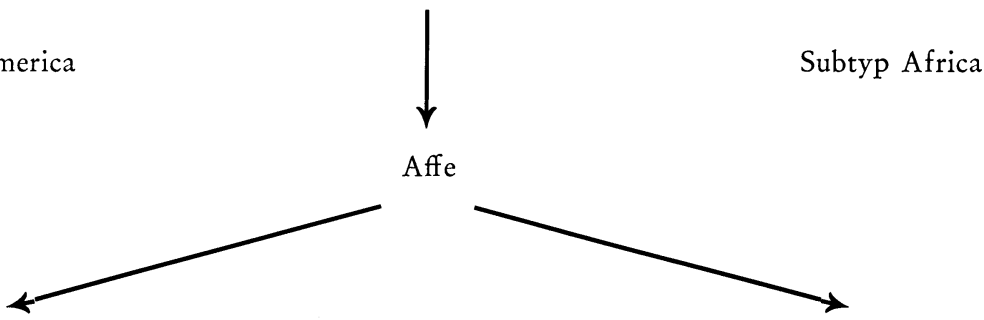

Affe

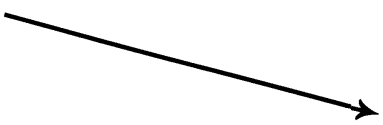

Haemagogus sp.

(vor allem H. spegazzinii)

(Südamerika)

Aedes africanus

bzw. Aedes simpsoni

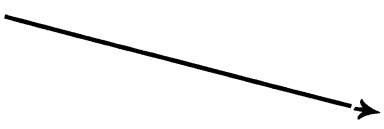

(Afrika)

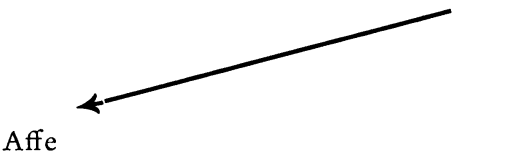

Dieser Zyklus hält das Virus unter natürlichen Bedingungen am Leben und ist infolge seiner Primitivität wohl als Grundzyklus des Gelbfiebers anzusehen. 
Man bezeichnet diese Form als „Busch- oder Dschungel-Gelbfieber“. Bei einem derartigen Zyklus wird der Mensch nur gelegentlich, also wenn er in einen solchen Fokus gerät, infiziert. Meist handelt es sich dabei nur um Einzelpersonen, so daß es sich im sporadischen Auftreten eventuell auch um eine Berufskrankheit handelt. Kommt aber ein im Fokus infizierter Mensch noch während der Virämie wieder in eine Siedlungszone zurück, in welcher Aedes aegypti vorkommt, dann ist die Möglichkeit einer Transformation in ein "Stadt-Gelbfieber" gegeben. Dabei erfolgt der Zyklus:

Mensch $\longrightarrow$ Aedes aegypti (Vektor) $\longrightarrow$ Mensch (Reservoir) $\longrightarrow$

Es hängt dann von dem Grad der Durchseuchung bzw. der Durchimmunisierung (eventuell auch mit anderen Stämmen der Gruppe B) der Population ab, ob dieses eingeschleppte Gelbfieber $\mathrm{zu}$ einem epidemieartigen Ausbruch Anlaß geben kann oder dieser casus sporadisch bleibt.

Aedes aegypti ist eine in enger Gemeinschaft mit dem Menschen lebende Stechmücke. Sie legt ihre Eier gern in Wasser enthaltende Gefäße, eventuell auch in Baum- und Bambushöhlen, meist am oberen Rand des Wasserspiegels ab. Die Eier sind sehr resistent gegen Trockenheit, und es genügen kleinste Wassermengen, um die Larven ausschlüpfen zu lassen. Die Weibchen stechen vor allem in den frühen Morgenstunden, fast immer im geschlossenen Raum. Die zur Entwicklung und Aktivität notwendige Temperatur beträgt $22-23^{\circ} \mathrm{C}$, so daß sie sich in allen warmen Zonen der Erde (auch im Süden Europas) ausbreiten können. Die äußere Inkubationszeit beträgt bei $37^{\circ} \mathrm{C} 4$ Tage, bei $25^{\circ} \mathrm{C} 8-10$ Tage und bei $18^{\circ} \mathrm{C} 30$ Tage. Die Gesamtlebenserwartung des Weibchens ist relativ kurz (zumal es nicht überwintert) und schwankt zwischen 2 und 5 Wochen.

Experimentelle Untersuchungen haben aber ergeben, daß man außer Aedes aegypti noch eine ganze Reihe von Stechmücken mit dem Virus infizieren kann; dies steht auch in guter Übereinstimmung mit Befunden über Isolierungen des Gelbfiebervirus aus diversen Culiciden in Amerika und Afrika. Inwiefern sie an einzelnen Orten substituierend für eine Verbreitung des Gelbfiebers verantwortlich gemacht werden können, hängt einerseits von der Dichte und von ihrem Verhalten (Wahl des Brutplatzes usw.) und andererseits vom Kontakt mit dem Menschen ab, so daß dann eine Endemie bzw. Epidemie resultieren kann.

Nach den letzten Informationen (1962) über Schutzimpfungen im internationalen Reiseverkehr wird als Gelbfieberendemiezone bezeichnet: Afrika (mit Ausnahme einiger wichtiger Städte) beiderseits des Äquators bis zum 15. nördlichen und südlichen Breitengrad, Südamerika (mit Ausnahme der wichtigsten Hafenstädte und der Panama-Kanalzone) nördlich vom Äquator und im Inneren bis etwa zum 15. südlichen Breitengrad.

Die Laboratoriumsdiagnose "Gelbfieber" stützt sich auf

1. die Virusisolierung aus Blut (1. Phase) und Leber (Viszerotomie oder Autopsie) 
2. den Antikörpernachweis (Konversion bzw. ansteigender Titer während der Phase 2)

3. die histologische Untersuchung von Leberpunktionen.

Die Präventivmaßnahmen sind einerseits ganz allgemein auf die Bekämpfung der Stechmücken, andererseits als Individualprophylaxe auf die Vakzination des Menschen, gerichtet.

Die Bekämpfung der Mücken verfolgt im wesentlichen das Ziel, Aedes aegypti auszurotten, da diese Spezies in erster Linie für die epidemische Verbreitung zuständig ist. Diesbezügliche Versuche wurden schon seit der Jahrhundertwende mit Erfolg begonnen und haben bis 1925 schon zu einem erheblichen Rückgang dieser Krankheit in den Hafenstädren Südamerikas geführt. Während und nach (seit 1947) dem Zweiten Weltkrieg wurden diese Kampagnen unter Einsatz von Insektiziden verstärkt, so daß bis 1960 schon in zahlreichen Staaten Amerikas Aedes aegypti zu einem völlig indifferenten und für den Menschen heute keine akute Gefahr mehr darstellenden Glied der Gesamtbiozönose geworden ist.

Für die Individualprophylaxe stehen heute der amerikanische Impfstoff mit dem 17-D-Stamm und der französische Impfstoff mit dem Dakar-Stamm zur Verfügung.

Der 17-D-Stamm wird im Hühnerembryo angereichert und s.c. verabfolgt, während der Dakar-Stamm in Gehirnpassagen von Mäusen gezüchtet wird; die Gehirne werden dann getrocknet und für den Gebrauch in Gummi-Arabicumlösung aufgeschwemmt. Die Impfung selbst erfolgt durch Skarifikation. Der Vorteil der amerikanischen Vakzine liegt in der guten Verträglichkeit gegenüber den manchmal nach der Impfung mit der französischen Vakzine beobachteten neurologischen Komplikationen. Dagegen ist die französische Vakzine infolge der simplen Impftechnik sehr gut für Massenimpfungen geeignet.

Entgegen allen Empfehlungen, die Gelbfieberimpfung nicht mit anderen Lebendvakzinen zu koppeln, wird aber in jüngster Zeit auch über erfolgreiche Simultanimpfung (Pocken + Gelbfieber) in Nigerien berichtet [111]. Die Indikation für diese Simultanimpfung dürfte aber hier auf die Notwendigkeit zurückzuführen sein, beide Impfungen unter den gegebenen lokalen Voraussetzungen im großen Stil anzubringen. Gemäß internationaler Bestimmungen wird ein sicherer immunbiologischer Schutz nach einer von der WHO autorisierten Gelbfiebervakzination für 6 Jahre angenommen.

\section{Die Meningoenzephalitiden, deren Erreger durch Stechmücken übertragen werden}

Eine Reihe von Arbo-Viren, die durch Stechmücken übertragen werden, können beim Menschen und auch gelegentlich unter natürlichen Bedingungen bei Tieren eine Meningo-Enzephalitis verursachen. Vom virologischen Standpunkt aus bieten diese human-neurotropen Viren keine Auffälligkeiten; sie lassen sich i. a. nach extraneuraler Applikation auch im Gehirn der adulten Maus an- 
reichern, jedoch wird man heute in der allgemeinen Routine die Gewebekultur vorziehen.

Das klinische Bild bietet dabei mit seiner großen Variationsbreite alle charakteristischen, aber unspezifischen Symptome einer virusbedingten Infektion des ZNS wie bei TBE, so daß auch die Diagnose in jedem Einzelfall nur durch gezielte virologisch-serologische Untersuchungen (Virusisolierung aus Parenchym, manchmal auch aus Liquor) gestellt werden kann. In jedem Fall geht dem Virusbefall des ZNS eine klinisch uncharakteristische erste Phase der Virämie (Virusisolierung aus dem Blut theoretisch möglich) voraus; da man aber zu Beginn der Phase 2 (Befall des ZNS) fast immer schon neutralisierende Antikörper im Patientenserum erwarten darf, wird man in der Routinediagnostik die KBR dem HHT bzw. NT vorziehen.

Im Gegensatz zu dem relativ einheitlichen klinischen Bild der menschlichen Erkrankung aber unterscheiden sich die einzelnen verantwortlichen Viren durch Antigenaufbau, Vektor, Wirtsreservoir und geographische Verbreitung.

\section{a) Die amerikanischen Pferde-Enzephalitiden}

Schon seit Ende des 19. Jahrhunderts wird über Epizootien unter Equiden mit Befall des ZNS, insbesondere im Westen der USA, berichtet. Es gelang aber erst MeYer et al. (1931) in Kalifornien das WEE-Virus aus dem Gehirn verstorbener Tiere, Ten Broeck und Merrill sowie Gietner und Strahan (1933) an der Ostküste der USA das EEE-Virus, und schließlich BEck und WyckofF (1938) in Venezuela das VEE-Virus zu isolieren. In Anschluß an diese Isolierungen entdeckte man auch den Kausalzusammenhang zwischen MeningoEnzephalitiden des Menschen und diesem Virus im Westen und Mittelwesten (WEE) und an der Ostküste der USA (EEE).

Diese drei Viren gehören zur Gruppe A und unterscheiden sich von den anderen Arbo-Viren durch ihre besondere Pathogenität für Equiden auch nach peripherer Infektion (Mückenstich!). Das elektronenoptisch dargestellte WEE"Provirus“ ist $22 \mathrm{~m} \mu$ groß; das reife WEE-Virus besteht (wie VEE-Virus) [121] aus einem dichten Kern von $30 \mathrm{~m} \mu$ und einer peripheren Membran mit einem Durchmesser von 45-48 $\mathrm{m} \mu$ [115].

Eine Inaktivierung der Viren mit Formalin ist möglich, so daß man Vakzinen zum Schutz von Pferden, aber auch von exponierten Personen im Laboratorium, gegen alle drei Enzephalitisviren verwenden kann.

\section{a) Western Equine Encephalitis (WEE)}

Das Virus ist in den USA, ähnlich SLE-Virus, nur westlich des Mississippi, aber auch in Kanada, Brasilien, Uruguay und Argentinien verbreitet. Die menschliche Erkrankung tritt vom Juni bis September (mit einem Maximum im 
Juli) auf, wobei vielfach Kinder befallen werden. Neben sporadisch auftretenden Fällen wird immer wieder auch über Epidemien unter Equiden und Menschen berichtet. Die Letalität schwankt zwischen 7-20\% (Durchschnitt 10\%). Das Virus wird in erster Linie von Culex tarsalis übertragen, jedoch findet man manchmal auch andere Stechmückenarten aus einer Reihe von Genera unter natürlichen Bedingungen infiziert vor. Das natürliche Virusreservoir sowie die Stätte der Überwinterung sind unbekannt; sicherlich spielen einerseits wild lebende (Zug-) Vögel sowie domestiziertes Geflügel eine besondere Rolle, wobei erstere möglicherweise das Virus in den Fokus jährlich neu einschleppen. Andererseits kann das Virus auch in experimentell infizierten Wassernattern (Thamnophis sp.) sowie auch in Imagines von Culex tarsalis selbst hibernieren [144, 192$]$.

Neben den ursprünglichen natürlichen Wirten können durch weibliche Stechmücken-Imagines alle im Fokus lebenden Wild- und Haustiere einschließlich des Menschen infiziert werden, wobei aber nur Equiden und der Mensch an einer Meningo-Enzephalitis erkranken können, die aber selbst für die Erhaltung des Zyklus des Virus in der Natur nur von inferiorer Bedeutung sind.

\section{B) Eastern Equine Encephalitis (EEE)}

Das Virus kommt als Subtyp Nordamerika im Osten Kanadas und der USA, in Mexiko und auf den Westindischen Inseln sowie als Subtyp Zentral-Südamerika in Südamerika (Panama, Brasilien, Argentinien) und in Südostasien vor. Die menschliche Erkrankung tritt im Spätsommer und Frühherbst auf und wird vor allem bei Kindern und Jugendlichen beobachtet; sie tritt sporadisch und auch in kleinen Epidemien auf.

Die Besonderheit liegt aber in der hohen Menschenpathogenität dieses Virus, die auf die hämorrhagische Diathese zurückzuführen ist. Die Phase 1 ist meist schon stark ausgeprägt (Fieber, Schwindel, Erbrechen, Kopfschmerzen) und in der Phase 2 entwickelt sich das Bild einer hämorrhagischen Meningo-Enzephalitis. Die Wirkungsweise auf das Gefäßsystem ist dabei noch ungeklärt. Diese klinisch auch schon sehr schwer verlaufende Meningo-Enzephalitis hat auch eine hohe Letalität, die bei der ersten erkannten Epidemie (1938) in Massachusetts Werte von $74 \%$ bei Menschen und $90 \%$ bei Pferden erreichte; jedoch gibt es auch Personen mit NT-Antikörpern ohne Erkrankungen des ZNS, so daß diese hohen Todesziffern eher als Ausdruck einer hohen Letalität und nicht einer hohen Mortalität auszulegen sind.

Über den natürlichen Vektor (Grundvektor für die Erhaltung des Zyklus in der Natur) weiß man nichts Genaues. Man hat zwar das Virus aus Culiseta, Mansonia, Culex, Anopheles, Aedes, vereinzelt auch aus Culicoides, verschiedenen Simuliiden und sogar Acarinen unter natülichen Bedingungen isoliert, und man nimmt an, daß Culiseta melanura für die Erhaltung des Grundzyklus (Wildvögel-Culiseta-Wildvögel) verantwortlich ist, jedoch findet man gerade 
auch gegen EEE-Virus unter zahlreichen Wirbeltieren Antikörper, so daß ein sicherer Schluß noch nicht zulässig ist. Auch die Úberwinterung des Virus ist wie bei WEE noch ungeklärt. Die Pferde sind aber auch genau so wie bei WEE nicht für die Erhaltung des Zyklus verantwortlich und werden genau so wie der Mensch eher als ein allerdings sehr empfindliches Endglied der Infektkette angesehen.

\section{r) Venezuelan Equine Encephalitis (VEE)}

Das Virus ist im Äquatorialbereich von Südamerika verbreitet. Im Gegensatz zu WEE und EEE ruft VEE-Virus unter natürlichen Bedingungen zwar bei Equiden, nicht aber beim Menschen, eine Enzephalitis, sondern nur eine einphasige fieberhafte Erkrankung hervor, die manchmal auch Dengue-artigen Charakter (Gelenk- und Gliederschmerzen) annehmen kann. Eine weitere Besonderheit stellt der Nachweis des Virus im Nasopharyngealraum infizierter Menschen und Equiden dar, so daß Übertragungen ohne Vektor im Gegensatz $\mathrm{zu}$ allen anderen Arbo-Virosen nicht ausgeschlossen werden können; das Virus wird auch von infizierten Equiden mit dem Urin und von experimentell infizierten Mäusen mit den Fäzes ausgeschieden. Diese auffallende Ex- und Sekretion des Virus dürfte auch für die sehr häufig beobachteten Laborinfektionen verantwortlich $\mathrm{zu}$ machen sein.

Unter natürlichen Bedingungen wird das VEE-Virus, wie die Isolierungen aus zahlreichen Culiciden-Spezies zeigen, von Stechmücken, namentlich von Mansonia titillans und Aedes taeniorhynchus, auf Mensch und Pferd übertragen; allerdings ist bisher nicht sicher bekannt, ob und welcher Spezies als Hauptvektor für die Erhaltung des Virus in der Natur eine besondere Rolle zukommt. Man vermutet das Virusreservoir in den Wildvögeln, wobei hier als Vektor Aedes triseriatus fungieren dürfte. Im Gegensatz $\mathrm{zu}$ WEE und EEE ist VEE-Virus nur in der tropischen Zone mit einem konstanten Klima verbreitet, so daß hier das Problem der Überwinterung nicht auftritt.

\section{b) Die St. Louis Encephalitis}

Im Sommer 1932 und 1933 wurden im Mittelwesten der USA Epidemien von Meningo-Enzephalitis beobachtet, die 1933 zur Isolierung des kausalen Agens führten. Dieses Virus gehört zur Gruppe B und ist in seinem Antigenaufbau mit JBE-Virus, MVE-Virus, WN-Virus und Ilheus-Virus verwandt. Heute erstreckt sich das Gesamtverbreitungsgebiet von SLE-Virus in den USA von der pazifischen Küste bis in den Mittelwesten (ähnlich WEE-Virus), aber auch auf Panama, West-Indien und Ecuador, jedoch wechselt der Standort von Epidemien von Jahr zu Jahr. Die bedeutendste und beststudierte Epidemie trat 1964 in Houston (Texas) auf. 
Die meisten Erkrankungen treten im Spätsommer und Frühherbst (gegenüber WEE jahreszeitlich um ca. einen Monat später) mit einem Maximum im August! September auf, wobei abwechselnd verschiedene Altersgruppen bevorzugt befallen werden; die klinischen Symptome sind oft inapparent (geschätzte Altersrate inapparent $=$ apparent $=64-209: 1$ ) [25] bzw. nur sehr geringgradig, so daß in Ermangelung der Erfassung aller Fälle die Angabe einer genauen Letalitätszahl (sicherlich eher niedrig) nicht möglich ist.

Das Virus wird in erster Linie aus Culex tarsalis isoliert, jedoch sind Virusisolierungen auch aus zahlreichen anderen Culiciden gelungen. Das natürliche Virusreservoir stellen wahrscheinlich wild lebende Vögel dar. Durch Stechmücken werden aber auch Hausgeflügel, Haustiere und wildlebende Mamalier infiziert. Die Überwinterung des Virus ist noch unbekannt.

\section{c) Die California Encephalitis}

California Encephalitis-Virus (CEV) wurde erstmalig von Culex tarsalis in Kalifornien [69 a, 69 b, 144 ] ] und auch von einem Hasen isoliert [29]. Außerdem wurden bei drei Patienten mit Enzephalitis in Kalifornien Antikörper gegen CEV gefunden. Die Bedeutung dieses Virus im Zusammenhang mit einer Infektion des ZNS des Menschen ist aber noch ungeklärt.

\section{d) Die Japonica B Encephalitis (JBE)}

Die ersten Beschreibungen dieser Erkrankung gehen schon auf KAWAKITA (1871) zurück, jedoch werden Epidemien regelmäßig in Japan erst seit 1924 registriert. 1934 gelang es dann erstmalig HAYASHI, den Erreger durch Übertragung auf Affen zu isolieren. 1935 wurde diese Infektion als B-Enzephalitis zum Unterschied von der Economo'schen (A-) Enzephalitis bezeichnet. Das Virus gehört zur Gruppe B und ist mit SLE-Virus serologisch verwandt. Heute erstreckt sich das Verbreitungsgebiet von JBE-Virus auf Ostasien, Indien und Mikronesien. Die meisten Erkrankungen treten in den gemäßigten Zonen von Mitte August bis Mitte Oktober (Herbst-Enzephalitis) [176] auf, wobei in Endemiegebieten bevorzugt Kinder und Jugendliche befallen werden. Die klinischen Symptome variieren von inapparenten bis $\mathrm{zu}$ letal endenden biphasischen Formen (wie bei TBE) mit einer Letalität von ca. 8\%. Dabei scheinen mehr enzephalitische als paralytische Formen beobachtet zu werden.

Das Virus wird von verschiedenen Culiciden (insbesondere Culex tritaeniorhynchus) übertragen. Das natürliche Virusreservoir stellen verschiedene Wildvögel dar, jedoch werden durch die Stechmücken auch diverse Haustiere (Schweine, Pferde!) infiziert, die möglicherweise auch für einen Nebenzyklus verantwortlich sein können. Vakzinationsversuche mit formolisierten, nicht vermehrungsfähigen Viren von Menschen und auch Pferden in Mittel- und Südjapan haben die Morbidität z. T. erheblich senken können [165]. 


\section{e) Die Murray Valley Encephalitis (MVE)}

In den Jahren 1917/1918 wurde in Australien erstmalig eine Enzephalitisepidemie (70\% Todesfälle) beobachtet, die in leichterer Form, vermutlich auch in den folgenden Jahren, durch das gleiche Agens verursacht wurde (Australian $\mathrm{X}$-Disease). 1951 trat im Osten Australiens neuerdings eine Epidemie auf, wobei es gelang, den Erreger zu isolieren. Das 1917 isolierte Agens war mittlerweile verlorengegangen, jedoch weisen serologische Untersuchungen auf die Identität (bzw. enge Verwandtschaft) der beiden Viren hin.

MVE-Virus gehört zur Gruppe B und ist mit JBE-Virus eng verwandt. Das Virus ist in Australien und in Neu-Guinea verbreitet. Die Isolierung gelang aus verschiedenen Culiciden, insbesondere aus Culex annulirostris, der in der Natur die größte Bedeutung zukommen dürfte.

\section{Das Pappataci-Fieber (Phlebotomus-Fieber)}

Das klinische Bild des Pappataci-Fiebers ist im adriatischen und Mittelmeerraum schon seit langer Zeit bekannt; die erste Beschreibung dieser Erkrankung als eine klinische Einheit stammt von Pick (1886). Doerr, Franz und TAussig gelang es schon 1909 nachzuweisen, daß es sich beim Erreger um ein Virus handelt, das im Blut der Patienten kreist und durch Phlebotomus papatasi übertragen wird. Damit gelang nach den Gelbfieberstudien auf Kuba der erste Virusnachweis und die erste Entdeckung eines Arbo-Virus-Zyklus in Europa einer militärärztlichen Kommission [75]. Während des $Z_{\text {weiten }}$ Weltkrieges gelang es dann SABIN [150] im Rahmen umfangreicher Untersuchungen an alliierten Soldaten im Mittelmeerraum mehrere Stämme zu isolieren und auf Grund experimenteller Untersuchungen an Freiwilligen zwei serologisch völlig differente Typen zu unterscheiden: Typ Sizilien (1943) und Typ Neapel (1944).

Die Viren sind ca. $50 \mathrm{~m} \mu$ groß und wurden aus Phlebotomen und Patientenblut durch Übertragung auf Saugmäuse isoliert; sie lassen sich auch an größere Mäuse bzw. an Gewebekulturen adaptieren, ansonsten sind sie nur auf den Menschen übertragbar. Im menschlichen Blut sind sie schon 24 Stunden vor und nach Beginn der klinischen Symptome nachweisbar.

Die Erkrankung setzt nach einer kurzen Inkubationszeit (3-6 Tage) akut mit hohem Fieber und Schüttelfrost, Kopfschmerzen und Lichtscheu ein; dabei sind Gesicht und Konjunktiven gerötet, so daß diese Erkrankung früher (im 19. Jahrhundert) auch als „Hundskrankheir“ (rote Augen!) bezeichnet wurde. Das Fieber geht dann am 2. und 3. Krankheitstag etwas zurück, so daß meist am 4. Krankheitstag schon die Normaltemperatur erreicht wird. Auffallend ist dabei die Leukopenie und die Bradykardie; Milzschwellung und Exantheme werden dagegen nicht beobachtet. Differentialdiagnostisch kommt infolge des akuten Beginns vor allem Malaria (Blutbild!) und Dengue-Fieber (Exanthem!) 
in Frage. Nach Überstehen der Erkrankung erwirbt der Mensch eine typspezifische Immunität, die im Neutralisationstest (besser als HHT und KBR) sicher nachgewiesen werden kann.

Unter natürlichen Bedingungen werden die Viren von Phlebotomus papatasi übertragen. Die Phlebotominae stellen eine Subfamilie der Psychodiden (deutsch: Schmetterlingsmücken) dar, weisen also keine engere Verwandtschaft zu den Culiciden auf. Sie sind blutsaugende (Mensch, Haustiere) Ektoparasiten und habituell durch ihre geringe Größe (etwa nur ein Drittel der Culicide) und sandgelbe Farbe (sandflies) von Stechmücken leicht $\mathrm{zu}$ unterscheiden. In ihrem Verhalten hat unter den vielen bekannten Phlebotomusarten Phlebotomus papatasi die Gewohnheit, sich vor allem ständig in Wohn- und Schlafräumen des Menschen aufzuhalten. Der Flugbereich ist im Gegensatz zu den meisten Culiciden gering und konzentriert sich 100 bis 200 Meter um die Brutplätze. Ihre Brutplätze finden sie (zum Unterschied von den Stechmücken) in Ansammlungen feuchten organischen Materials wie in Höhlungen (Nagerlöcher), feuchten Mauerritzen („Ruinenkrankheit"), Abfällen, Tierdung u. dgl. Ein voller Entwicklungszyklus dauert ca. 6 Wochen, so daß sich gewöhnlich zwei Generationen während eines Sommers entwickeln. Die Imagines ( $(+)$ nehmen wie Stechmücken Blut als Nahrung auf, jedoch sind diese Phlebotomenstiche (oft mehrere für eine Mahlzeit!) besonders schmerzhaft.

Als Virusreservoir dient vornehmlich der Mensch, wenn er während der Virämie (ca. 2 Tage) von Imagines gestochen wird. Die äußere Inkubationszeit bei Imagines schwankt zwischen 6 und 10 Tagen. Überdies wurde auch behauptet, daß sich schon die Larven von Phlebotomus infizieren könnten, wenn sie Fäzes von infizierten Imagines bzw. deren Kadaver als Nahrung aufnehmen. Auch eine transovarielle Übertragung des Virus wurde angenommen, jedoch nicht bewiesen.

Die Erkrankung ist im Süden Europas (Südrußland, Balkan, Italien, Südfrankreich), Nordafrika, Zentralasien, Indien, nicht aber auf dem amerikanischen Kontinent (trotz Vorkommens menschenblutsaugender Phlebotomen) verbreitet und läßt je nach Generationsfolge der Phlebotomen sogar zwei Jahresgipfel (Juni und September) unterscheiden.

Prophylaktische Maßnahmen zeigen insbesondere durch Einsatz moderner Insektizide großen Erfolg, wenn man sie im Haus und dessen Umkreis von 100-200 m systematisch versprayt. Daneben soll man aber vor allem eventuelle Brutstätten (Abfälle, Komposthaufen, Dung usw.) beseitigen bzw. sanieren.

\section{Neue in Europa gefundene und vermutete Arbo-Viren}

\section{a) Das Čalovo-Virus}

BÁRdos und Čupková isolierten 1960 in der Slowakei aus einem Pool von Anopheles maculipennis das nach dem Ort der Isolierung von ihnen benannte Čalovo-Virus [13]. Unabhängig davon wurde das gleiche Virus aus Anopheles 
barbirostris als Chittoor-Virus in Indien und aus Culex gelidus 1955 von Elisboy und Buescher als Batai-Virus in Malaya isoliert. Auf Grund serologischer Untersuchungen wird dieses Virus in die Bunyamwera-Gruppe eingereiht. Ein Zusammenhang zwischen Čalovo-Virus und Erkrankungen des Menschen ist zwar noch nicht nachgewiesen worden, jedoch wurden in Österreich vereinzelt Antikörper gegen dieses Virus im Serum von Menschen gefunden [88].

\section{b) Das Kemerovo-Virus}

Aus Ixodes persulcatus in West-Sibirien [38 a] sowie aus Ixodes ricinus in der Slowakei [96 c, 64 a] und in Finnland [25 a] konnten bisher unbekannte Virusstämme isoliert werden, die vermutlich sehr nahe antigenverwandt (vielleicht sogar identisch) nach ihrem ersten Fundort als Kemerovo-Viren bezeichnet werden.

Dieses Kemerovo-Virus besitzt weder eine Antigenverwandtschaft zum TBEKomplex, noch zu anderen Arbo-Viren und wird daher als ein noch ungruppiertes Arbo-Virus eingereiht. Dieses Virus ist weniger stabil als das TBE-Virus und nur pathogen für 1-3 Tage alte Saugmäuse [106 a], kann aber auch in Hühnerembryonalzellkulturen primär isoliert werden [96 d]. Das Virus scheint in dem in West-Sibirien untersuchten Herd weniger dicht verbreitet zu sein als das TBEVirus, da man unter Wild- und Haustieren neutralisierende Antikörper nicht so häufig findet wie gegen TBE-Virus.

Dagegen war die Infektionsrate der Zecken in der Slowakei mit KemerovoVirus fünfmal so hoch $(1,0-1,3 \%)$ als mit TBE-Virus $(0,2 \%)$ [96 b].

Die Bedeutung dieses Virus für den Menschen ist noch nicht sicher geklärt. Zwar wurde das Virus vereinzelt aus dem Liquor von Patienten mit fieberhaften Infekten und leichtem Meningismus isoliert, jedoch fehlen hierzu noch nähere, auch klinische Angaben über den Kausalzusammenhang.

Es geht aber die Infektion beim Menschen an, da man neutralisierende Antikörper als Ausdruck der Durchseuchung bei gesunden Personen (2,8\%), wenn auch in einem wesentlich geringeren Prozentsatz als gegen TBE-Virus $(83,8 \%)$, zumindest in dem westsibirischen Herd, nachweisen konnte [96 b]. Der Zyklus des Virus in der Natur verläuft wahrscheinlich ähnlich wie bei TBE-Virus, da die gleichen Wirtsarten der Zecken mit diesen beiden Viren durchseucht sind und das Virus auch aus Kleinsäugern isoliert werden konnte.

\section{c) Das Tabyna-Virus}

Bardos und Danielova isolierten erstmals 1958 in der Slowakei aus je einem Mückenpool von Aedes caspius und Aedes vexans das nach dem Ort der Isolierung benannte Tabyna-Virus [15]. Dieses Virus wurde als Arbo-Virus identifiziert $[9,14]$ und gehört auf Grund serologischer Untersuchungen in den Cali- 
fornia Encephalitis-Komplex [351]. Später gelang es auch LIKAR, in Slowenien im Rahmen von Survey-Untersuchungen an 5000 Serumproben zwei Stämme (TROICA) $\mathrm{zu}$ isolieren, die sich in der KBR serologisch wie Tahyna-Virus verhielten $[96$ a].

Das Virus scheint in verschiedenen Gegenden [8] Mittel- und Südosteuropas [11], aber auch in Südfrankreich verbreitet zu sein, da man bei stichprobenweise untersuchten Blutproben von Menschen immer wieder Antikörper nachweisen kann. Bevorzugt sind vor allem Gegenden wie z. B. die Donauauen, in welchen es auch kürzlich von Aspöck aus Stechmücken isoliert werden konnte. Hier findet man Antikörper unter der Bevölkerung bis zu 60\% [17, 88].

Den Hauptvektor stellt Aedes vexans dar, die auch experimentell mit TahynaVirus infiziert werden kann, wobei eine äußere Inkubationszeit von mindestens 7 Tagen angenommen werden darf. Es kann jedoch mit Sicherheit angenommen werden, daß noch andere Mückenspezies eine essentielle Rolle im Zyklus des Virus spielen, weil das Virus weder in Aedes vexans überwintern kann, noch von dieser erst im Juni auftretenden Mückenspezies im Frühjahr von virämischen heterothermen Vertebraten übernommen werden kann [4a].

Uber die Rolle von Wirtstieren als Virusreservoir ist man sich noch nicht im klaren. So scheinen weder Vögel in den Viruszyklus eingeschaltet zu sein [10, 169], noch ist es wahrscheinlich, daß große Haustiere oder Muriden etwas mit der Verbreitung des Virus in der Natur zu tun haben [16, 170]. Möglicherweise aber können Hasen und Kaninchen als Virusreservoir fungieren, da bei Hasen ein hoher Grad der natürlichen Durchseuchung festgestellt wurde und nach experimenteller Infektion bei beiden Tierarten eine Virämie auftritt $[170$ a].

Die Frage, inwieweit diesem Virus eine Bedeutung als Krankheitserreger beim Menschen zukommt, kann noch nicht mit Sicherheit beantwortet werden. Es wurden zwar einzelne Fälle mit atypischer Pneumonie auf Grund serologischer Befunde mit Tahyna-Virus in kausalen Zusammenhang gebracht [ 9 a], jedoch kann daraus noch nicht extrapoliert werden, daß Erkrankungen des Respirationstraktes beim Menschen erwartet werden können. Dies müßte in weiteren Untersuchungen unter Einschluß von Virusisolierungen noch bestätigt werden.

\section{d) Andere vermutete Viren}

Mit der Isolierung von Čalovo und Tahyna-Virus wurde erstmalig auch die Existenz von durch Mücken übertragenen Arbo-Viren in Mitteleuropa bestätigt. Es scheinen aber neben diesen beiden Viren noch andere Arbo-Viren in Mitteleuropa verbreitet zu sein, die man zwar noch nicht isoliert hat, gegen welche aber Antikörper in menschlichen Sera gefunden wurden.

Diesbezüglich können die schon 1954 erhobenen Befunde über Antikörper gegen WEE- und EEE-Virus [6, 7, 12, 94] zwar nicht als Beweis für die Existenz dieser beiden Viren, aber vielleicht für ein Virus der Gruppe A inter- 
pretiert werden. Dies wird durch ähnliche Ergebnisse in Jugoslawien [123], Italien [161] und Österreich [88] unterstützt. Außerdem fand man in menschlichen Sera aus Ớsterreich hämagglutinationshemmende Antikörper gegen Phlebotomus-Fieber-Virus (Typ Neapel), Viren der Gruppe B (MVE, Ntaya, WN) auch bei Personen, die ihren engeren Heimatbezirk nie verlassen hatten. $\mathrm{Da}$ insbesondere letztere Befunde auf Grund der Azetonbehandlung der Sera als absolut spezifisch im Sinn einer positiven Antikörperreaktion gewertet werden können, ist es sehr wahrscheinlich, daß man noch mit der Entdeckung weiterer Arbo-Viren auch in Mitteleuropa wird rechnen dürfen.

Im Gegensatz zu diesen auf Grund sicherer serologischer Anhaltspunkte vermuteten Arbo-Viren gibt es noch kein Indiz für die Existenz von Viren des Hämorrhagischen Fiebers. Zwar findet man eine Reihe von klinischen Beobachtungen über derartige Krankheitsfälle in Nordskandinavien, wie auch in Ungarn und Südosteuropa. Es steht aber weder fest, ob es sich hierbei um ein einheitliches Krankheitsbild sui generis handelt, noch ob diese Erkrankungen durch Arbo-Viren hervorgerufen werden.

\section{Schrifttum}

1 Ada, G. L., S. G. Anderson a. A. Аввот: J. Gen. Microbiol. 24, 177-186 (1961)

1a AdA, G. L., S. G. Anderson a. F. D. Collins: J. Gen. Microbiol. 29, 165 (1962)

2 Altstein, A. D.: Acta virologica 6, 481-486 (1962)

2a Altstein, A. D., V. Kazantseva a. G. A. Shirman: Acta virol. 6, 421-427 (1962)

3 Anderson, S. G. a. G. L. Ada: Nature 188, 876 (1960)

4 Angeloff, St. u. P. Panajotov: Arch. exp. Vet. Med.. 14, 520-527 (1960)

4a Aspöck, H.: XII th International Congress of Entomology, London, 1964

5 Avakian, A. A., S. B. Shemshilevich a. V. M. Meshchenko: Vop. Virusol. 4, 87-92 (1959)

6 BARDos, V.: Acta virologica 1, 172-179 (1957)

7 Bardos, V.: Cs. EMI 6, 381-391 (1957)

8 BARDos, V.: J. of HEMI 4, 54-60 (1960)

9 Bardos, V.: Acta virologica 5, 50-56 (1961)

9a Bardos, V. a. F. Sluka: Časopis Lékařu Českých Prague 102, 394-402 (1963)

10 Bardos, V., J, Adamcova, F. Balat a. K. Hudec: J, of HEMI 4, 382-386 (1960)

11 Bardos, V., J. Adamcova, S. Dedel, N. Gjini, B. Rosicky a. A. Simkova: J. of HEMI 3, 277-282 (1959)

12 Bardos, V., R. Brezina, J. Hympan, E. Kmety, J. Kratochvil, H. Libikova, O. Macicka, A. Milosovicova, B. Rosicky u. V. Somodska: Bratisl. lek. Listy 34, 1166-1194 (1954)

13 Bardos, V., a. E. Cupkova: J. of HEMI 6, 186-192 (1962)

14 Bardos, V., E. Cupkova a. L. Sefcovicova: Acta virologica 5, 93-100 (1961)

15 Bardos, V. a. Kl. Danielova: J. of HEMI 3, 264-276 (1959)

16 BARdos, V. a. J. JAKUBIK: Acta virologica 5, 228-231 (1961)

17 Bardos, V. a. L. Sefcovicova: J. of HEMI 5, 501-504 (1961) 
31 Casals, J.: Acta virologica 6, 140-143 (1962)

31a Casals, J.: Anais de Microbiologia XI, 13-34 (1963)

32 Casals, J. a. L. Brown: J. Exper. Med. 99, 429-449 (1954)

33 Casals, J., P. K. Olitsky a. R. O. Anslow: J. Exper. Med. 94, 123-137 (1951)

34 Casals, J. a. L. T. Webster: J. Exper. Med. 79, 45-63 (1944)

Najdich, N. F. Chumak, L. M. Wilner, G. D. Casuchina, W. K. Izotov, W. A. Ziclinskaja u. K. G. Umanskij: Vop. Virusol. 8, 307-315 (1963)

38a Chumakov, M. P., E. S. Sarmanova, M. V. Bychkova, G. G. Bannova, G. P. Pivanova, L. G. Karpovich, V. K. Izotov a. O. E. Rzakhova: Vop. Virusol 8, 440-444 (1963)

39 Clarke, D. H. a. J. Casals: Amer. J. Trop. Med. Hyg. 7, 561-573 (1958)

40 Clarke, D. H.: Symposion on the Biology of Viruses of the Tick-BorneEncephalitis Complex. Smolenice, 1960, p. 67-75, Czechoslovak. Acad. of Sciences, Praha 1962

41 Clarke, D. H.: J. Exper. Med. 111, 21-32 (1960)

41a Clarke, D. H.: Anais de Microbiologia 11, 143-148 (1963)

42 Colter, J. S., H. H. Bird, A. W. Moyer a. R. A. Brown: Virology 4, 522-532 (1957)

42a Cooper, P. D.: J. Gen. Microbiol. 19, 350 (1958)

42b Cooper, P. D. a. A. J. D. Bellet: J. Gen. Microbiol. 21, 485 (1959)

43 Corbet, P. S., M. C. Williams a. J. D. Gillett: Trans. Roy. Soc. Trop. Med. Hyg. 55, 463-480 (1961)

44 DANEs, L. a. R. BENDA: Acta virologica 4, 25-36 (1960)

45 Danes, L. a. R. Benda: Acta virologica 4, 82-93 (1960)

46 Danielova, V.: Acta virologica 6, 227-230 (1962)

46a Deinhardt, F. a. G. Henle: J. Immunol. 84, 608-614 (1960)

47 Dessyatskova, R. G., L. S. Diskina a. O. G. Andjaparidze: Vop. virusol. 8, 20-24 (1963) 
48 Dulbecco, R., M. Vogt a. A. G. R. Strickland: Virology 2, 162-205 (1956)

49 Duncan, A.: Trans. Highld. and agric. soc. Scottld. 3, 339-535 (1807)

50 ENGEL, R.: Klin. Wschr. 54, 1004-1008 (1941)

51 Fornosi, F. u. E. Molnar: Acad. Sci. hung. 1, 9-21 (1954)

52 Franklin, R. M.: Prog. Med. Virol. 4, 1-53 (1962)

52a Freundt, E. A.: Ugeskr. Læg. 125, 1098-1104 (1963)

53 Fulton, F. a. K. R. Dumbell: J. Gen. Microbiol. 3, 97-111 (1949)

54 Gajdusek, D. C.: Acute infectious hemorrhagic fevers and mycotoxicoses in the Union of Soviet Socialist Republics. Medical Science Publication 2, Army Med. Serv. Grad. School, Walter Reed Army Med. Center (1953)

55 GajduseK, D. C.: Klin. Wschr. 34, 769-777 (1956)

56 Glasgow, L. A. a. K. HABEL: J. Exper. Med. 117, 149-160 (1963)

57 Gordon-SMith, C. E.: Nature 178, 581-582 (1956)

58 Gordon-Smith, C. E. a. D. Holt: Bull. World Health Organizat. 24, 749-759 (1961)

59 Gordon-Smith, C. E.: Zbl. Bakt., I. Abt., Ref. 188, 458-459 (1963)

59a Gordon-Smith, C. E.: Persönl. Mitteilung

60 Gorchakovskaja, N. N.: Med. Parasit. u. Parasitenkrkh. 31, 67-72 (1962)

61 Greenway, D. J., H. R. Rugiero, A. S. Parodi, M. Frigerio, E. Rivero, J. M. de la Barrera, F. Garzon, M. Boxaca, N. Mettler, L. B. de Guerrero a. N. Nota: Publ. Health Rep. (Wash.) 74, 1011-1014 (1959)

62 Gresikova, M.: Acta virologica 2, 113-119 (1958)

63 Gresikova-Kohutova, M.: Acta virologica 3, 159-167 (1959)

64 Gresikova-Kohutova, M.: Cs. EMI 8, 26-32 (1959)

64a Gresikova, M., O. Kozuch, E. Ernek a. J. Nosek: Proc. of a Symposion on theoretical questions of nat. foci of dis., 1963, Prag

65 Gresikova, M. u. J. Rehacek: Arch. Virusforsch. 9, 360-364 (1959)

66 Gresikova, M., I. Havranek a. F. Görner: Acta virologica 5, 31-36 (1961)

67 Grinschgl, G., W. Kovac a. F. Seitelberger: Encephalitides, AmsterdamLondon-New York-Princeton: Elsevier 1961, pp. 3-16

67a Groll, E., J. Krausler, Ch. Kunz a. H. Moritsch: Arch. Virusf. (im Druck)

68 Haagen, E. u. M. Theiler: Zbl. Bakt. I. Abt. Orig. 125, 145-158 (1932)

69 Haddow, A. J., C. W. Davies a. A. J. Walker: Roy. Soc. Trop. Med. Hyg. 54, $517-522(1960)$

69a Hammon, W. M. a. W. C. Reeves: Californ. Med. 77, 303-309 (1952)

69b Hammon, W. M., W. C. Reeves a. G. Sather: J. Immunol. 69, 493-510 (1952)

70 Henderson, J. R. a. R. M. TAylor: Virology 13, 477-484 (1961)

71 Hitchсоск, G. a. J. S. Porterfield: Virology 13, 363-365 (1961)

72 Hloucal, L.: Schweiz. med. Wschr. 83, 78-81 (1953)

72a Ho, M. a. M. K. Breinig: J. Immunol. 89, 177-186 (1962)

73 Ilyenko, V. J.: Acta virologica 4, 37-46 (1960)

74 IsaAcs, A.: Brit. Med. J. 5301, 353-355 (1962)

75 Jantsch, M. u. G. H. Marcus: Wien. med. Wschr. 111, 801-803 (1961)

76 Jellinger, K. u. W. Kovac: Path. Microbiol. 23, 375-392 (1960)

77 Jellinger, K. u. F. Seitelberger: XXVIe Réun. Neurol. Int. Paris, 11.-12.6. 1963, Rev. Neurol. 108, 910-917 (1963)

78 Jesserer, H., Ch. Kunz u. E. Prohaska: Klin. Wschr. 41, 1007-1010 (1963)

79 Jettmar, H. M.: Zbl. Bakt. I. Abt. Ref. 163, 275-278 (1957)

80 Jettmar, H. M.: Zschr. Tropenmed. 12, 240-262 (1961) 
81 JubA, A.: Acta med. Acad. scient. Hungar. 14, 33-49 (1959)

81a Kaplan, M. M., E. WeCKER, Z. Forsek a. H. Koprowski: Nature 186, 821 (1960)

82 Kmet, I., I. Vesenjak-Zmijanac, M. Bedjanic a. S. Rus: Bull. World Health Organizat. 12, 491-501 (1955)

83 Kolman, J. u. O. Havlik: Cs. EMI 4, 180 (1955)

83a Kono, Y.: Nat. Inst. Anim. Hlth. Quart. Tokio 2, 1 (1962)

84 KöRnYeY, St.: Verh. Dtsch. Ges. inn. Med. 61, 231-235 (1955)

85 Kovac, W. u. H. Moritsch: Zbl. Bakt., I. Abt. Orig. 174, 440—456 (1959)

86 Kovac, W., Ch. Kunz u. L. Stockinger: Arch. Virusforsch. 11, 544-567 (1962)

87 Kunz, Ch.: Zbl. Bakt. I. Abt. Orig. 184, 362-365 (1962)

88 Kunz, Ch.: Zbl. Bakt. I. Abt. Orig. 190, 174-182 (1963)

88a Kunz, Ch.: Virology (1964) (im Druck)

89 Kunz, Ch., F. Gabler u. F. Herzog: Mikroskopie 16, 1-7 (1961)

90 Kunz, Ch. u. J. Krausler: Arch. Virusforsch. 14, 499-507 (1964)

91 Kunz, Ch. u. H. Moritsch: Arch. Virusforsch. 11, 568-582 (1961)

91a Lennette, E. H. a. H. Koprowski: J. Exper. Med. 83, 195 (1946)

91b Levine, S.: Virology 5, 150-167 (1958)

91c Levine, S.: Virology 17, 593-595 (1962)

92 Levkovich, E. N. a. V. V. Pogodina: Vop. virusol. 7, 193-198 (1962)

93 Levkovich, E. N. a. G. D. Zasukhina: Zbl. Bakt., I. Abt. Orig. 177, 448-453 (1960)

94 Libikova, H.: Acta virologica 1, 93-101 (1957)

95 Libikova, H. a. J. Vilcek: Acta virologica 4, 165-172 (1960)

96 Libikova, H. a. J. Vilcek: Acta virologica 5, 379-385 (1961)

96a Likar, M. a. J. CASAls: Nature 197, 1131 (1963)

96b Libikova, H., J. Rehacek a. V. Mayer: Proc. of a Symposion on theoretical questions of nat. foci of dis., 1963, Prag

96c Libikova, H., J. Rehacek, M. Gresikova, O. Kozuch, J. Somogyiova a. E. ERNeK: Acta virol. 8, 96 (1964)

96d Libikova, H., V. Mayer, O. Kozuch, J. Rehacek, E. Ernek a. P. Albrecht: Acta virol. 8, 289-301 (1964)

97 Likar, M. a. D. Dane: Lancet $I I, 456-458$ (1958)

98 Lloyd, W., M. Theiler a. N. I. Ricci: Trans. Roy. Soc. Trop. Med. Hyg. 29, $481-529$ (1936)

98a LockarT, R. Z. jr.: J. Bact. 85, 556-566 (1963)

98b Lockart, R. Z. jr. a. N. B. Groman: J. Inf. Dis. 103, 163-171 (1958)

99 LoEw, J.: Zbl. Bakt. I. Abt. Ref. 179, 324 (1961).

100 Loew, J., G. Pretzmann u. A. Radda: Zbl. Bakt., I. Abt. Orig. 190, 173-206 (1963)

100a Mackenzie, R. B., H. K. Beye, L. Valverde Ch. a. H. Garron: Am. J. Trop. Med. a. Hygiene 13, 620-625 (1964)

101 McLean, D. M. a. W. L. Donohue: Canad. Med. Ass. J. 80, 708-711 (1959)

102 Malkova, D.: Acta virologica 4, 233-240 (1960)

103 Malkova, D.: Acta virologica 4, 283-289 (1960)

104 Malkova, D.: Acta virologica 4, 290-295 (1960)

105 Malkova, D.: Acta virologica 5, 137-140 (1961)

106 Malkova, D. a. V. Frankova: Acta virologica 3, 210-214 (1959)

106a Mayer, V., O. Kozuch, H. Libikova a. J. Zavada: Acta virol. 8, 302-311 (1964)

107 Mayer, V., F. SoKol a. J. Vilcek: Virology 16, 359-362 (1962) 
114 a Molnar, E.: Acta microbiol. acad. scient. Hung. 10, 365-369 (1963)

140 Pretzmann, G., J. Loew u. A. Radda: Zbl. Bakt., I. Abt. Orig. 190, 299-312 (1963)

141 Price, W. H., R. W. Lee, W. F. Gunkel a. W. O’Leary: Amer. J. Trop. Med. Hyg. 10, 403-422 (1961)

Mayer, V., J. Zavada a. R. Skoda: Symposion on the Biology of Viruses of the Tick-borne Encephalitis Complex, Smolenice 1960

Mayr, A.: Mhefte Tierheilk. 13, 102-111 (1961)

MaYr, A. u. K. Bögel: Zbl. Bakt., I. Abt. Orig. 182, 564-570 (1961)

Meers, P. D.: Trans. Roy. Soc. Trop. Med. Hyg. 54, 493-501 (1960)

Mettleer, N. E., Lester G. MacNamara a. R. E. Shope: J. Exper. Med. 116, 665-678 (1962)

Miles, J. A. R.: Bull. World Health Organizat. 22, 339-371 (1960)

Morgan, C., C. Howe a. H. M. Rose: J. Exper. Med. 113, 219-234 (1961)

Moritsch, H.: Ergeb. inn. Med. Kinderhk., NF, 17, 1-57 (1962)

Moritsch, H. u. J. Krausler: Wien. klin. Wschr. 69, 921-926, 961-965 u. 965-970 (1957)

Moritsch, H. u. J. Krausler: Zbl. Bakt., I. Abt. Orig. 176, 377-383 (1959)

Moritsch, H. u. J. KrausLer: Wien. klin. Wschr. 71, 766-767 (1959)

Moritsch, H. u. W. Kovac: Symposion on the Biology of Viruses of the Tickborne Encephalitis Complex. Proceedings of a Symposium, pp. 283-285, Czechoslovak Academy of Sciences 1961.

Mussgay, M. a. J. Weibel: Virology 16, 52-62 (1962)

Nabokow, W. A., M. A. Larjuchin, I. A. Tarabuchin, N. F. Cumak a. J. D. Cigirik: Med. Paras. u. Paras.krkh. 27, 199-207 (1958)

Nestorowa, L. a. M. Likar: Pathologia et Microbiologia 24, 1129-1134 (1961)

Netski, G. J. u. O. W. Rawdonikas: XI. Internat. Kongr. f. Entomologie, Wien 17.-25. 8. 1960, Verhandlungen II Sektion VII bis XIV

Nielsen, G. u. J. Markquard: Arch. Virusforsch. 12, 335-345 (1962)

Oker-Blom, B.: Ann. Med. exp. Fenn. 34, 309-318 (1956)

Okuno, T., A. Oya u. T. Ito: Japan. J. Med. Sci. \& Biol. 14, 51-59 (1961)

Ormay, L., M. P. Aradi, J. J. Nikodemusz u. Gy. Losonczy: Zbl. Bakt., I. Abt. Orig. 178, 279-290 (1960)

Pattyn, S. R. et R. Wyler: Bull. organ. mond. santé 12, 581-589 (1955)

PAwlowsky, E. N.: Acta medica URSS 3, 187-199 (1940)

Pirosky, I., J. Zuccarini, E. A. Molinelli, A. Di Pietro, O. J. G. Barrera, P. Martini a. A. R. Copello: Hemorrhagic viroses of north-west Buenos Aires, pp. 197. Instituto Nacional de Microbiologia, Buenos Aires 1959

Piyaratn, P.: Amer. J. Trop. Med. Hyg. 10, 767-772 (1961)

Pool, W.: Vet. J. 87, 177-200, 222-239 (1931)

Pool, W., A. Brownlee a. D. R. Wilson: J. Comp. Path. 43, 253-290 (1930)

Porterfield, J. S.: Lancet $I I, 326-327$ (1959)

Porterfield, J. S.: Bull. World Health Organizat. 22, 373-380 (1960)

Porterfield, J. S. a. C. E. Rowe: Virology 11, 765-770 (1960)

Porterfield, J. S. a. C. E. Rowe: Virology 11, 765-770 (1960)

Pretzmann, G.: XI. Internat. Entomologen-Kongreß, Wien 1960, Verhandlungen Bd. III, S. 134

(10. 
142 Przesmycki, F., Z. Wroblewska, R. Semkov, R. Stanczyk, Z. Kamieniecka, I. Kirkowska u. H. Kicinska: Ann. Inst. Pasteur (suppl.) 91, 3-8 (1956)

143 Radda, A., G. Pretzmann u. J. Loew: Zbl. Bakt., I. Abt. Orig. 190, 281-298 (1963)

144 Reeves, W. C.: Progr. med. Virol. 3, 59-78, S. Karger AG, Basel/New York 1961

144a Reeves, W. C. a. W. M. Hammon: J. Immunol. 69, 511-514 (1952)

145 RеHACEK, J.: J. of HEMI 5, 282-285 (1961)

146 Rehacek, J.: Acta virologica 6, 220-226 (1962)

147 Rivers, T. M. a. F. F. Schwentker: J. Exper. Med. 59, 669-685 (1934)

147a Ruiz-Gomes, J. a. A. Isaacs: Virology 19, 1-7 (1963)

148 Ross, C. A. C.: Lancet 527-528 (1961)

149 SABIN, A. B.: Bact. Rev. 14, 225-232 (1950)

150 SABIN, A. B.: Arch. Virusforsch. 4, 367-410 (1951)

151 SABIN, A. B.: Amer. J. Trop. Med. Hyg. 1, 30-50 (1952)

152 Salminen, A.: Ann. Med. Exper. Fenn. 37, 400-406 (1959)

153 Salminen, A.: Ann. Med. Exper. Fenn. 38, 267-280 (1960)

154 Salminen, A.: Ann. Med. Exper. Fenn. 38, 281-287 (1960)

155 Salminen, A.: Acta Pathol. et Microbiol. Scand. Suppl., 154, 341-342 (1962)

156 Salminen, A.: Nature 194, 1301-1302 (1962)

157 Salminen, A.: Virology 16, 201-203 (1962)

158 Salminen, A., A. W. Eriksson a. N. Oker-Blom: Arch. Virusforsch. 11, 215-223 (1961)

159 Salminen, A., O. V. Renkonen a. O. Renkonen: Ann. Med. Exper. Fenn. 38, $447-455(1960)$

160 Salminen, A., O. V. Renkonen a. O. Renkonen: Ann. Med. Exper. Fenn. 38, 456-464 (1960)

161 Sanna, A. u. B. Angelillo: L'igiena moderna 54, 249-255 (1961). Ref.: Zbl. Bakt., I. Abt. Ref. 183, 317 (1962)

162 Seitelberger, F.: Acta neuroveg. 15, 510-513 (1957)

163 Seitelberger, F. u. K. Jellinger: Nervenarzt 31, 49-60 (1960)

164 Seitelberger, F.: Acta neuroveg. 26, 494-509 (1964)

165 Shiraki, H., A. Goto u. H. Narabayashi: Rapports présentes à la 26e Réunion neurologique internationale. Paris 11.-12. 6. 1963, Masson et Cie., Paris, p. $49-112$

166 Shope, R. E., L. G. Mac Namara a. R. Mangold: J. Exper. Med. 111, 155-170 (1960)

167 Shope, R. E. a. O. R. Causey: Amer. J. Trop. Med. 11, 283-290 (1962)

168 Shore, H.: Trans. Roy. Soc. Trop. Med. Hyg. 55, 361-373 (1961)

169 Simkova, A: Acta virologica 6, 190 (1962)

170 Simkova, A.: Acta virologica 6, 281 (1962)

170a Simkova, A.: Acta virol. 7, 414-420 (1963)

171 Sinnecker, H.: Zbl. Bakt., I. Abt. Orig. 180, 12-18 (1960)

172 SinNECKER, H.: J. of HEMI 6, 483-488 (1962)

173 Slonim, D. u. J. Kramar: Zbl. Bakt., I. Abt. Orig. 165, 64-68 (1956)

174 Smorodintsev, A. A.: Arch. Virusforsch. I, 468-480 (1940)

175 Smorodintsev, A. A.: Progr. med. virol. 1, 210-248 (1958)

175a Smorodintsev, A. A., N. W. Kagan, E. N. Bevkovich a. N. L. Dankovskij: Arch. Virusforsch. 2, 1-25 (1941) 
176 Smorodintsev, A. A., A. K. Shubladze a. V. D. Neustroev: Arch. Virusforsch. 1, 549-559 (1940)

177 Sокоц, F.: Symposium on the Biology of Viruses of the Tick-borne Encephalitis Complex, Smolenice 1960, pp. S6-97. Czechoslovak Academy of Sciences, Praha 1962

178 Sokol, F., H. Libikova a. J. Zemla: Nature 184, 1581 (1959)

179 Strode, G. K. et al.: Yellow Fever. Mc Graw-Hill Book Comp. Inc., New York -Toronto-London 1951

179a Strohmaier, K.: Persönl. Mitteilung, 1963

180 Svedmyr, A., G. v. Zeipel, B. Holmgren a. J. Lindahl: Arch. Virusforsch. 8, 565-576 (1958)

181 Symposion on the Evolution of Arbo-viruses Diseases, London 1960. Trans. Roy. Soc. Trop. Med. Hyg. 54, No. 2 (1960)

182 Symposion on Hemorrhagic Fever. August 10 and 11, 1961, Bangkok, Thailand. SEATO Med. Res. Monogr. No. 2

183 SCHNEIDER, H.: Wien. klin. Wschr. 44, 350-352 (1931)

184 Schneider, H.: Die epidemische akute „Meningitis serosa“. W. Maudrich, Wien 1932

185 Stokes, A., J. H. Bauer a. N. P. Hudson: Amer. J. Trop. Med. 8, 103-164 (1928)

186 Streissle, G.: Zbl. Bakt., I. Abt. Orig. 179, 189-297 (1960)

187 Streissle, G.: Zbl. Bakt., I. Abt. Orig. 182, 159-169 (1961)

188 Streissle, G.: Zbl. Bakt., I. Abt. Ref. 179, 324 (1962)

188a TAYLOR, C. S.: J. Immunol. 71, 125-133 (1953)

189 Theiler, M.: Ann. Trop. Med. 24, 249-272 (1930)

190 Theiler, M.: Proc. Soc. Exper. Biol. (N. Y.) 96, 380-382 (1957)

191 Theiler, M., J. Casals a. C. Moutousses: Proc. Soc. Exper. Biol. Med. (N. Y.) 103, 244-246 (1960)

192 Thomas, L. A. a. C. M. Eklund: Proc. Soc. Exper. Biol. Med. 105, 52-55 (1960)

193 Tongeren, H. A. E. van: Central European Encephalitis - Epidemiology and Vectors. VI. Int. Congr. on Trop. Med. and Malaria, Lissabon 1958

194 Verlinde, J., H. A. E. van Tongeren, S. R. Pattyn a. A. Rosenzweig: Bull. World Health Organizat. 12, 565-579 (1955)

195 Vilcek, J.: Nature 187, 73-74 (1960)

196 VILCEK, J.: Acta virologica 5, 278-282 (1961)

197 VILCEK, J.: Acta virologica 6, 144-150 (1962)

198 VILCEK, J.: Acta virologica 7, 107-115 (1963)

199 Vilcek, J. a. B. RadA: Acta virologica 6, 9-16 (1962)

199a WAGNER, R. R.: Virology 19, 215-224 (1963)

199b Wagner, R. R., A. H. Levy, R. M. Snyder, G. A. Ratcliff jr. a. D. F. Hyatt: J. Immunol. 91, 112-122 (1963)

200 WeCKER, E.: Zschr. Naturforsch. 14b, 370-378 (1959)

201 WeCKer, E.: Zschr. Naturforsch. 15b, 71-78 (1960)

202 WeCKER, E.: Virology 7, 241-243 (1959)

203 WeCKer, E. u. W. Schäfer: Zschr. Naturforsch. 12b, 415-417 (1957)

204 Wenner, H. A. a. Te Yong Lou: Progr. med. virol. 5, 219-294 (1963)

204a Wiebenga, N. H., A. Shelokov, Cl. J. Gibbs a. R. B. Mackenzie: Am. J. Trop. Med. a. Hygiene 13, 626-628 (1964) 
205 Wiedermann, G., F. Reinhardt u. Ch. Kunz: Zbl. Bakt., I. Abt. Orig. 189, 15-25 (1963)

206 Williams, H. a. H. Thorburn: Scot. med. J. Glasgow 7, 353-355 (1962)

208 Williams, M. C. a. J. P. Woodall: Trans. Roy. Soc. Trop. Med. Hyg. 55, 135-141 (1961)

209 Wittman, G. a. H. D. Matheka: Mhefte Tierhk. 10, 161-169 (1958)

210 Work, T. H.: Progr. med. virol. 1, 248-277 (1958)

211 World Health Organization, Techn. Rep. Series No. 206: 11th Report of the Expert Committee on Insecticides (1961)

212 ZeMLA, J. a. J. VILCEK: Acta virologica 5, 367-372 (1961)

212a Zemla, J.: Diskussion p. 117 in H. Libikova: "Biology of Viruses of the Tick borne Encephalitis Complex". Czechoslovak. Acad. Sc. Prag, 1962

213 Zilber, L. A.: Vop. Virusol. 6, 323 (1957). Ref.: Zbl. Bakt., I. Abt. Ref. 168, 302 (1958)

214 ZILBER, L. A.: J. of HEMI 6, 113-127 (1962)

215 Zilber, L. A.: J. of HEMI 6, 128-135 (1962) 